\title{
الثقافة المنظمية واثرها في تعزيز الاداء الوظيفي بحث في شركة صناعات الاصباغ الحديثة
}

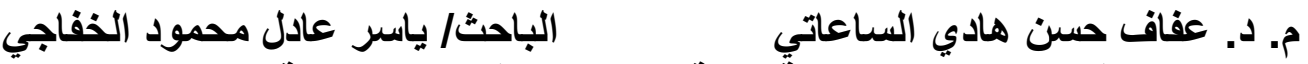

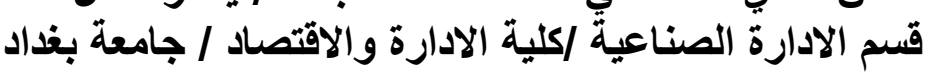

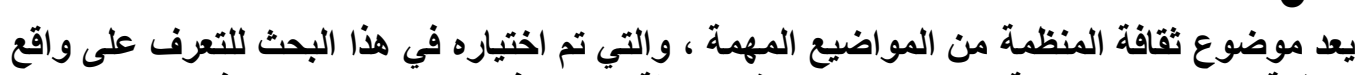

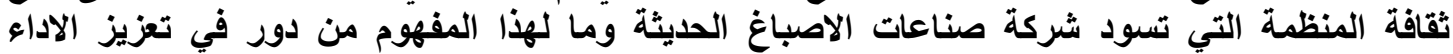

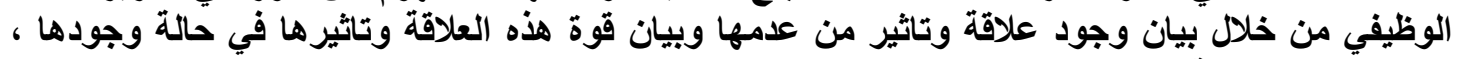

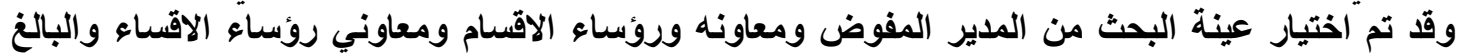

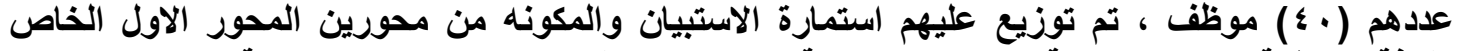

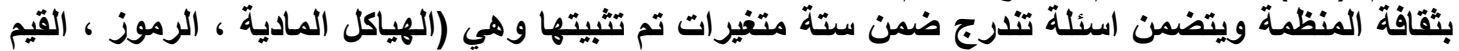

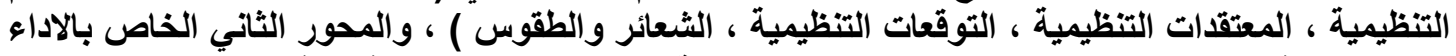

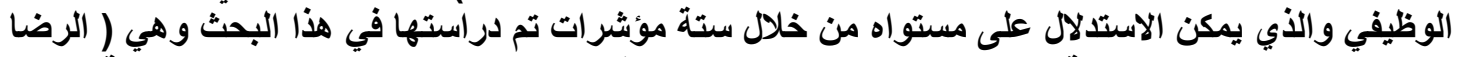

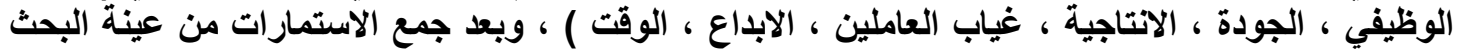

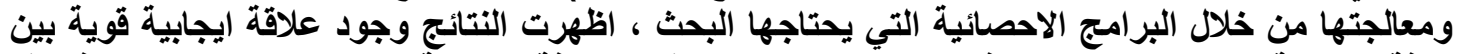

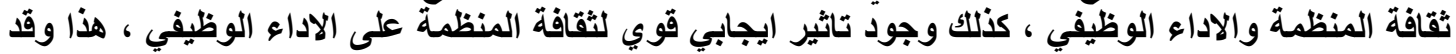

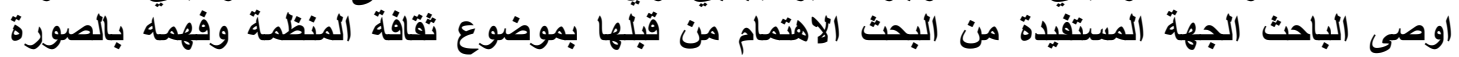

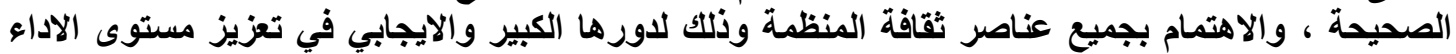

الوظيفي . الصحة ،

الاصطاحمات الرئيسية للبمث/ ثقافة المنظمة ـ الاداء الوظيفي .

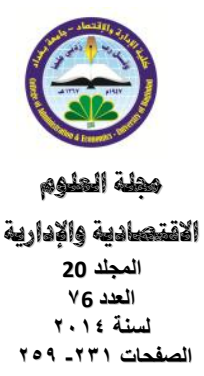




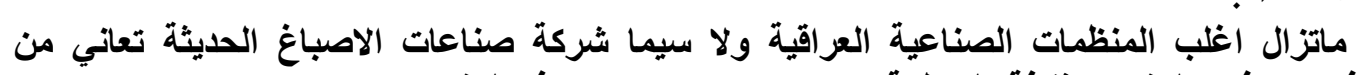

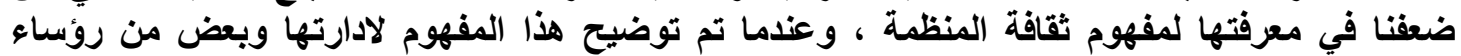

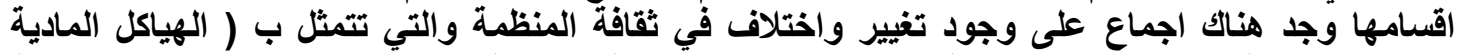

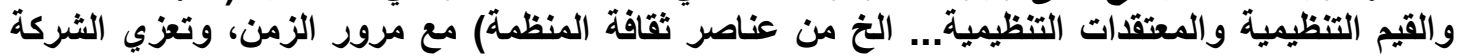

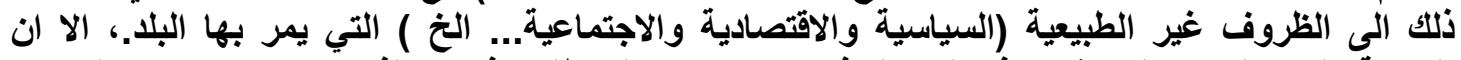

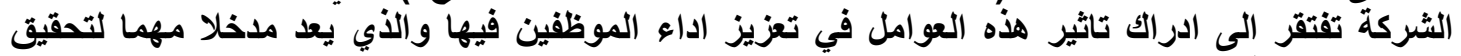

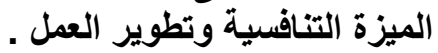

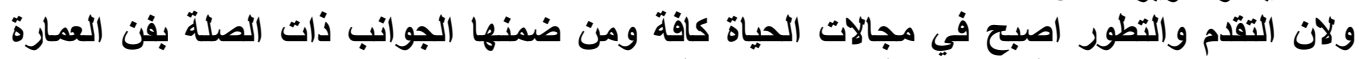

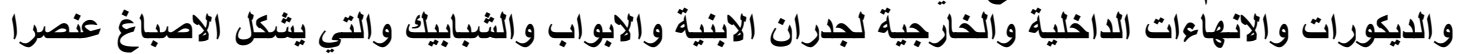

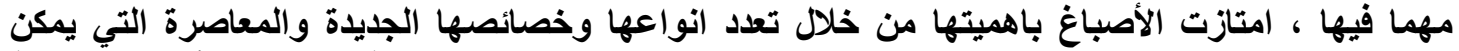

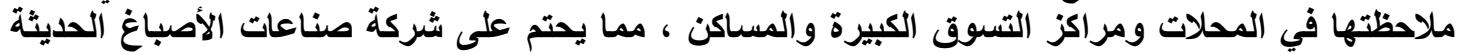

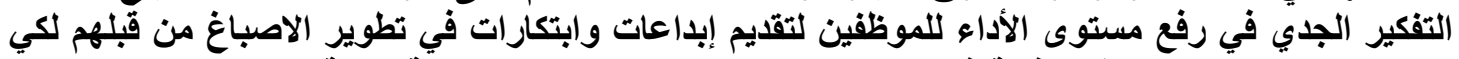

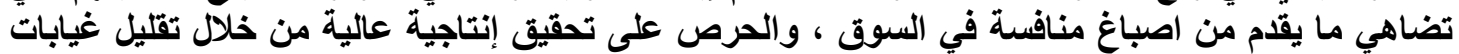

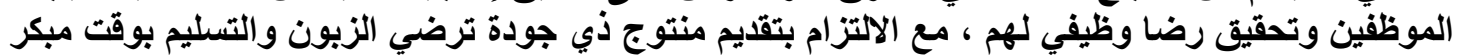

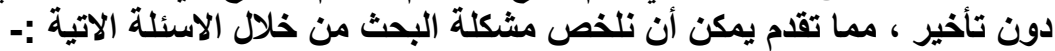

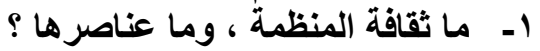

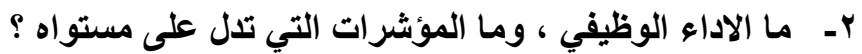

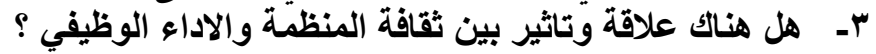

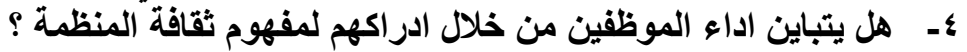

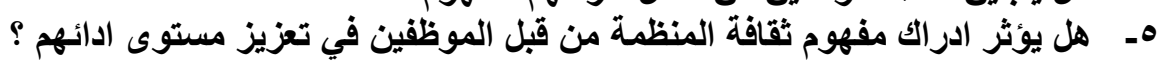

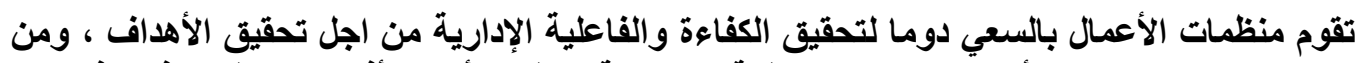

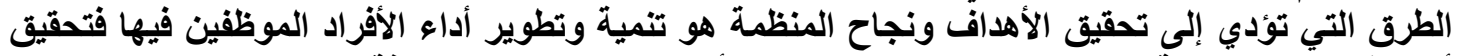

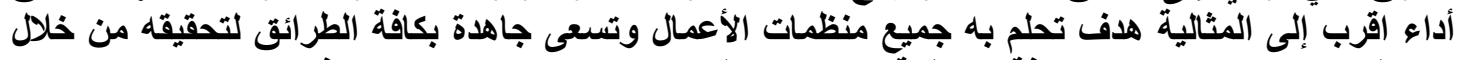

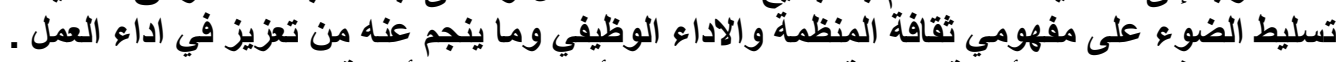

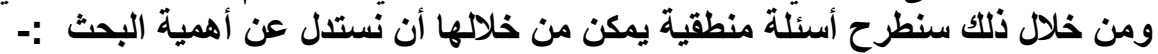

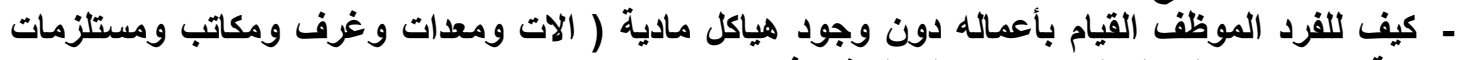

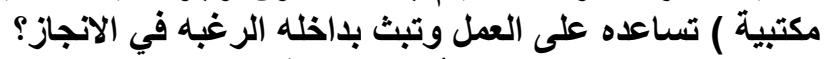

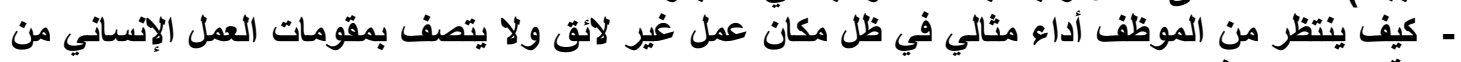

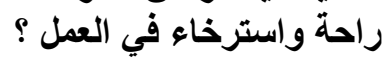
- كيف للفرد الموظف القيام بأداء واجباته على أكمل وجه دون وجود قيم الإخلاص والولاء والحرص

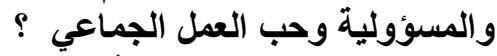

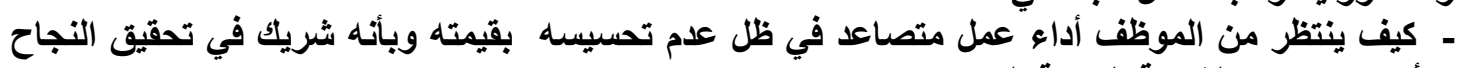

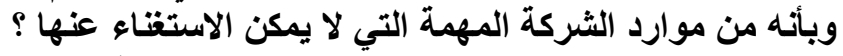

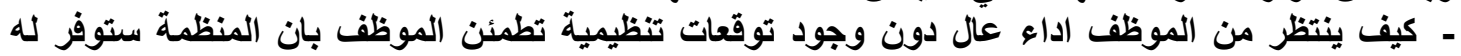

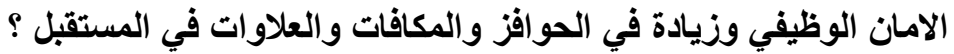

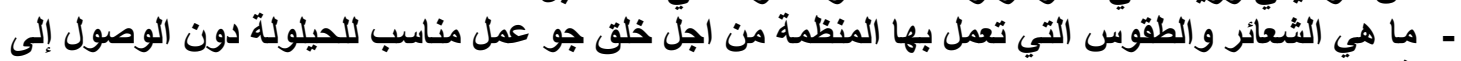

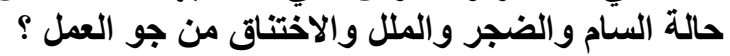

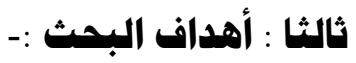
I - تعريف شركة صناعات الأصباغ الحديثة بمفهومي ثقافة المنظمة والاداء الوظيفي . 


\section{بهث في شركة صنا عات الاصباغ الهدبثة}

r - التعرف على واقع الثقافة التنظيمية في شركة صناعات الأصباغ الحديثة ومستوى الأداء الوظيفي فيها.

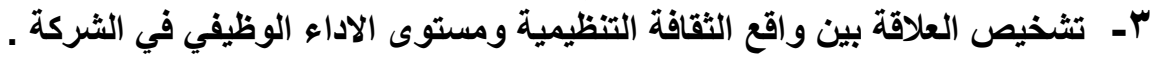

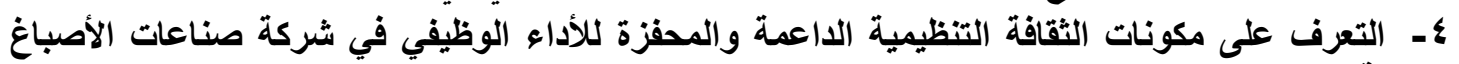
الحديثة. هـ - محاولة الكثف عن الهم عوامل ثقافة المنظمة التي يمكن من خلالها تعزيز الاداء الوظيفي للموظفين فيها . ج- - تفعيل دور ثقافة المنظمة في شركة صناعات الاصباغ الدايثة استنادا الى المسوغات العلمية والعملية

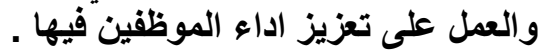

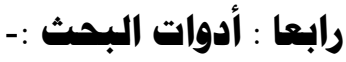
لقد تم الاعتماد على عدد من الوسائل الخاصة بجمع البيانات وتحليلها للوصول الى النتائج النهائية للبحث

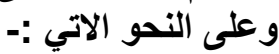

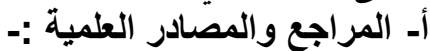

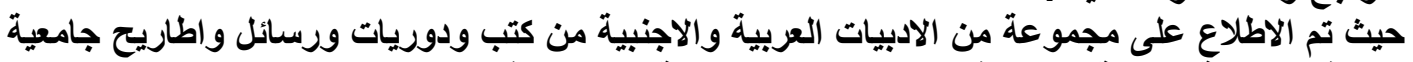

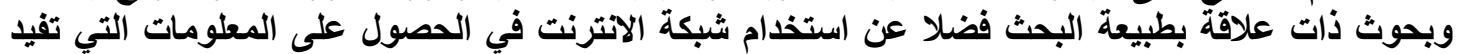

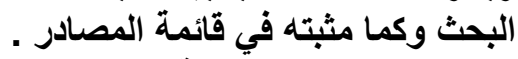

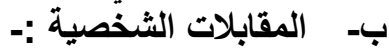

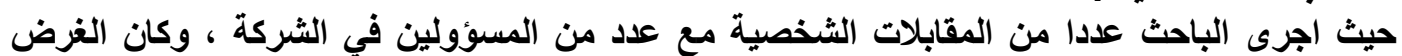

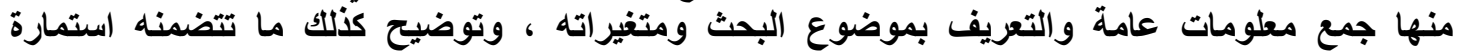

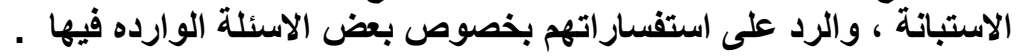

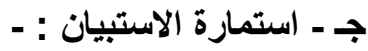

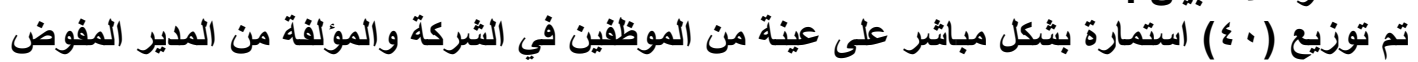

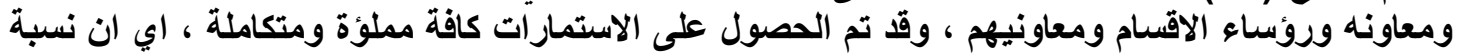

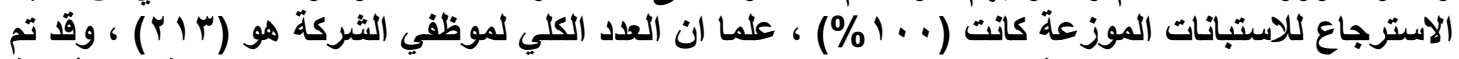

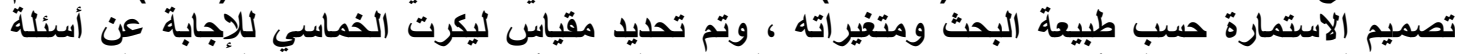

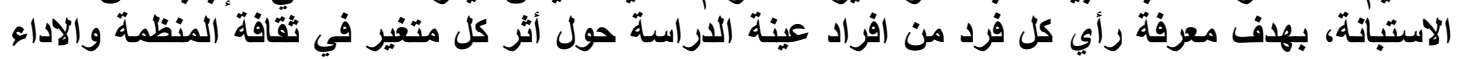
الوظيفي وهو كما يأني :

\begin{tabular}{|c|c|c|c|c|}
\hline غيرموافق & موافير & محايد & موافق & موافق بشدة \\
\hline 1 & $r$ & $r$ & \{ & 0 \\
\hline
\end{tabular}




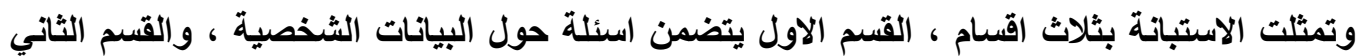

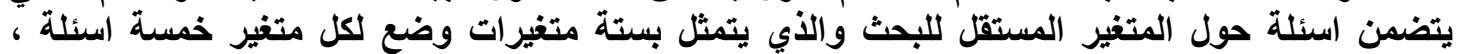

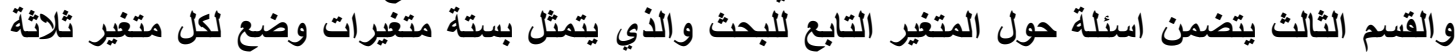

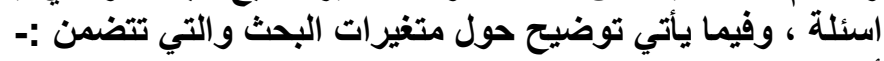

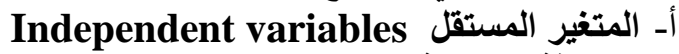
تمثل ثقافة المنظمة المتغير المستقل ، والتي تثمل عدة عناصر ، وقد تم تثبيت ستة عناصر ليتم دراستها وهي :- تصن

• (الهياكل المادية ( Physical structures) ( الرموز (Symbols) • • (Values (القيم التظيمية (

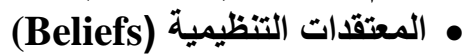

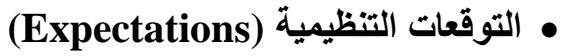

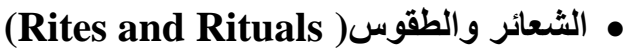

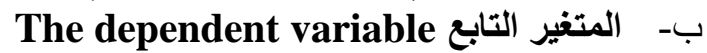
يشتمل البحث على المتفير التابع الرئيس وهو الأداء الوظيفي ، والذي سيتم التعرف على مستواه من خلال

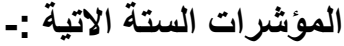

ا- الرضا الوظيفي (Job Satisfaction)

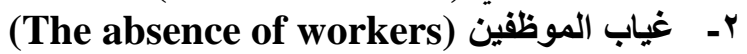

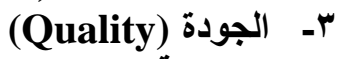
ع- الإنتاجية (Productivity)

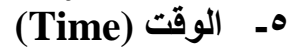

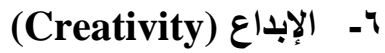
• الفرضية الرئيسة الأولى : توجد علاقة ارتباط ذات دلالة معنوية بين ثقافة المنظمة ومستوى الأداء

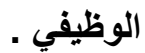
وتتفرع منها الفرضيات الفرعية الآتية :

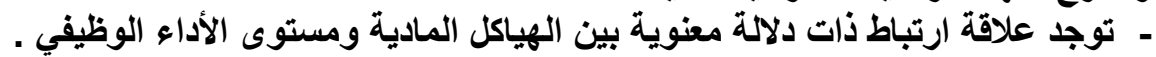

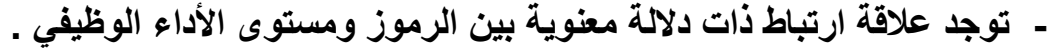

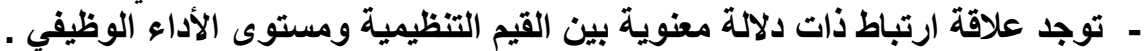

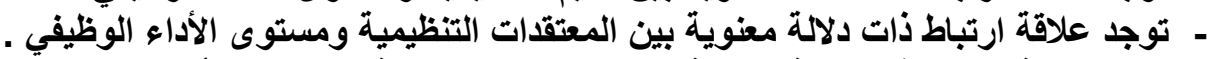

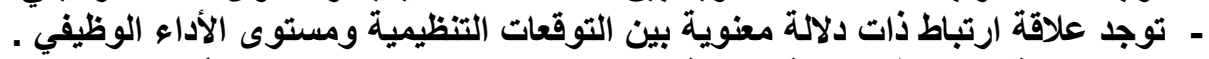

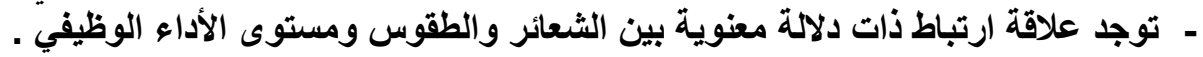

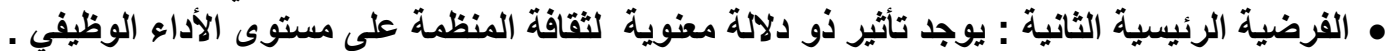

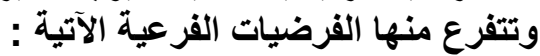

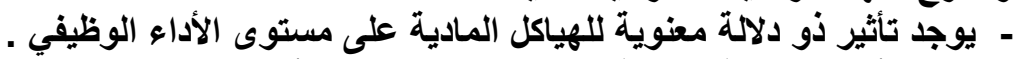

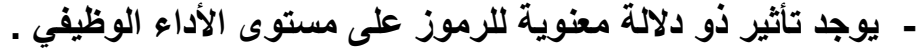

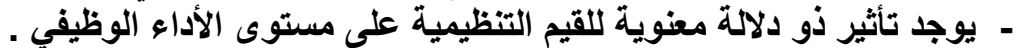

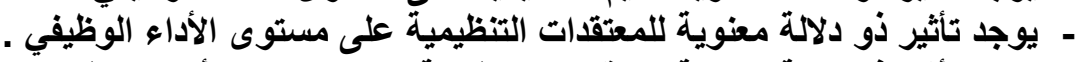

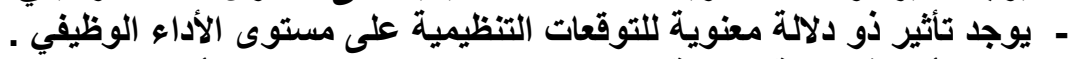

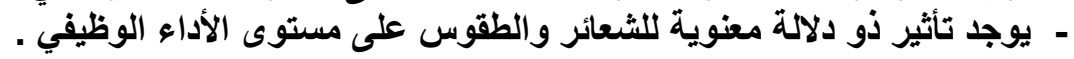




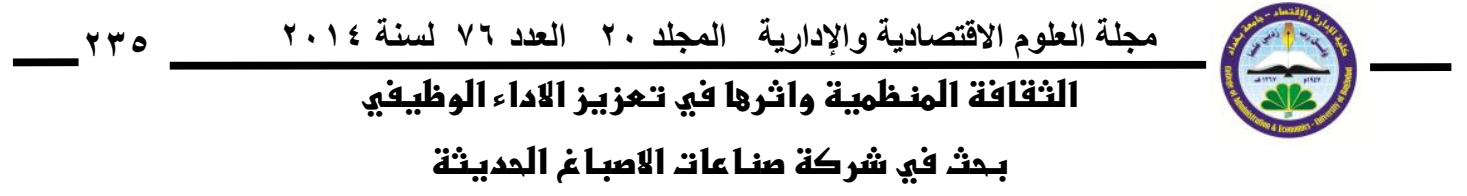

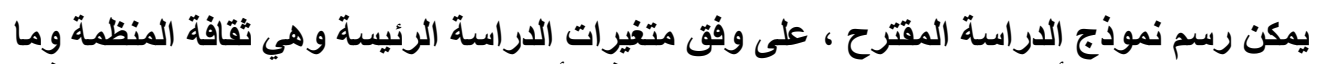

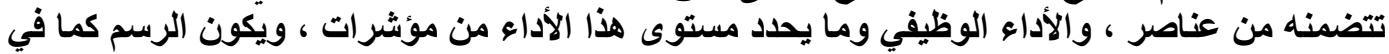

$$
\text { الشكل رقم (1) :- }
$$

شكل رقم (1) المخطط الافتر اضي للبحث
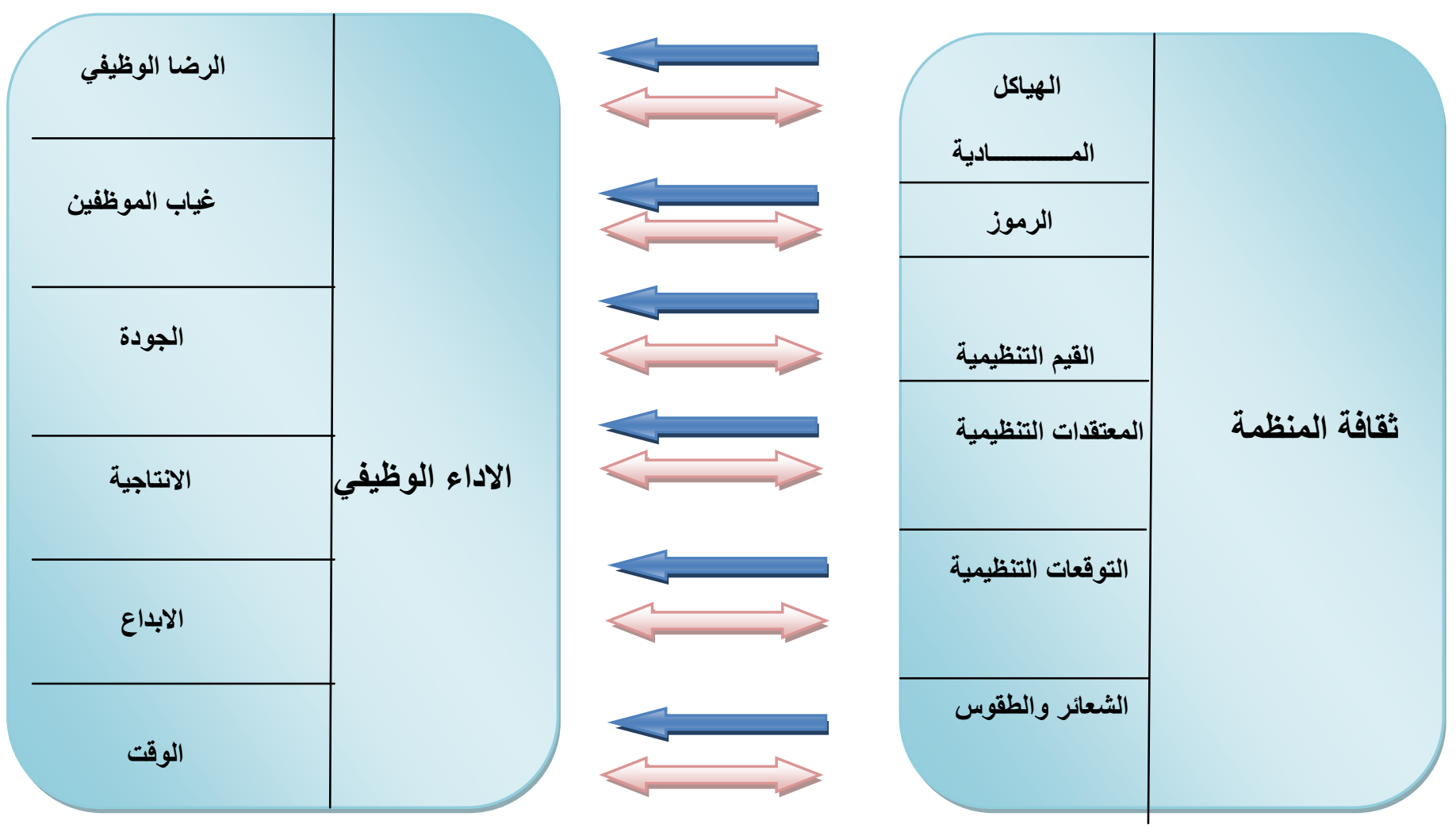

علاقة ارتباط 


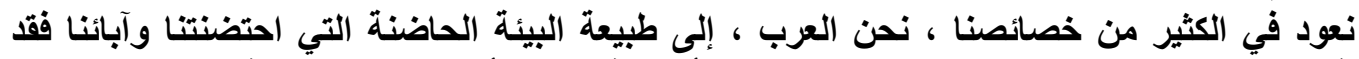

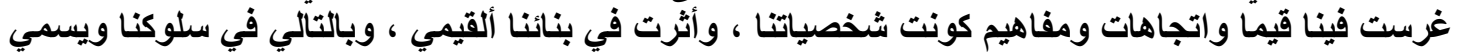

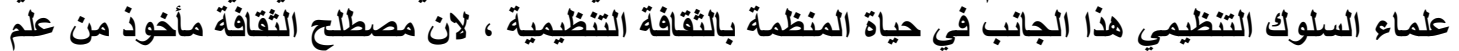

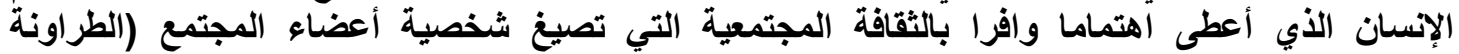

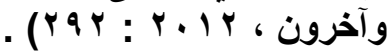

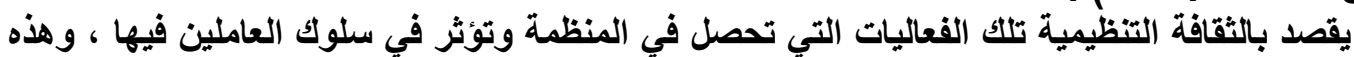

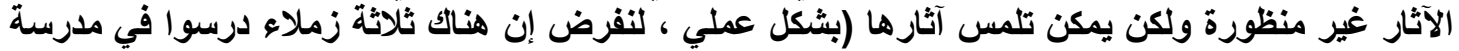

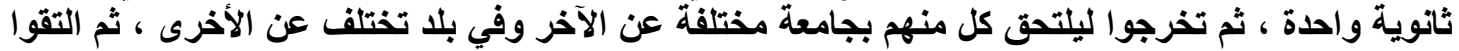

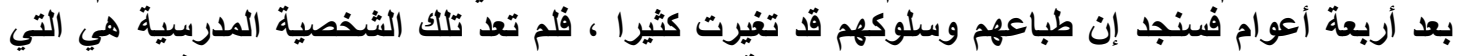

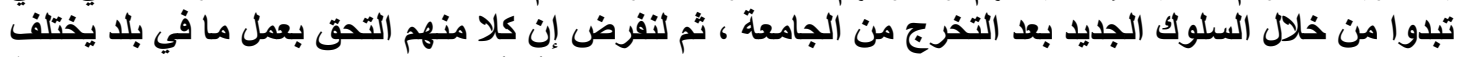

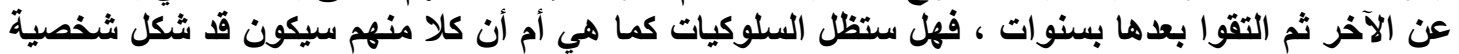

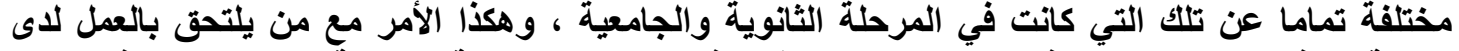

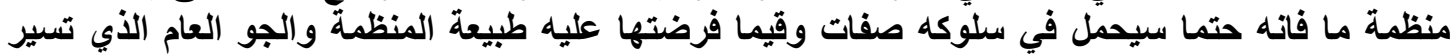

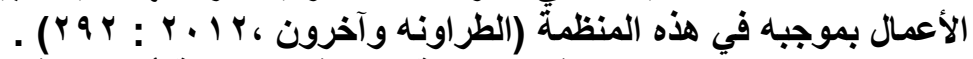

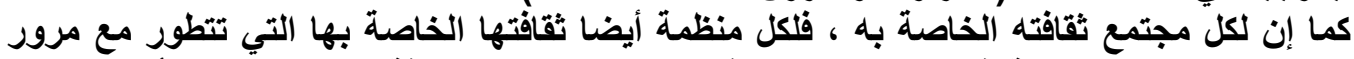

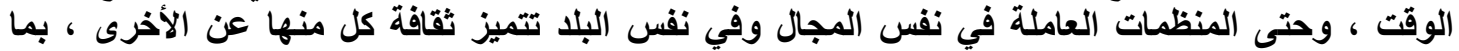

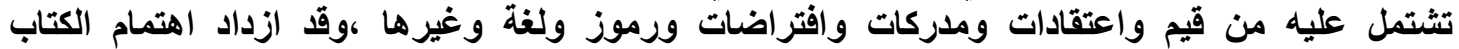

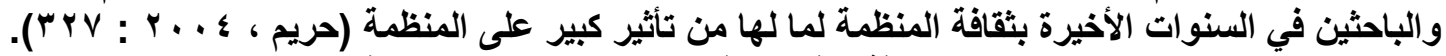

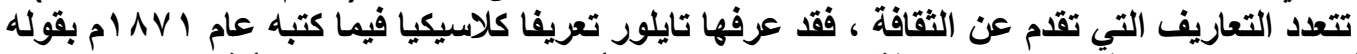

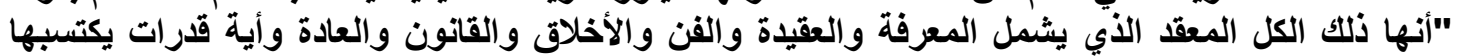

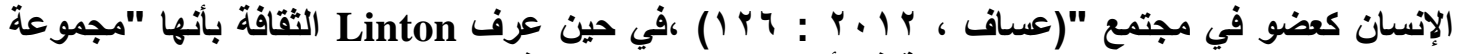

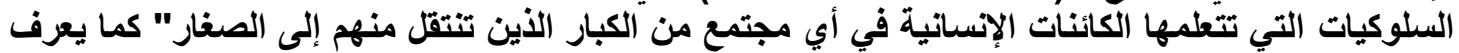

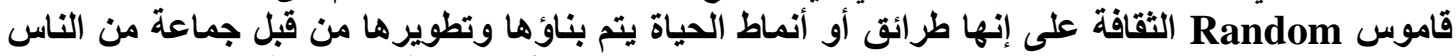

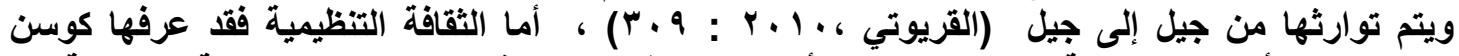
Kossen

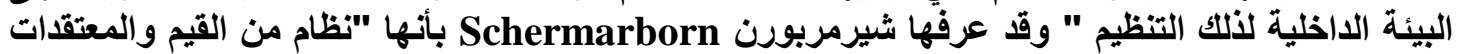

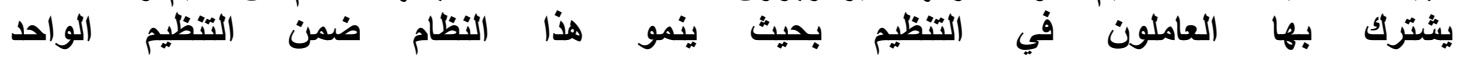

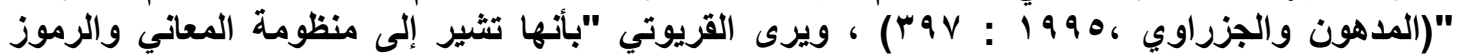

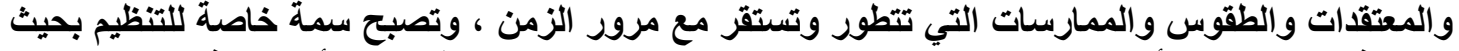

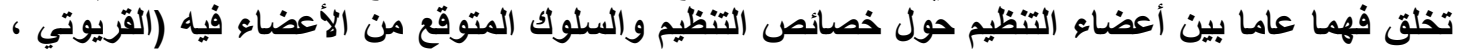




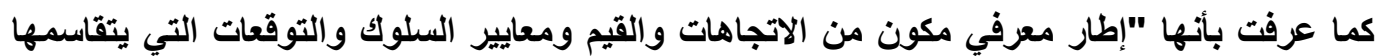

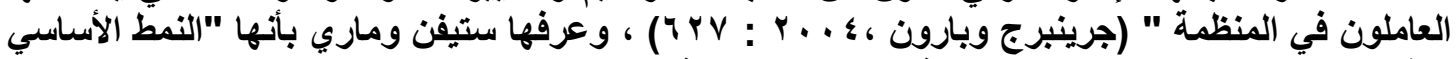

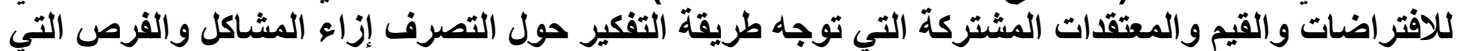

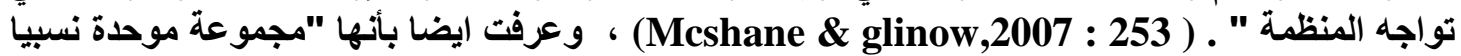

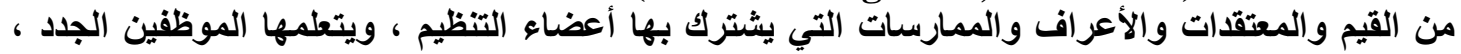
فهي تنتقل من جيل إلى جيل آخر من الموظفين" (643 :

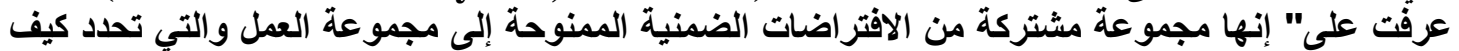

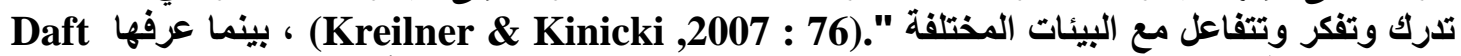

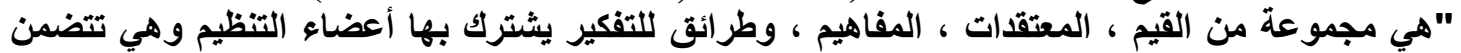

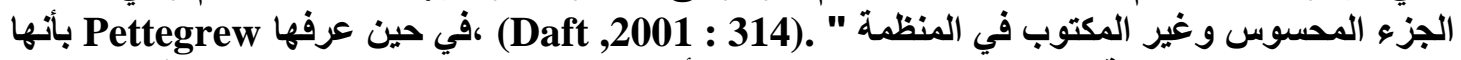

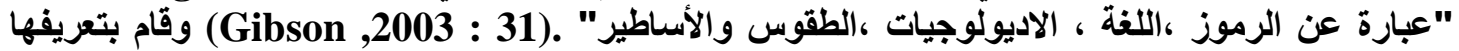

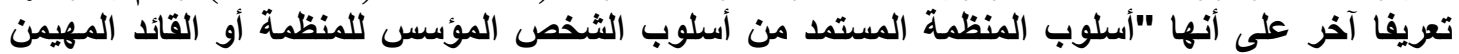
" المعتقات والتوقعات والأفكار والقيم والسلوكيات التي يتقاسمها أعضاء المنظمة والتي تكون مستمرة عبر التمان

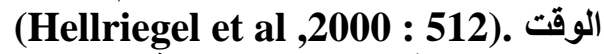

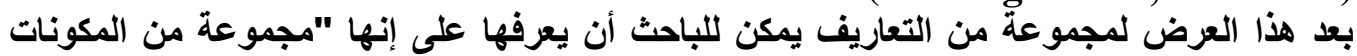

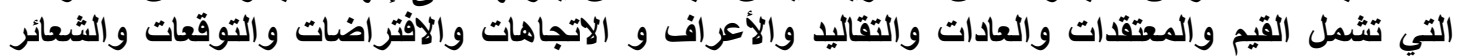

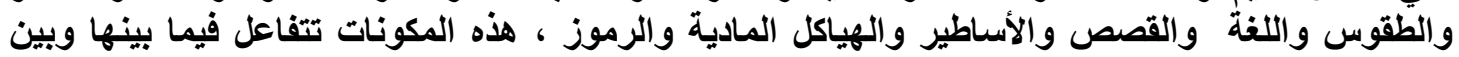

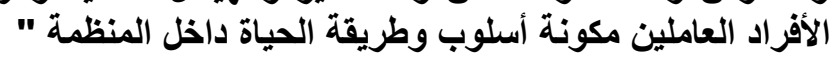

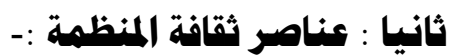

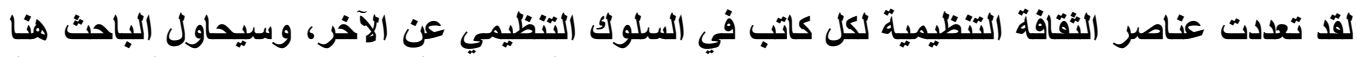

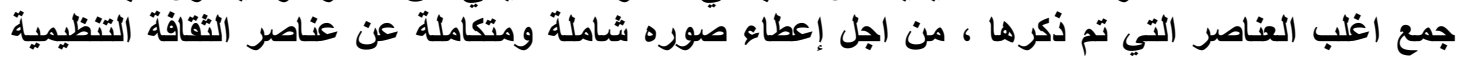
وهي:-

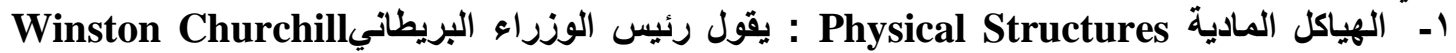

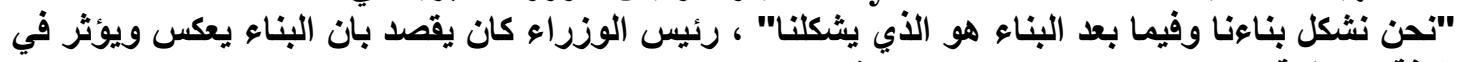

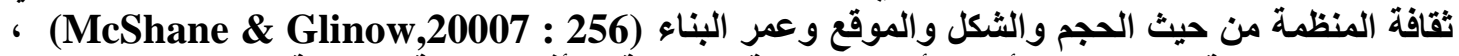
إن الهياكل المادية تعرف على الهن أنها الأشياء المادية المحيطة بالأفراد كبناية المنظمة والماء الملابس والمكاتب

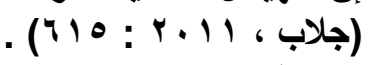

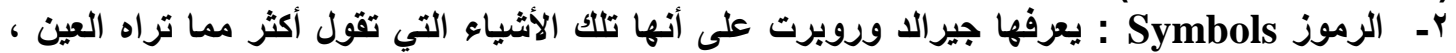

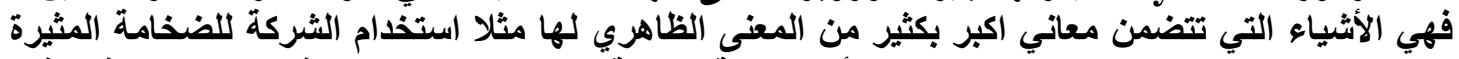

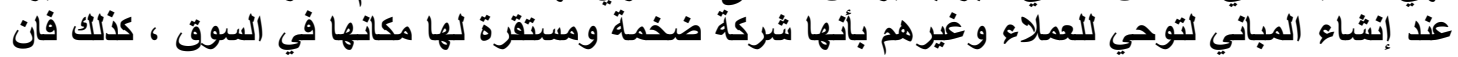

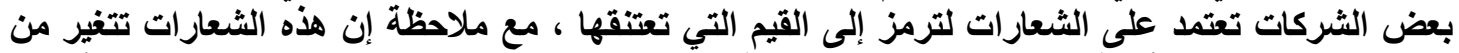

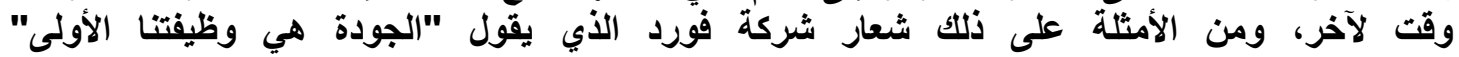

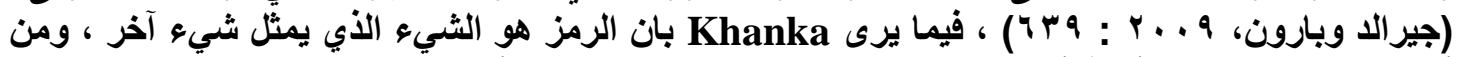

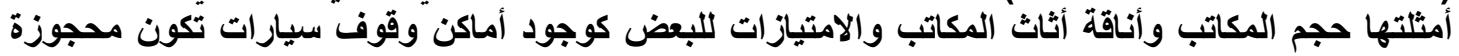

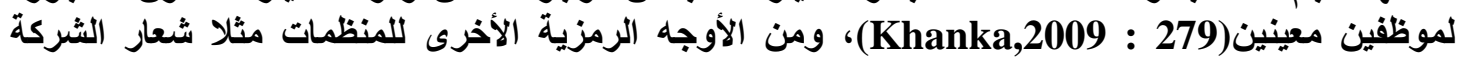

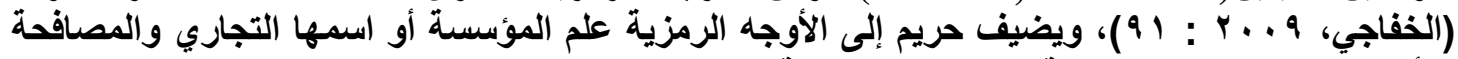

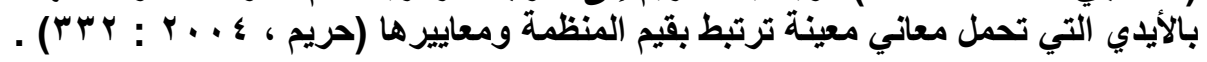




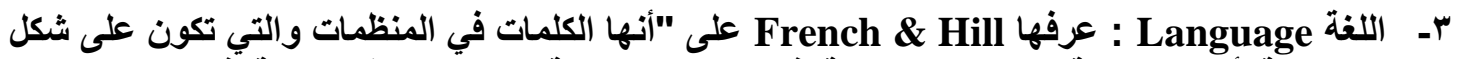

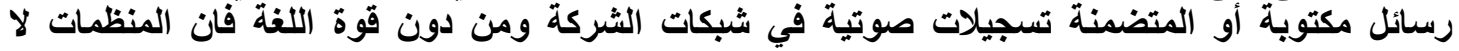

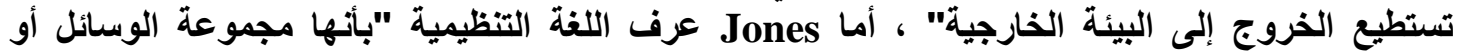

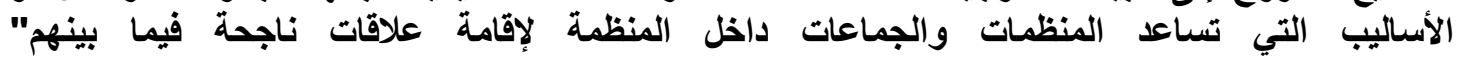

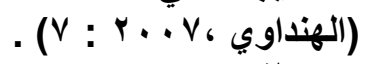

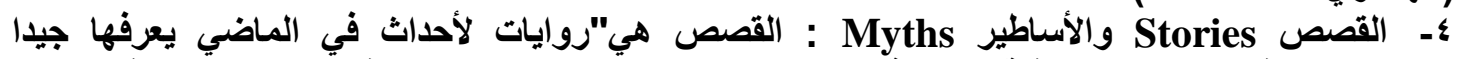

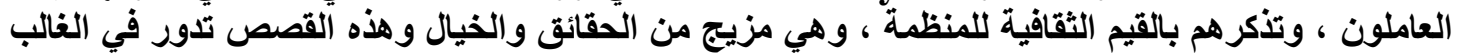

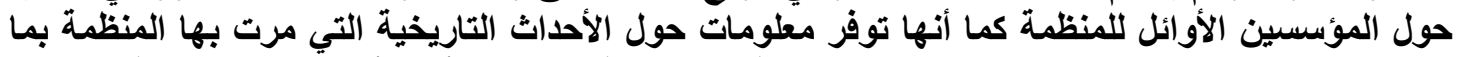

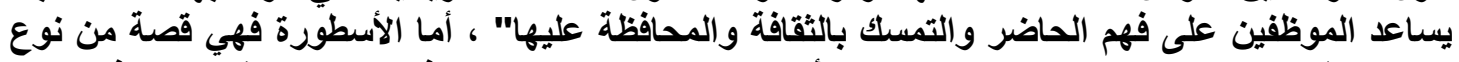

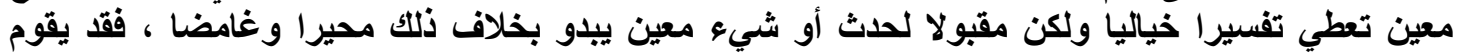

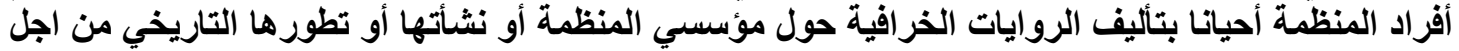

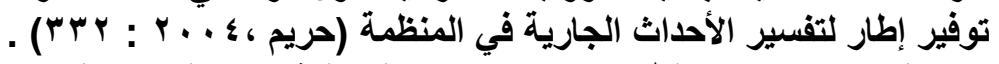

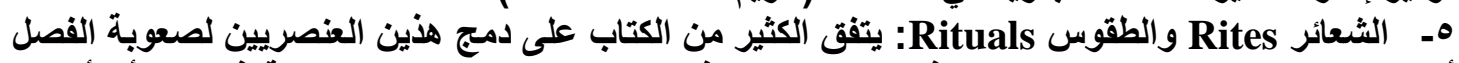

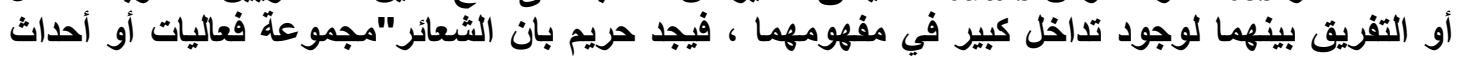

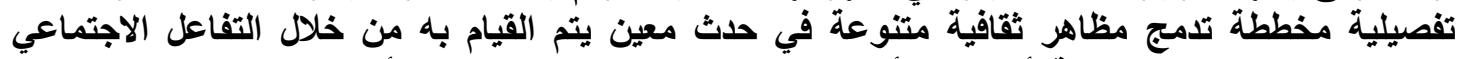

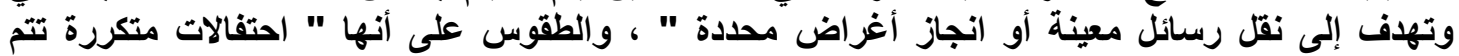

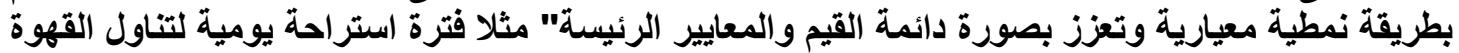

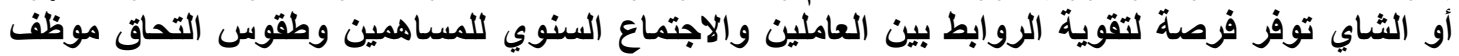

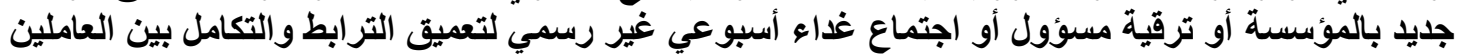

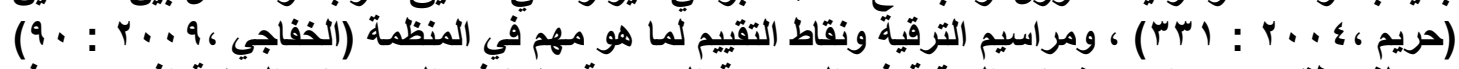

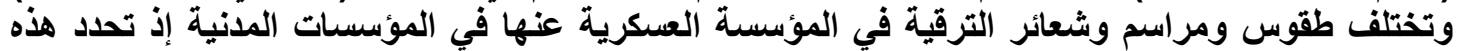

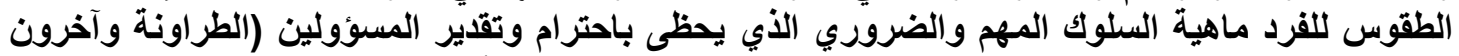

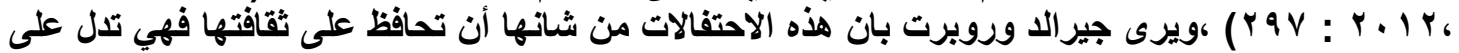

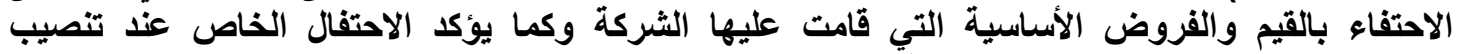

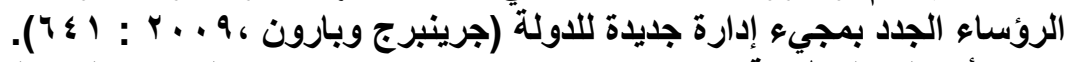

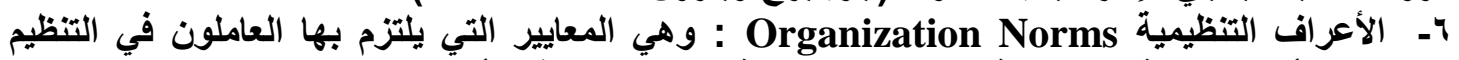

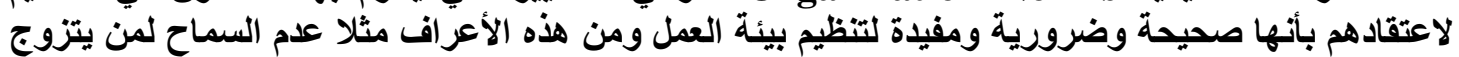

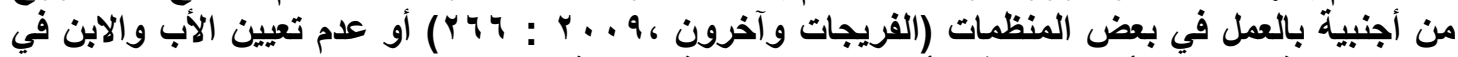

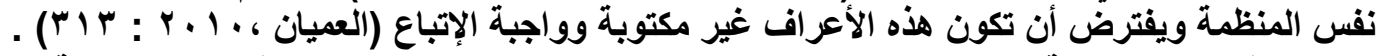

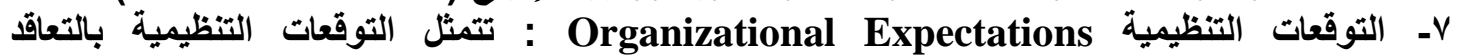

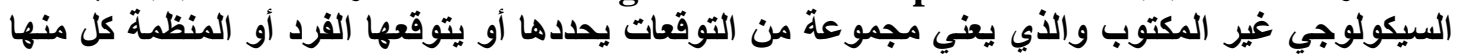

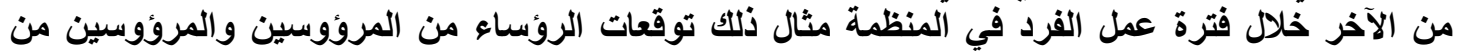

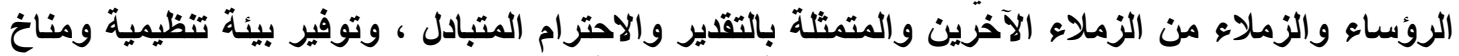

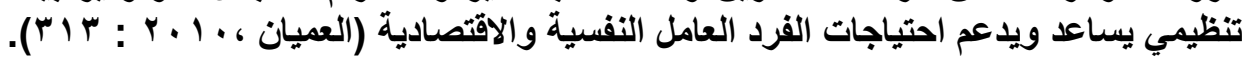


1- - القيم التظيمية Organizational Values : القيم عبارة عن اتفاقات مشتركة بين اعضاء التنظيم

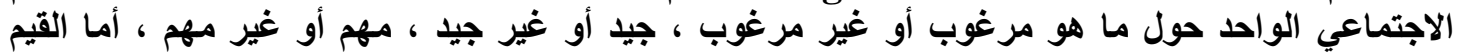

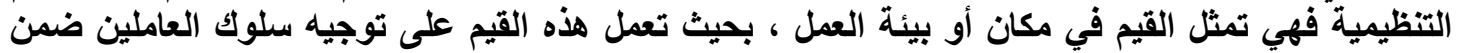

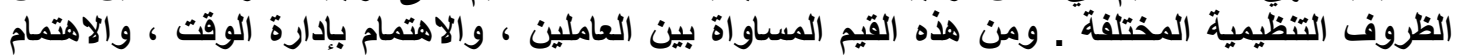

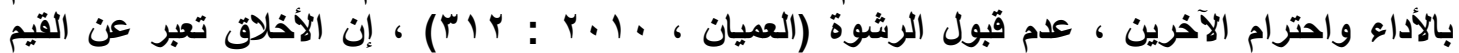

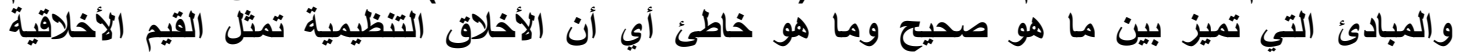

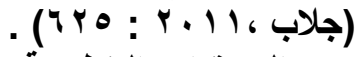
9- ألمعتقدات التنظيمية Organization Beliefs : وهي الأفكار المشتركة حول طبيعة العمل والحياة

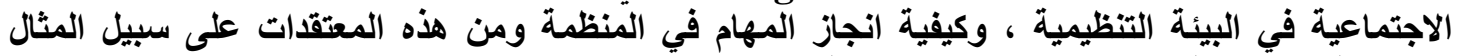

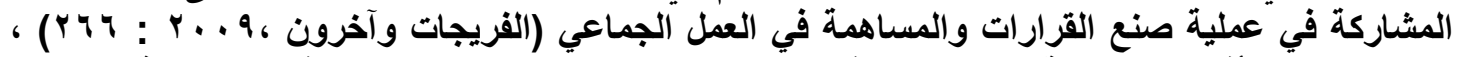

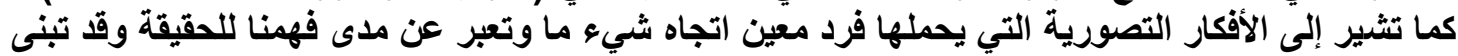

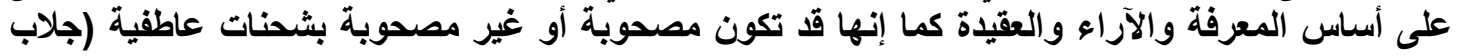
. (7r.: Y. Y T)، • ـ الاتجاهات Attitudes والافتراضات Assumptions: يضيف جلاب هذين المفهومين ،حيث يشير إلى

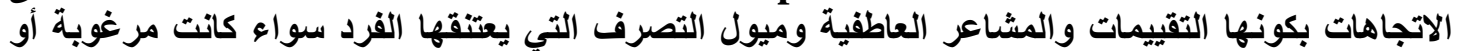

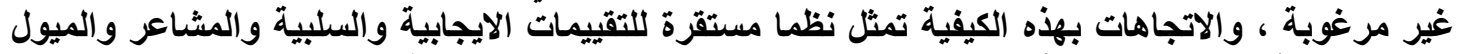

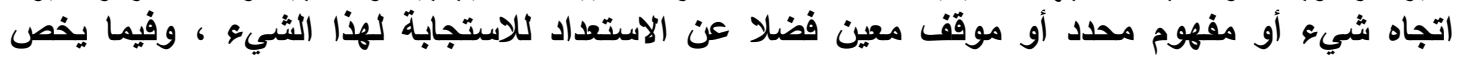

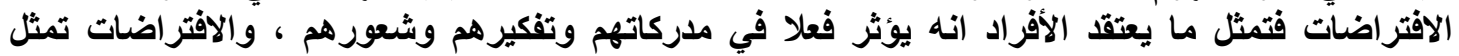

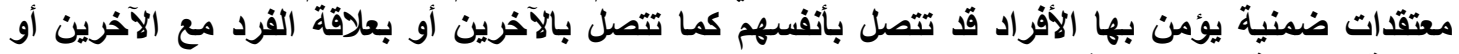

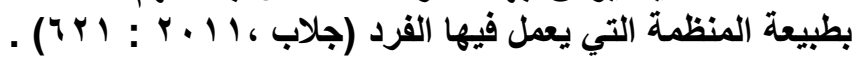

ثالثا : أهميية ثقافة المنظمهة :-

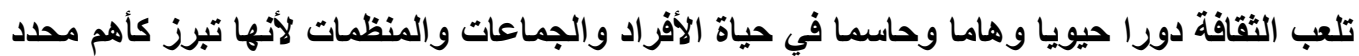

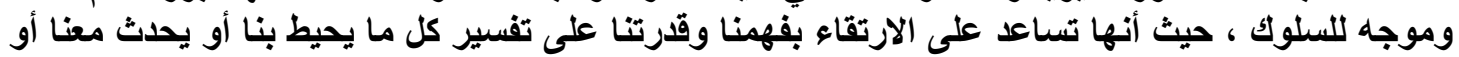

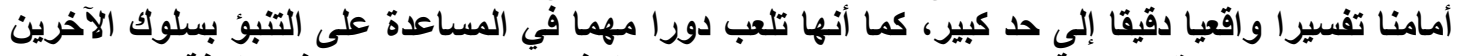

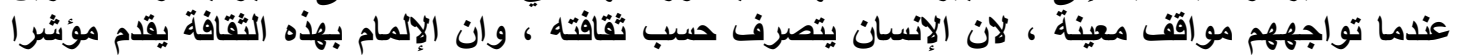

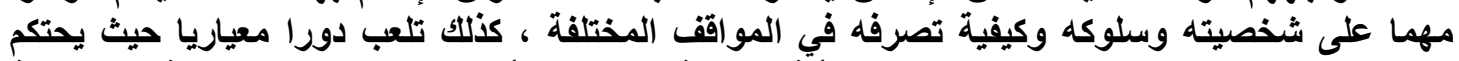

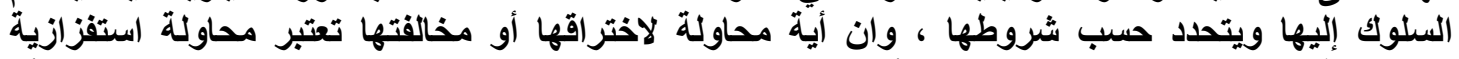

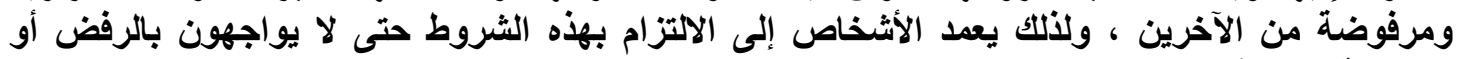

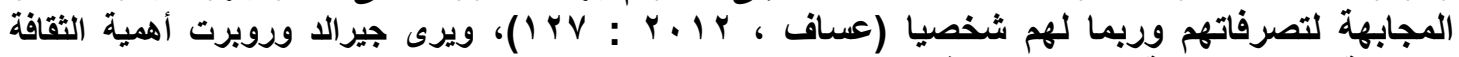

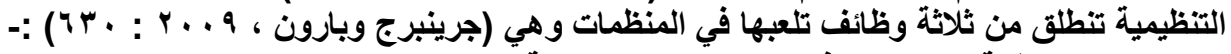

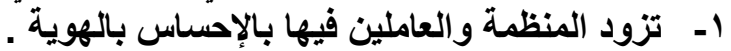

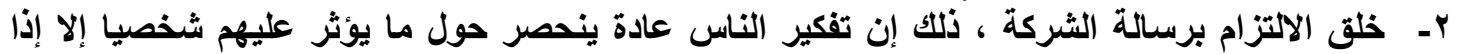

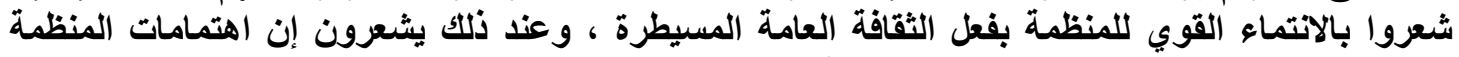

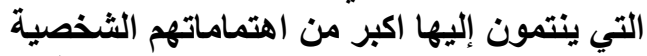

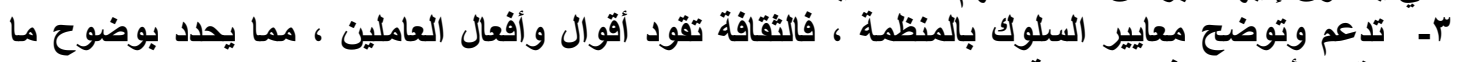

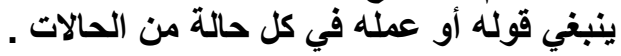




\section{بحث في شركة صنا عات الاصباغ الهديثة}

إن الثقافة تثثل أنماط مشتركة من المفاهيم المعرفية حول القيم أو المعتقدات التي تحيط بها المنظمة

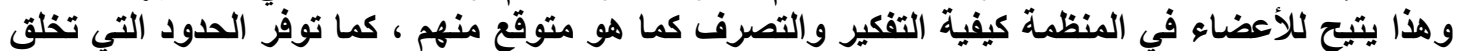

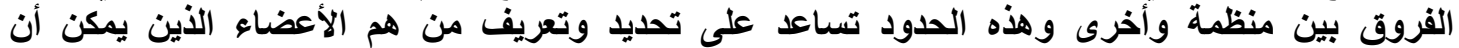

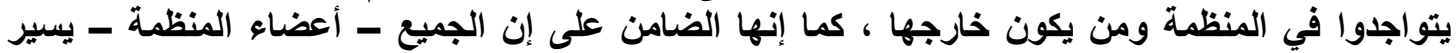

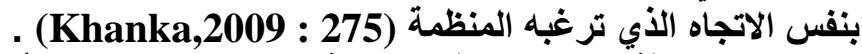

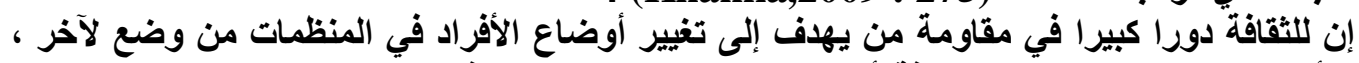

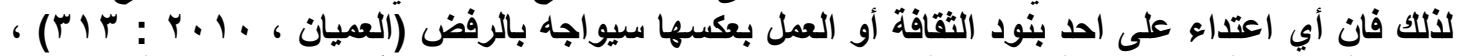

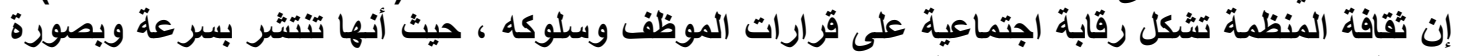

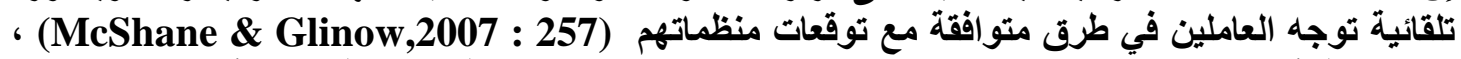

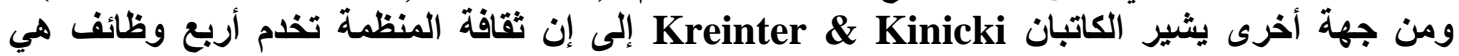
-:(Kreitner \& Kinicki,2007 : 81)

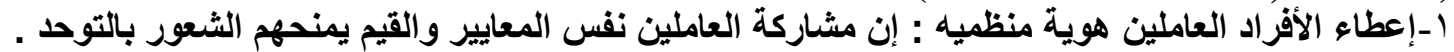

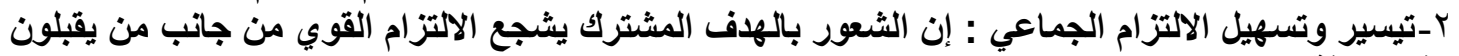
هذه الثقافة ب-تثكيل السلوك الأي يساعد الأعضاء على فهم ما يحيط بهم : فثقافة المنظمة توفر مصدرا للمعاني

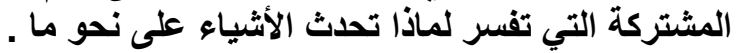
ـ ـتعزيز الاستقرار للنظام الاجتماعي : تثجع الثقافة على التنسيق والتعاون الألثائمين بين أعضاء المنظمة .

\section{رابعا : انهواع ثقافة المنظمة المبنة}

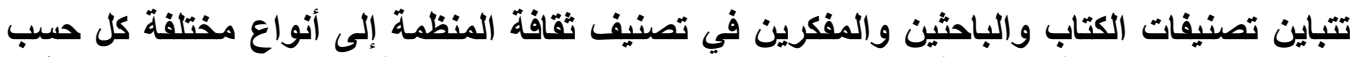

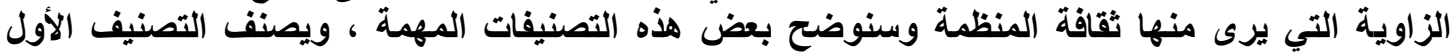
الثقافة التنظيمية إلى :- التئية ا- الثقافة القويةة :- تعرف الثقافة القوية بأنها " الحد الأي يجعل الأعضاء يتبعون ما تمليه عليهم الإدارة

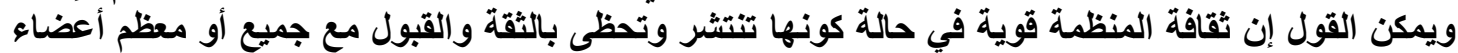

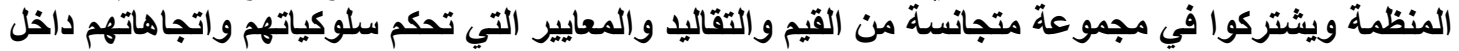

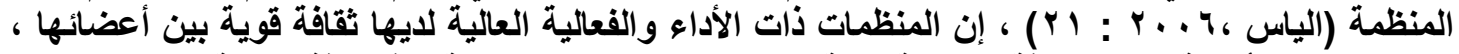

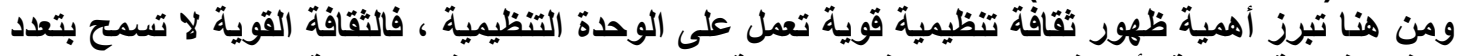

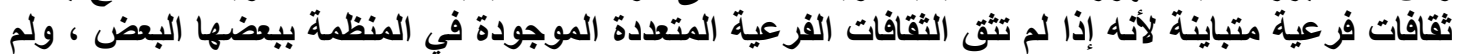

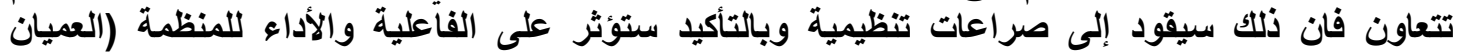

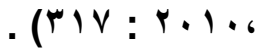

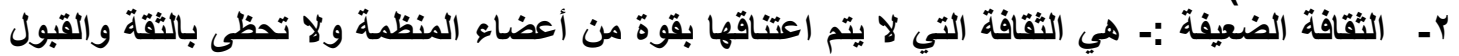

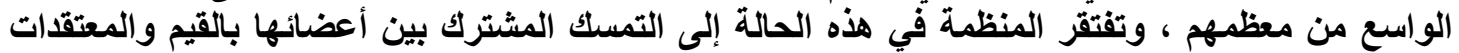

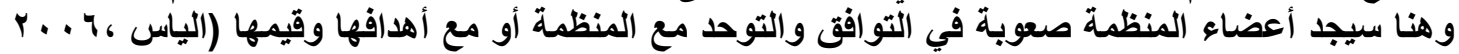

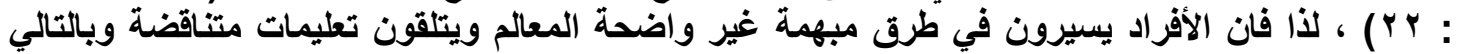

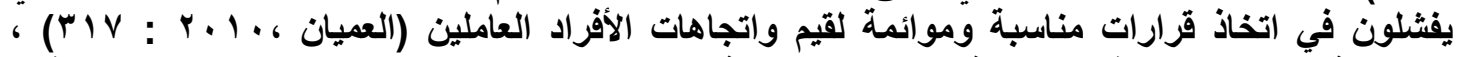

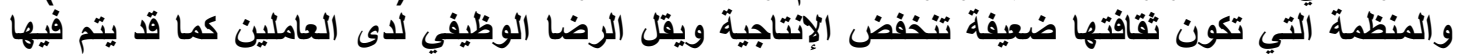

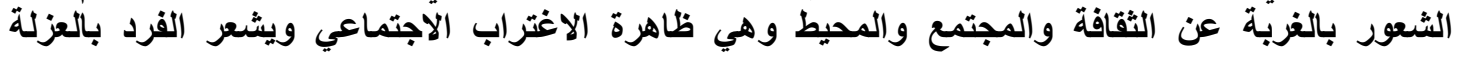

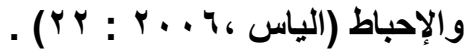




\section{بحث في شركة صنا عات الاصباغ الهديثة}

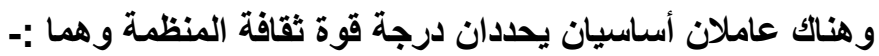

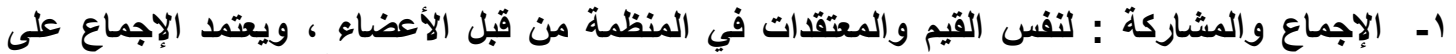
تعريف الأفراد بالقيم السائدة في المنظمة وعلى الحوافز من عوائد ومكافآت تمنح للأفراد الملتزمين (العميان

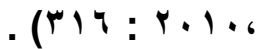

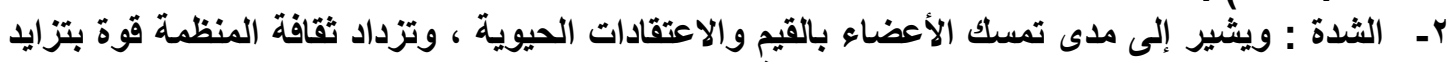

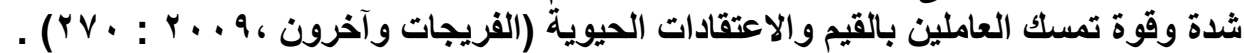

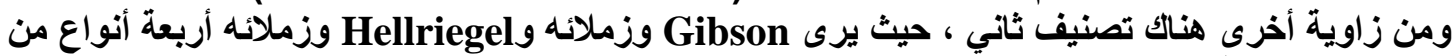

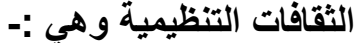

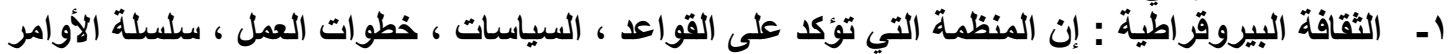

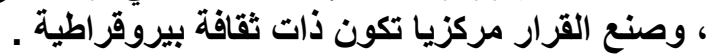

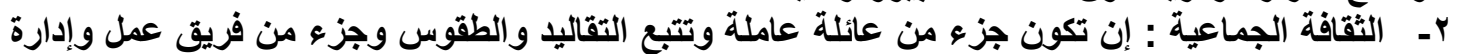

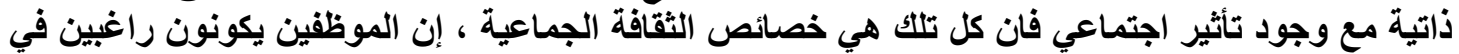

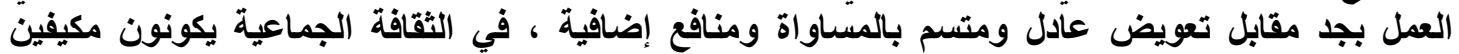

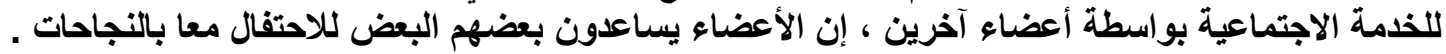

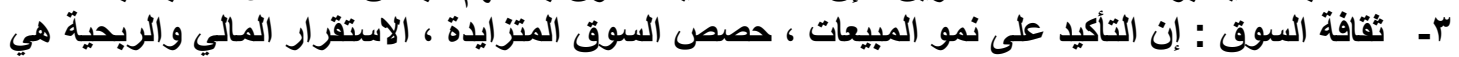

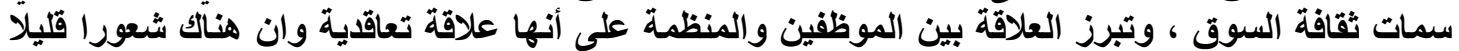

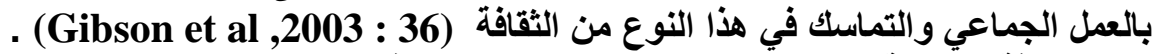

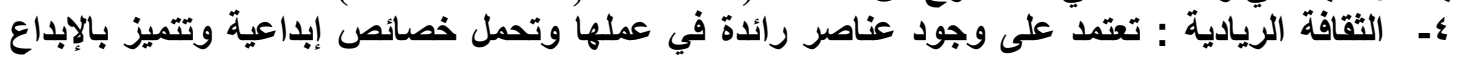

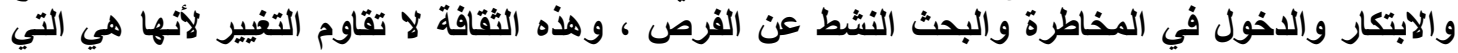
تخلق التغيير وتمتلك الفاعلية لتزويد المنتجات الجديدة والفريدة وتستجيب للنمو

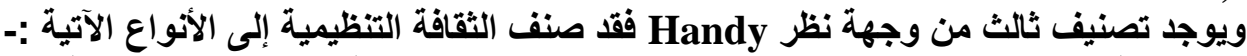

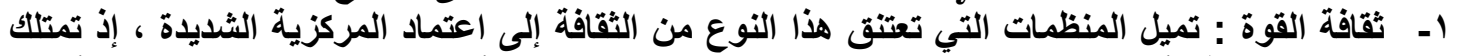

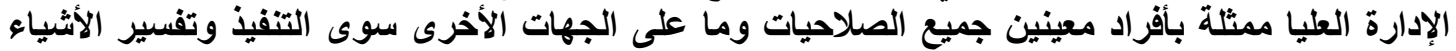

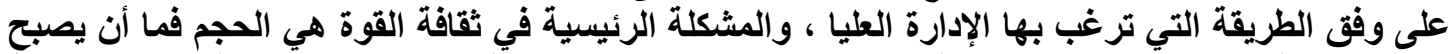

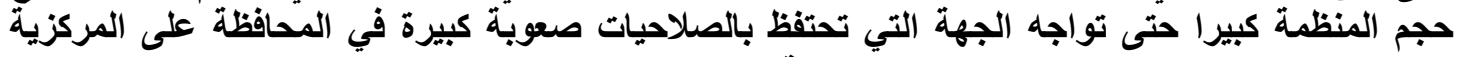

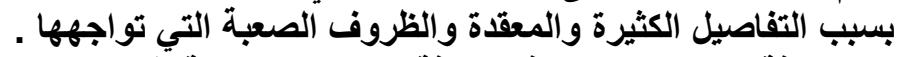

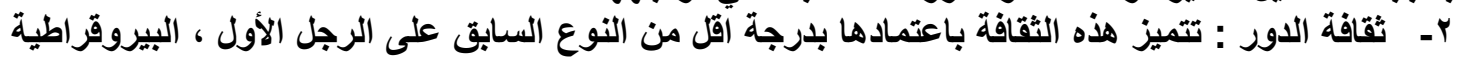

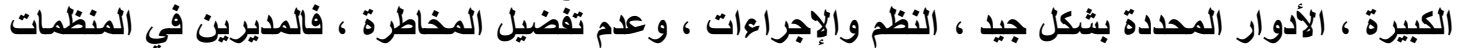

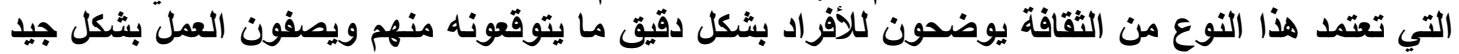

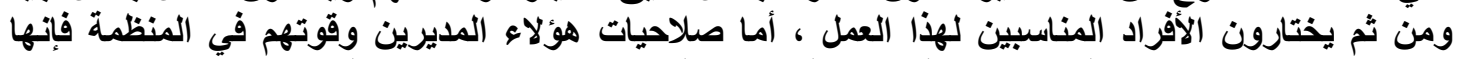

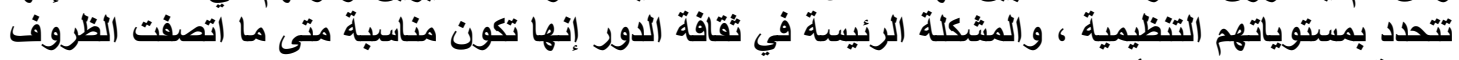

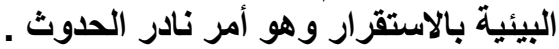

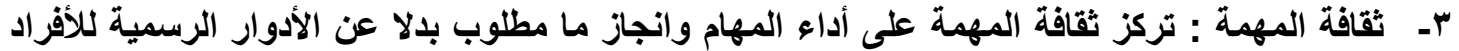

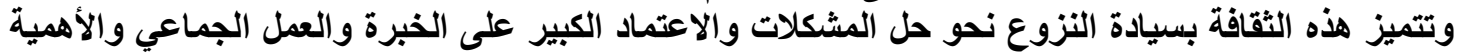

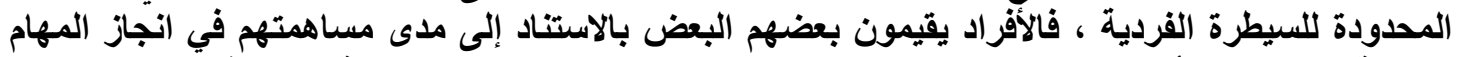

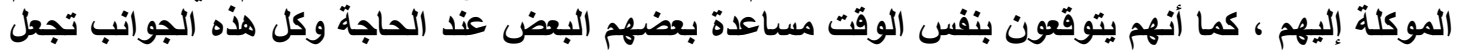

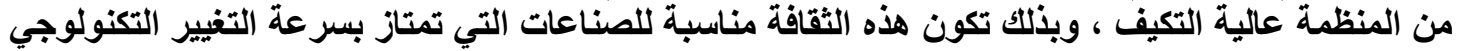

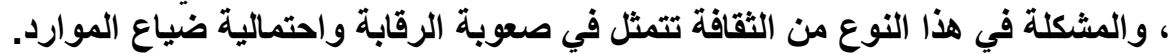

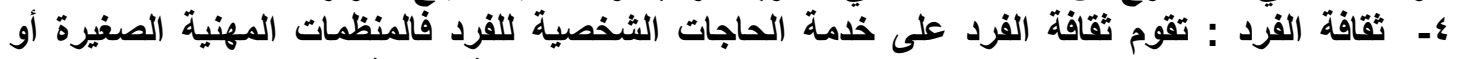

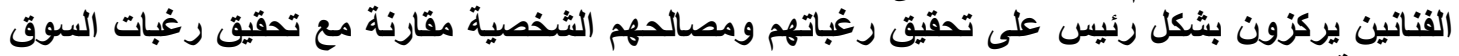

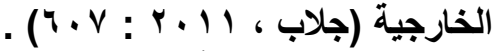

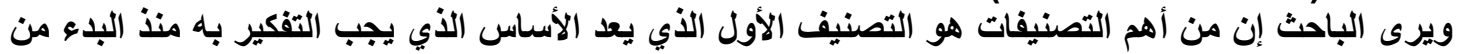

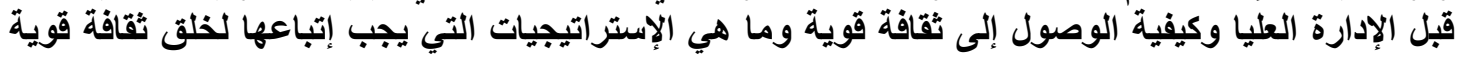




\section{بحث في شركة صناعات الاصبا غ الهديثة}

في المنظمة تعمل على تحقيق الأهداف ، أما باقي التصنيفات فقد تعطي خطوات واضحة لكيفية الوصول

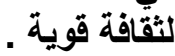

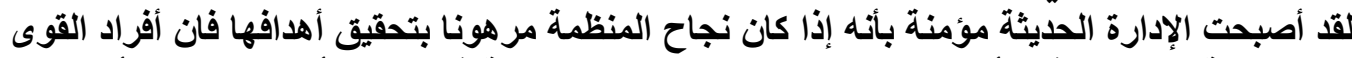

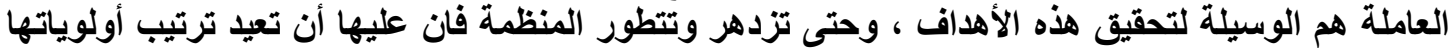

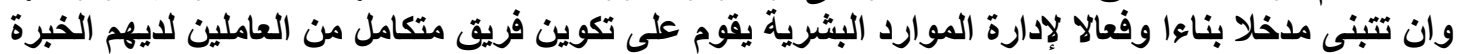

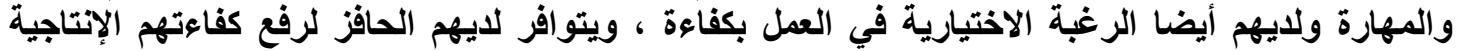

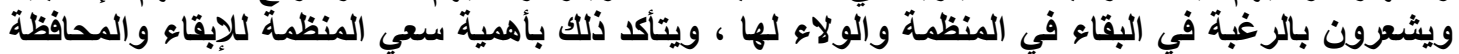

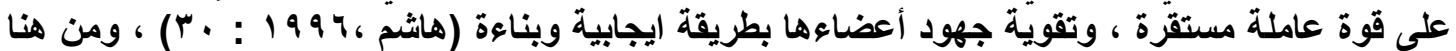

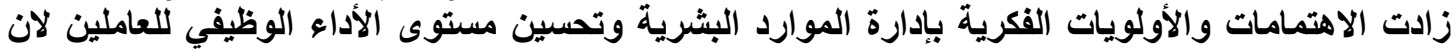

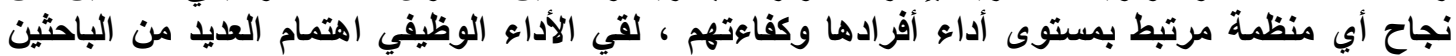

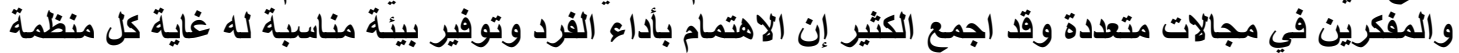

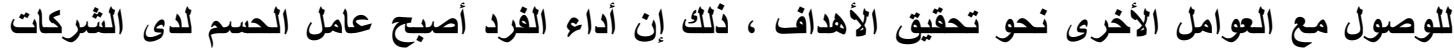

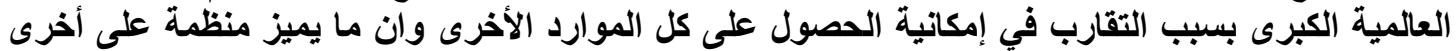

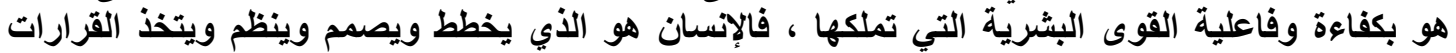

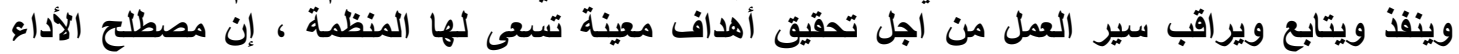

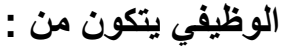

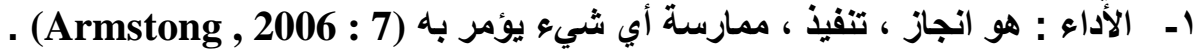

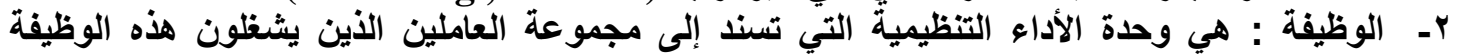

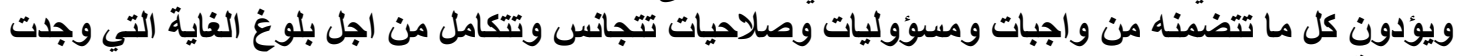

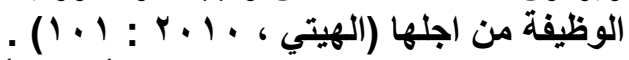

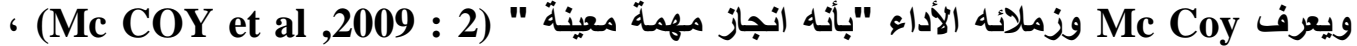

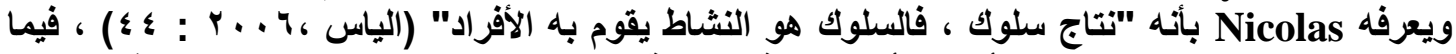

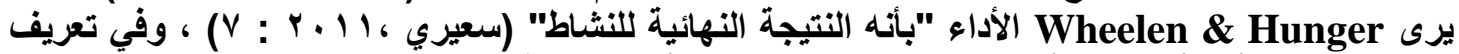

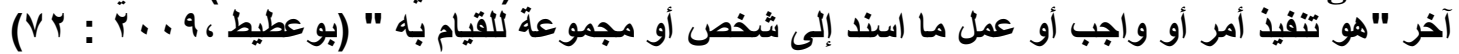
، ويمكن تعريف الأداء الوظيفي "بأنه تنفيذ الموظف لإعماله ومسئولياته التي تكلفه بها التها المنظمة أو الجهة

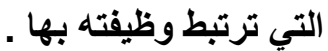




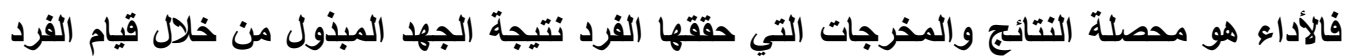

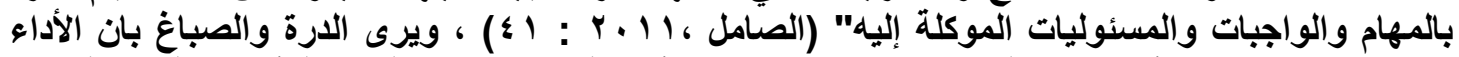

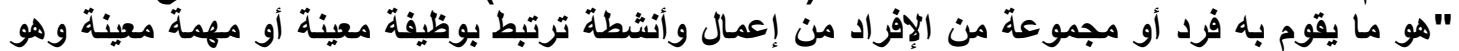

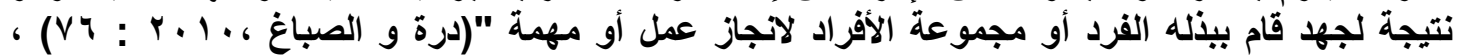

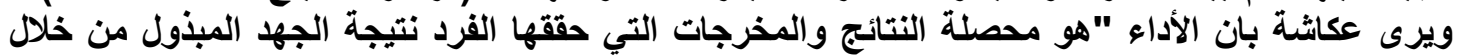

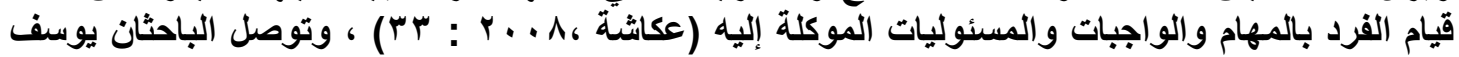

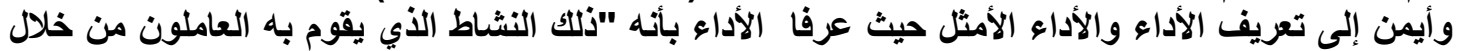

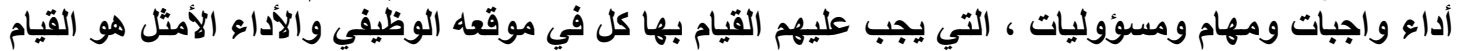

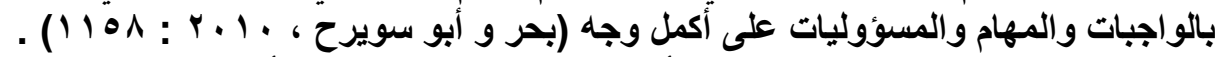

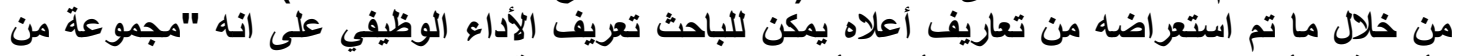

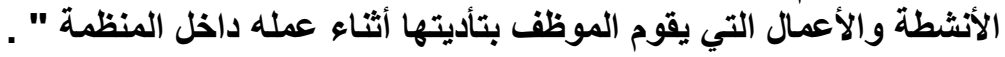

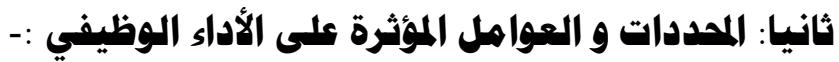

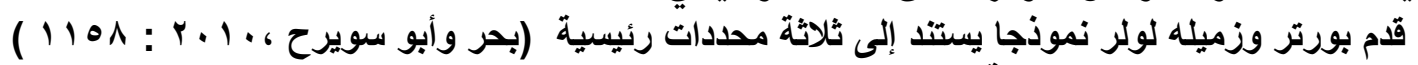

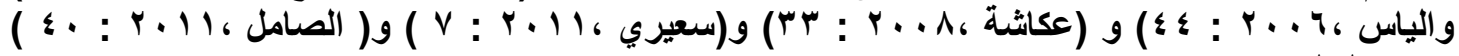

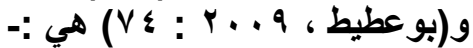
ا- الجهد المبذول : يشير الجها إلى الطاقة الجسمانية والعقلية التي يبذلها الفرد لأداء مهمته أو وظيفته

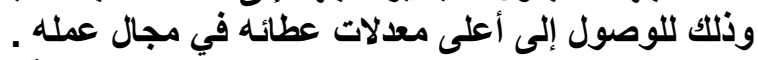

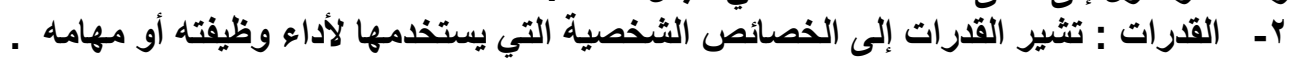

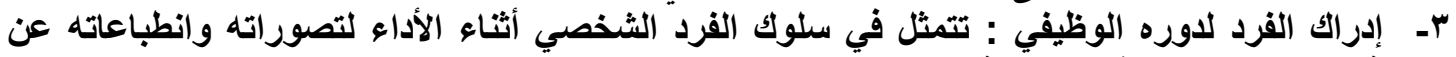

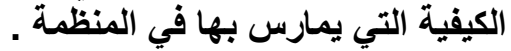

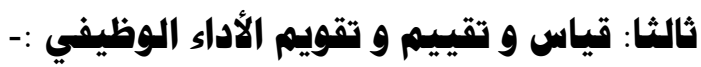

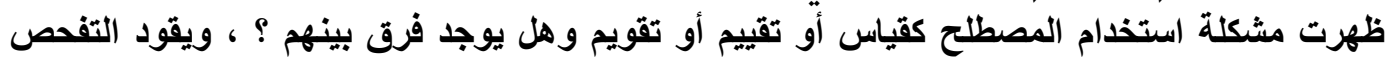

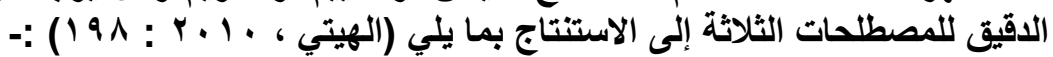

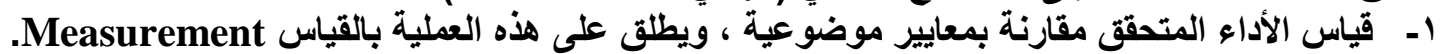

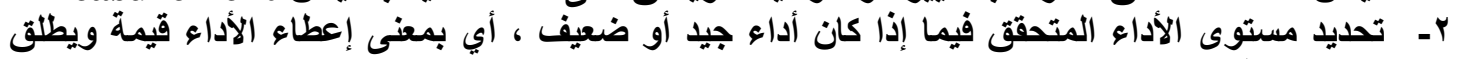

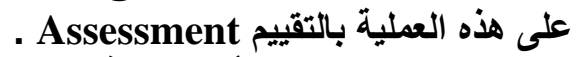
r- تعزيز نقاط القوة أو معالجة نقاط الضعف في الأداء المتحقق ويطلق على هذه العملية بالتقويم . Evaluation

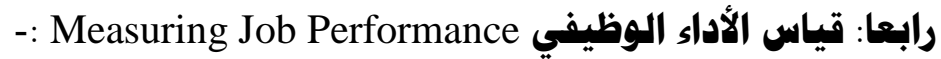

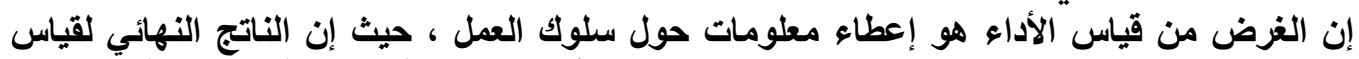

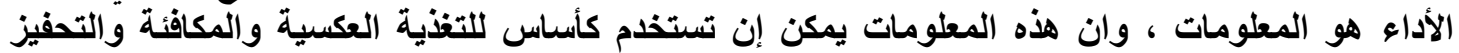

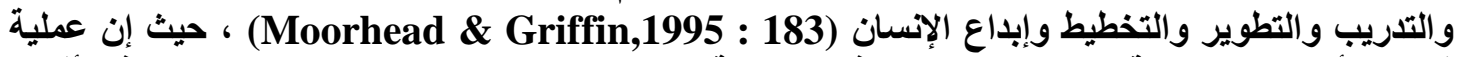

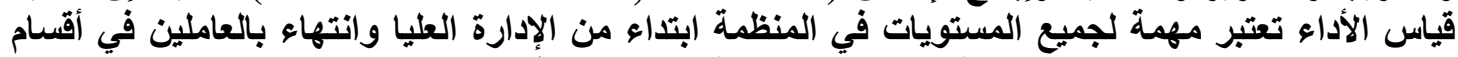

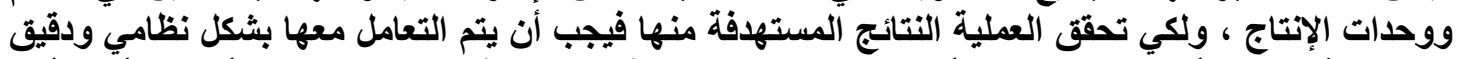

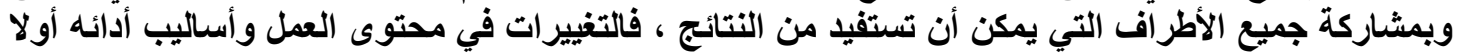

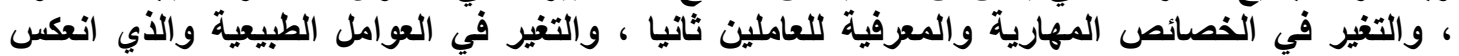

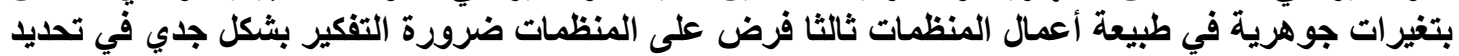

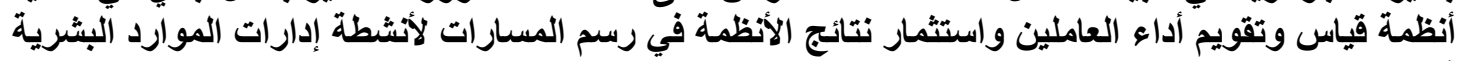

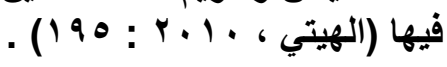




\section{بهث في شركة صنا عات الاصباغ الهديثة}

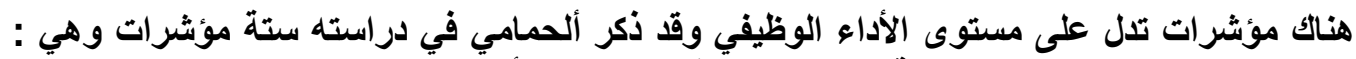

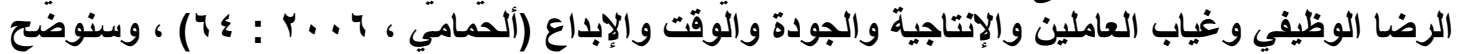

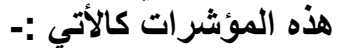

أولا : الرضا الوظيفي Job Satisfaction :- يشير الرضا الوظيفي أو الرضا عن العمل بصفة عامة إلى الى الرئ

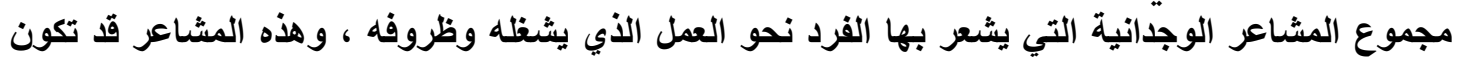

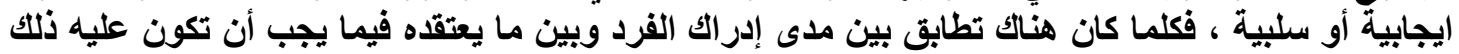

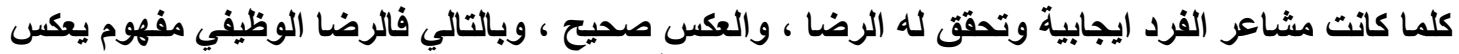

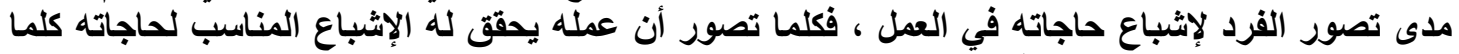

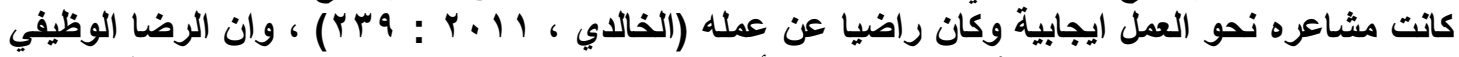

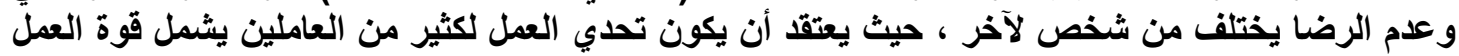

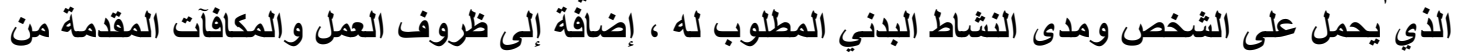

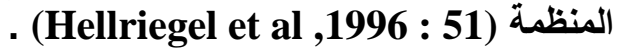

ويعرف Locke الرضا الوظيفي على "أنها حالة عاطفية ممتعة أو ايجابية ناتجة عن تقييم الوظيفة

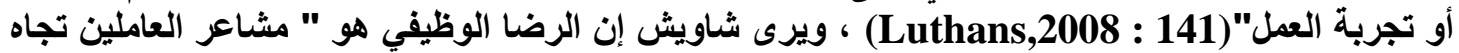

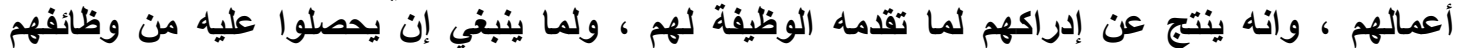

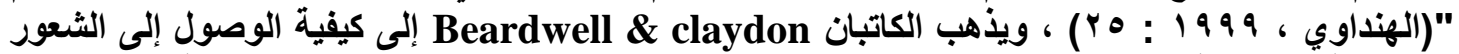

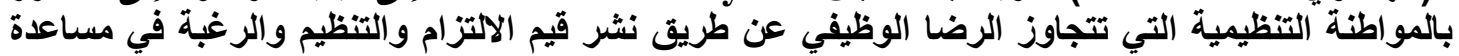

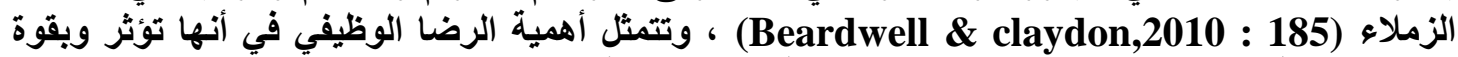

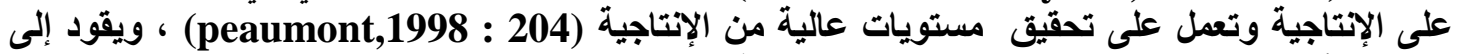

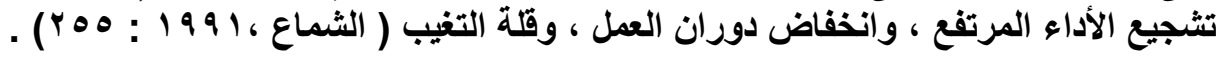

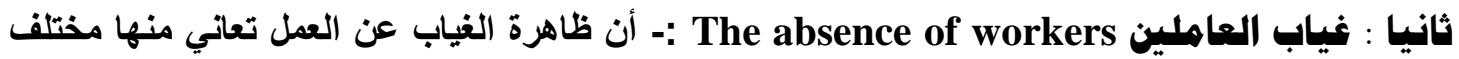

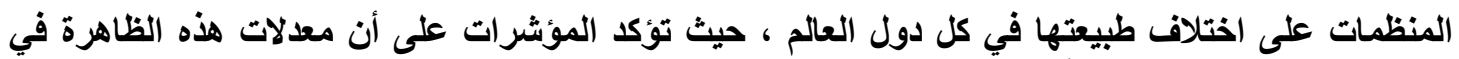

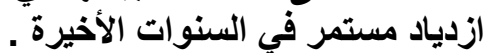

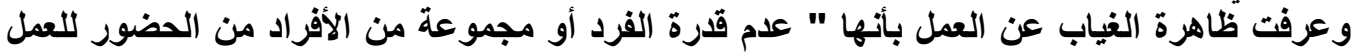

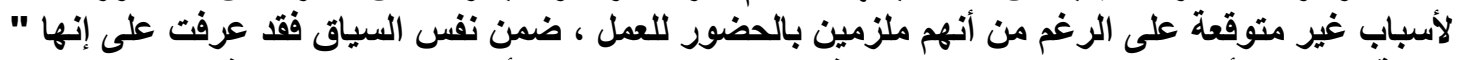

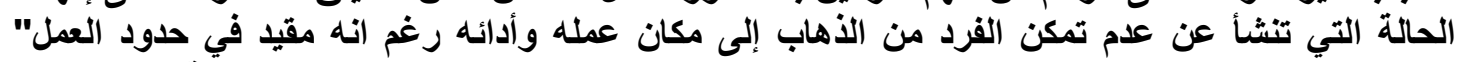

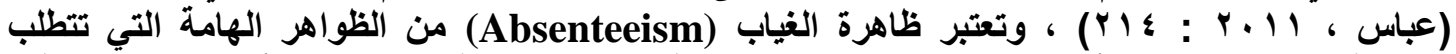

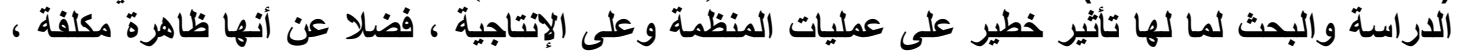

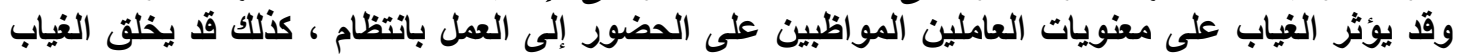

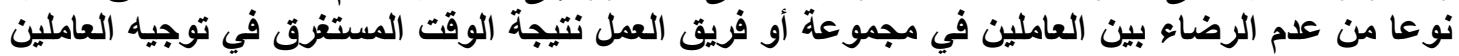

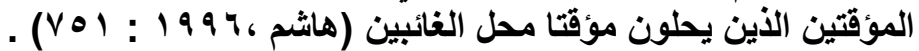
ثالثا : الإنتاجية Productivity :- تمثل الإتتاجية إحدى أهم القضايا الحيوية التي تؤثر على معدلات النمو

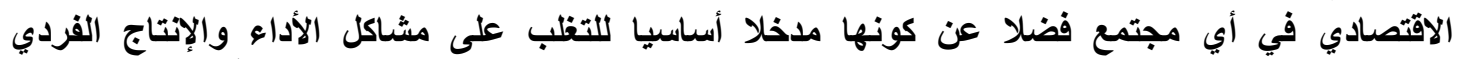

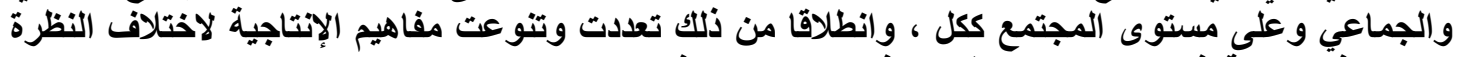

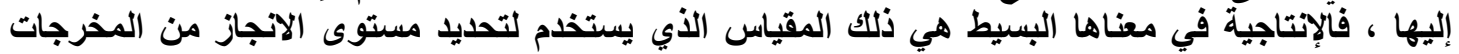

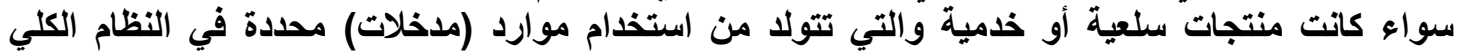

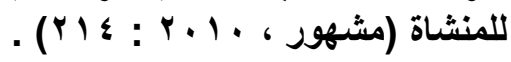




\section{بهث في شركة صنا عات الاصباغ الهديثة}

ويعرفها Reid \& Sanders على أنها "مقياس لمدى كفاءة المنظمة التي تحول المدخلات إلى إلى مخرجات (41) : 41 (Reid \& Sanders,2010) ، و يرى Haizer \& Render على أنها نسبة المخرجات

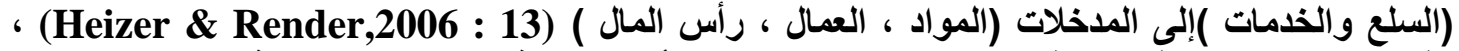

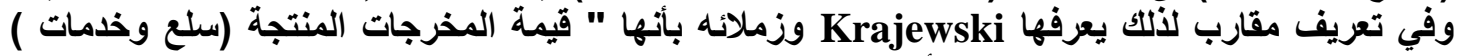
، وقسوما على المدخلات من الموارد (الأجور وتكاليف المعدات ....الخ) (13: ، ويذهب Davis إلى تعريفها بأنها " كفاءة العملية التي تحول المدخلات إلى مخرجات " (Davis et 152) .al ,2007 :

رابعا : الجودة Quality :- : أصبحت الجودة عاملا مهما في اختيار المستهلك للسلعة أو الخدمة ، لقد

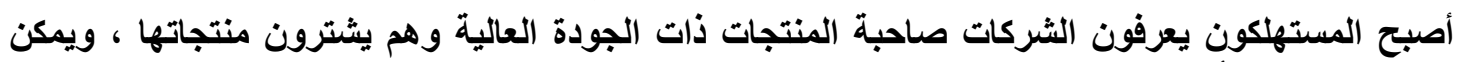

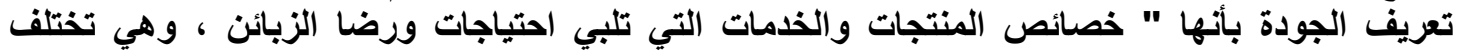

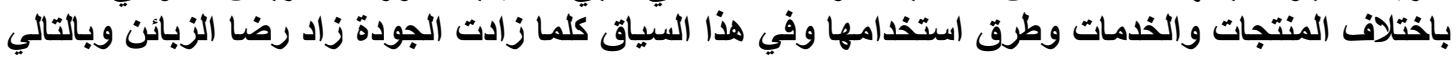

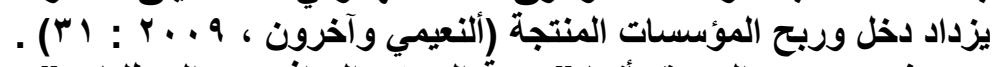

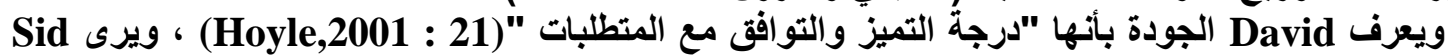

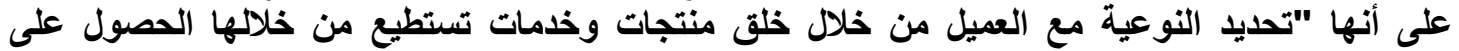

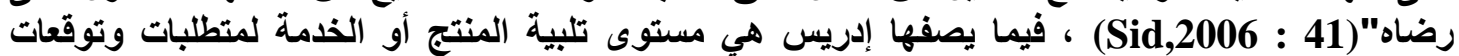

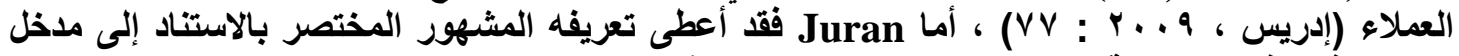

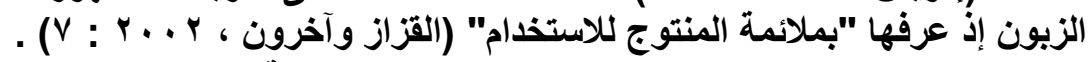

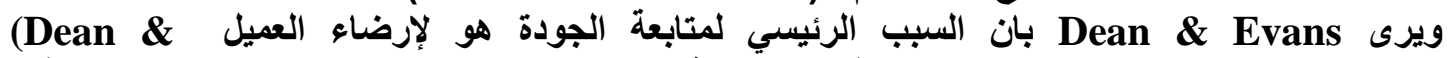

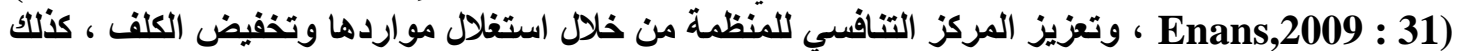

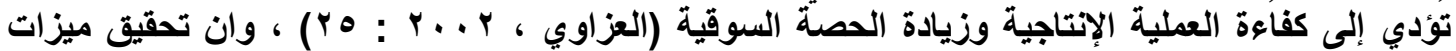

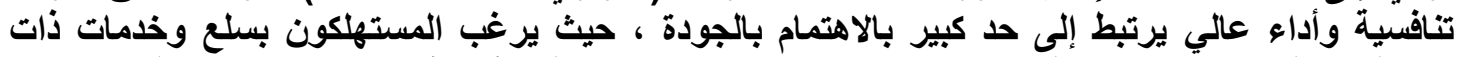

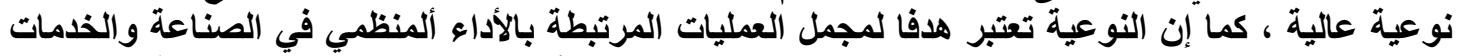

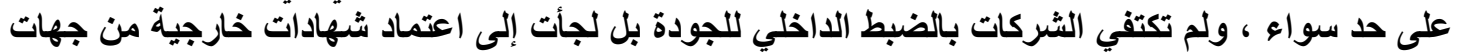

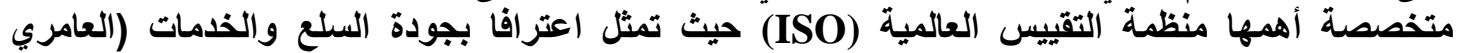

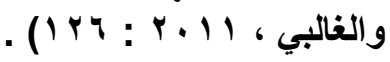
خاهسا : الوقت Time :- : يعد الوقت من أهم عناصر الإدارة ، وهو يمر بسرعة ودون توقف ، ولا يمكن

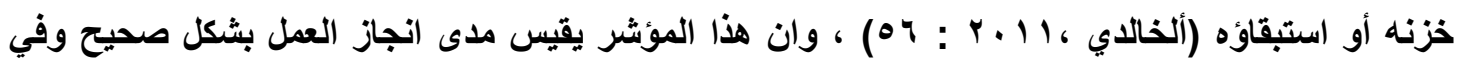

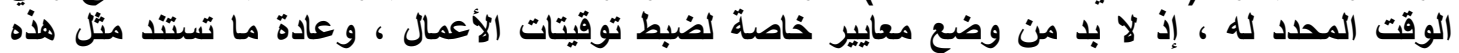

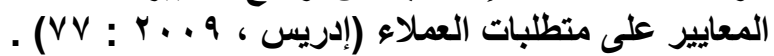

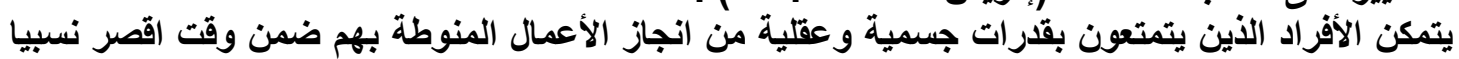

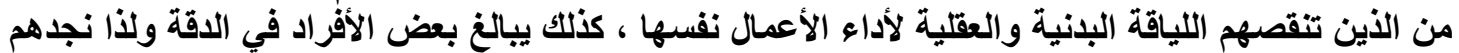

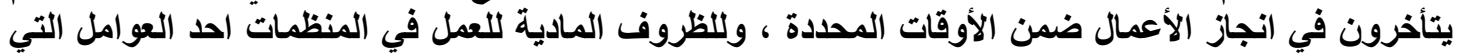

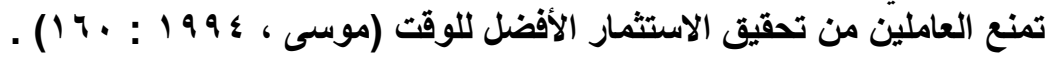




\section{بحث في شركة صنا عات الاصباغ الهديثة}

سادسا : الإبداع Creativity :- يتمثل الإبداع بأنه أفكار تتصف بأنها جليدة ومفيدة ومتصلة بحل امثل

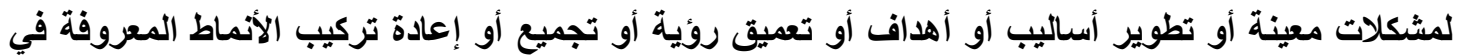

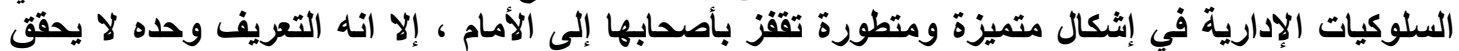

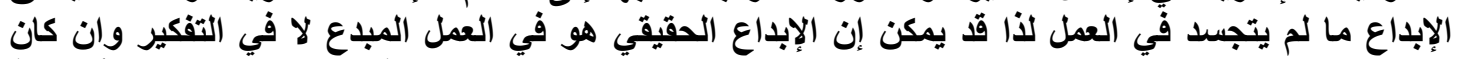

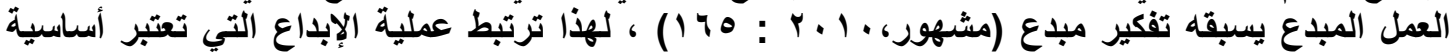

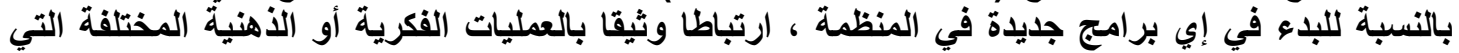

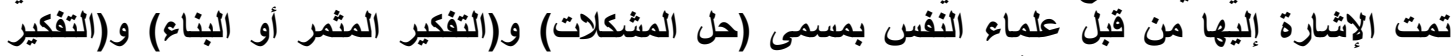

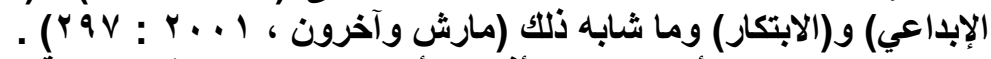

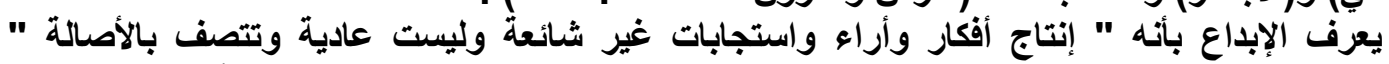

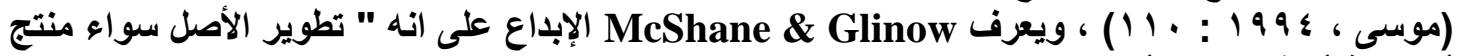

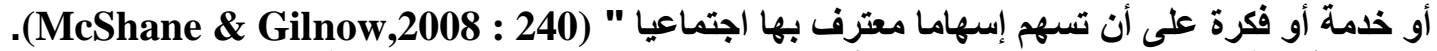

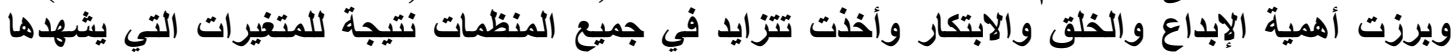

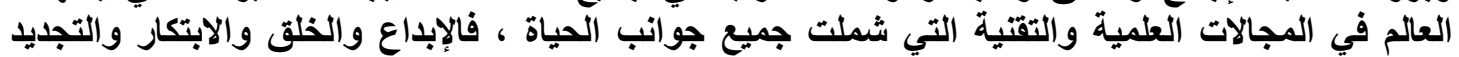

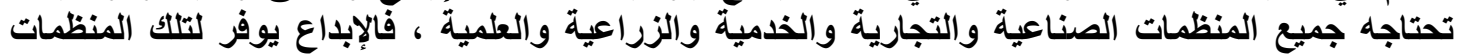

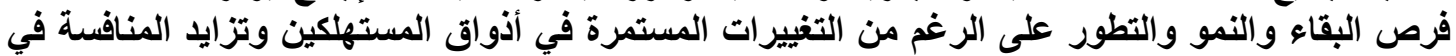

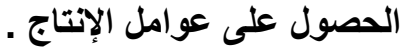

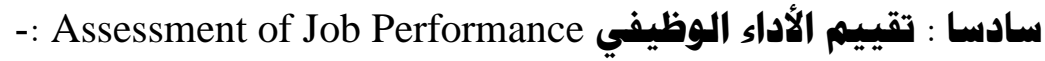

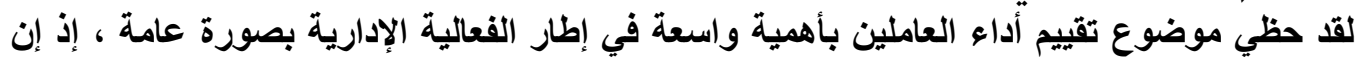

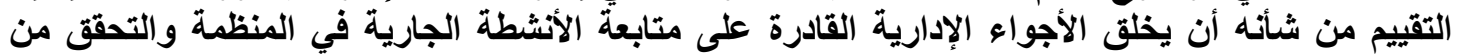

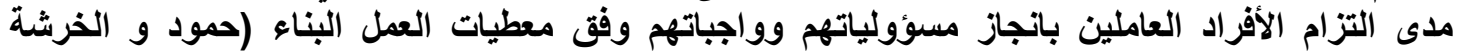
(lor: r. 11،

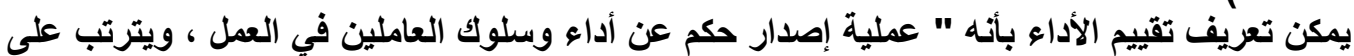

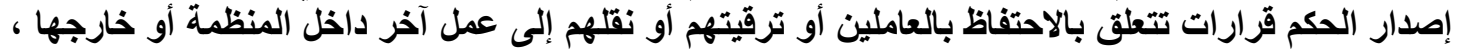

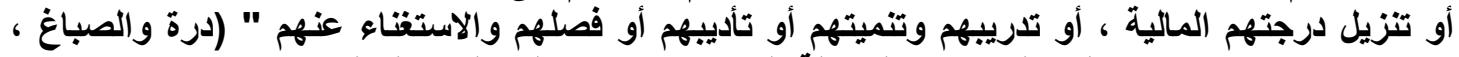

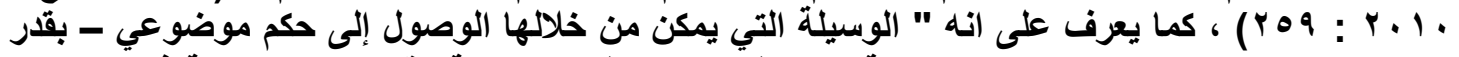

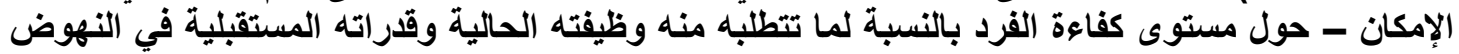

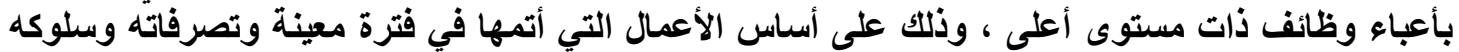

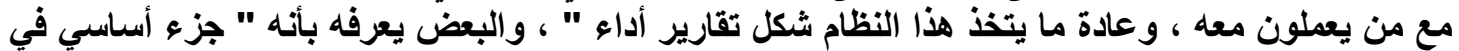

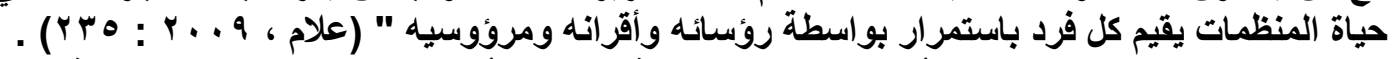

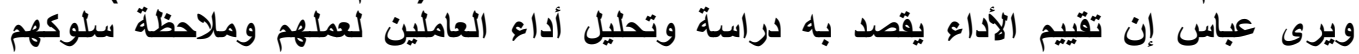

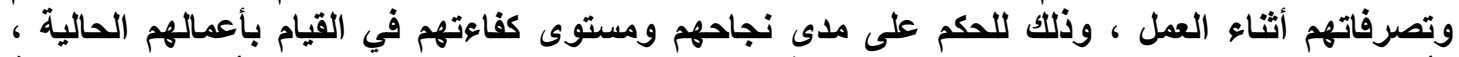

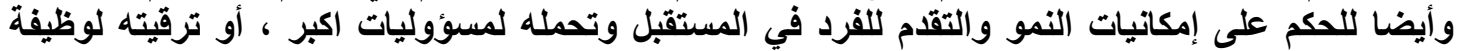

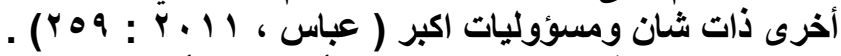

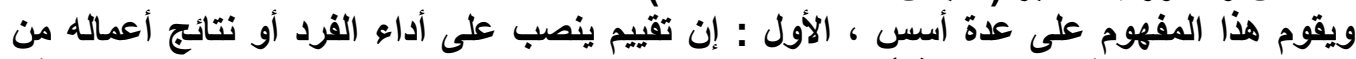

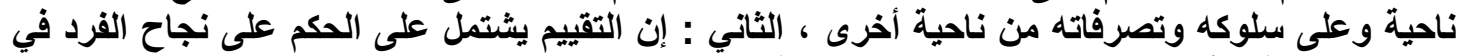

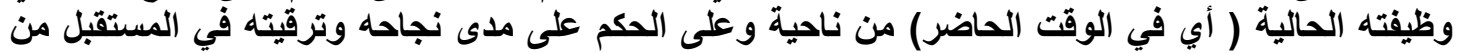

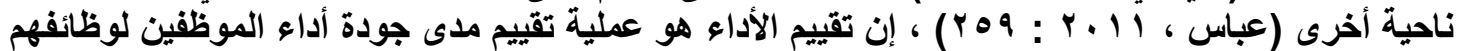

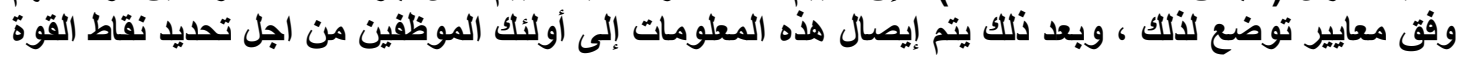

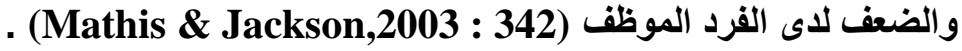




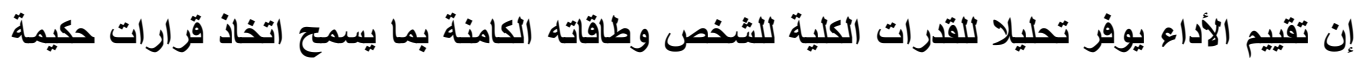

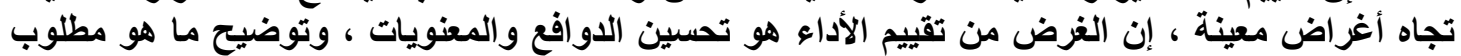

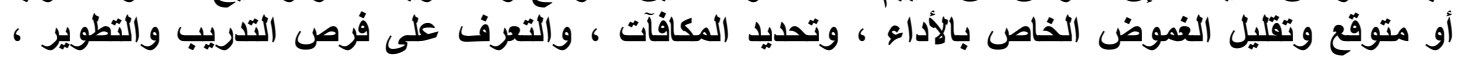

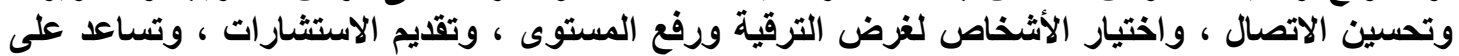

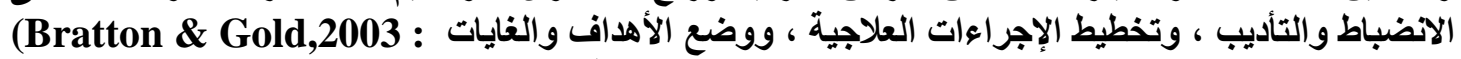

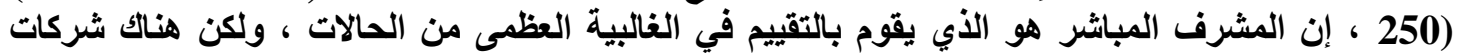

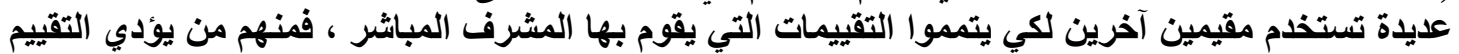

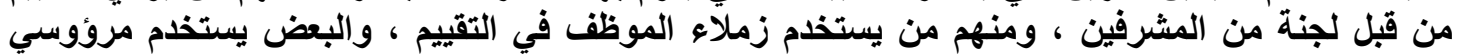

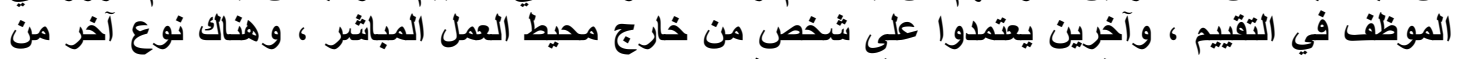

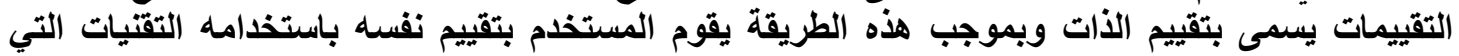
يستخدمها المقيمون الآخرون ، ولكن هذه الطريقة تقابلها المنظمات بالثك (265 : ويضيف Torrington \& Hall بوجود مراكز للتقييم متخصصة تقوم بعملية التقييم \&orrington \&

. Hall,1998 : 321)

قد يفثل نظام تقييم الأداء للعديد من الأسباب ، منها عدم تحديد الفترة الزمنية التي يجب تقبيم

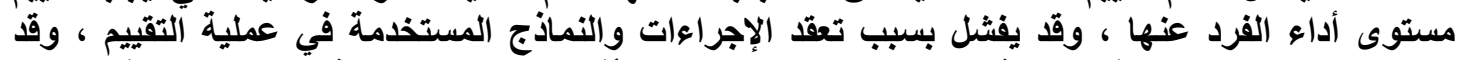

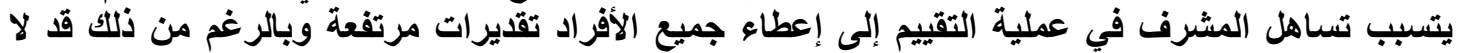

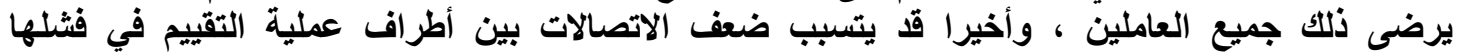

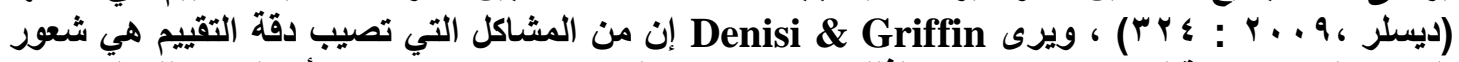

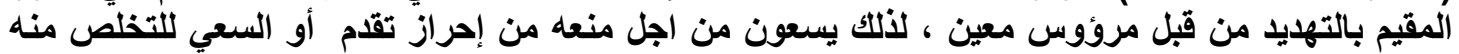

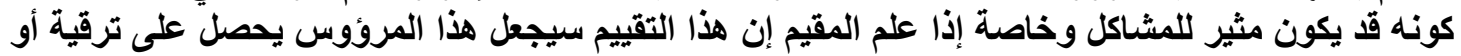

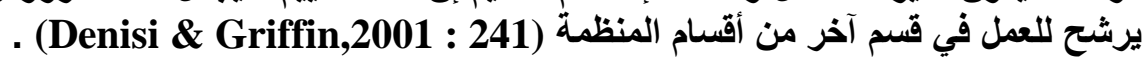

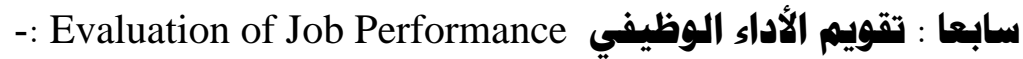

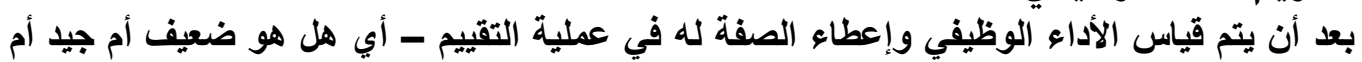

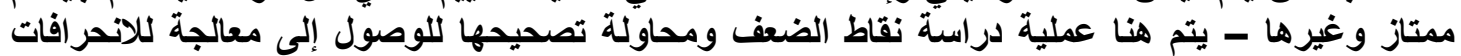

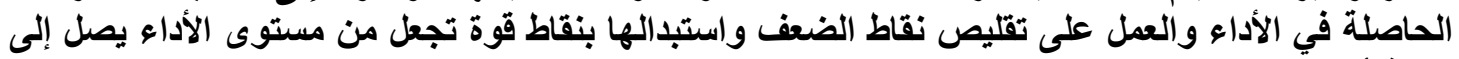

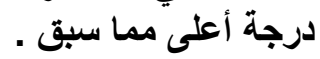

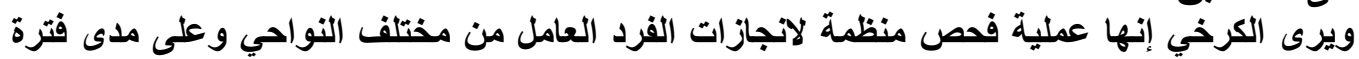

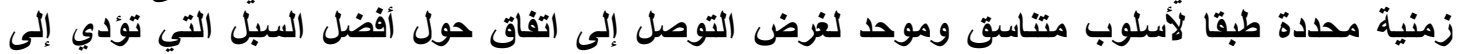

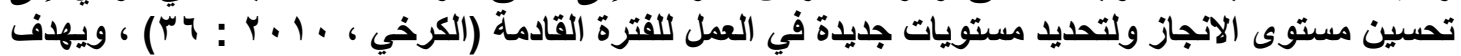

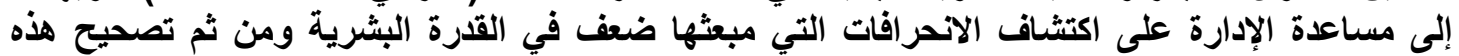

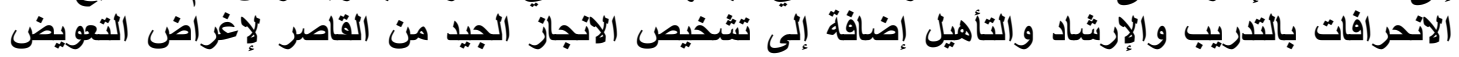

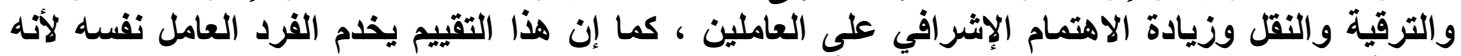

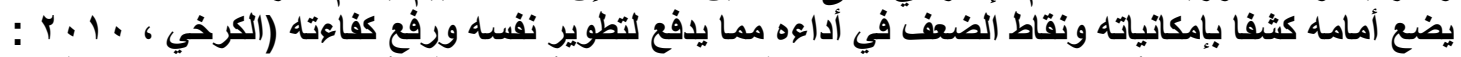

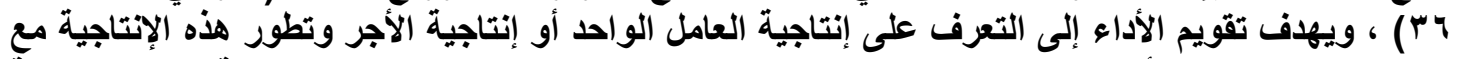

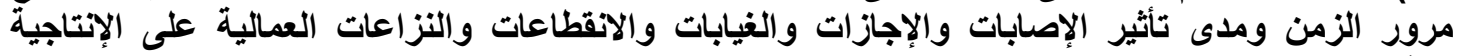

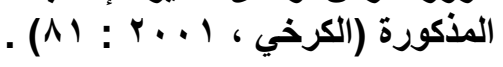




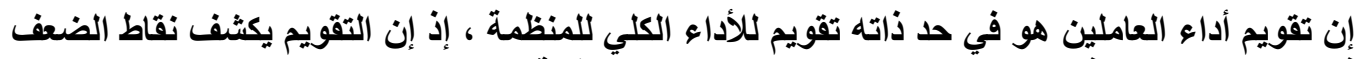

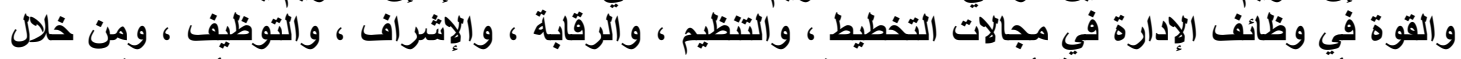

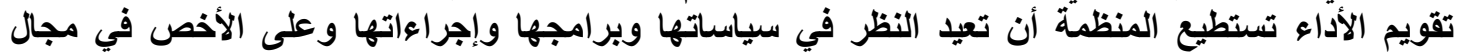

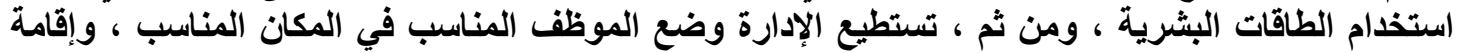

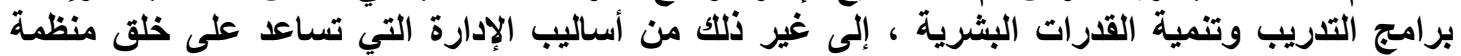

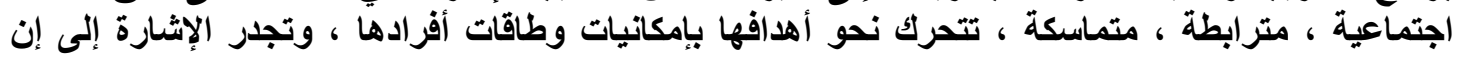

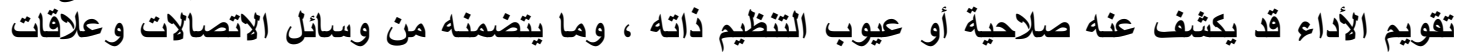

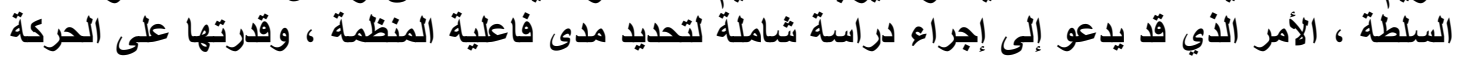

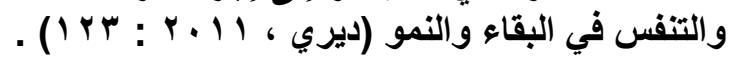

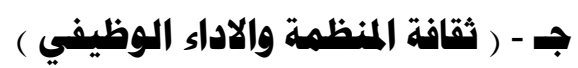

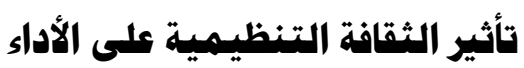

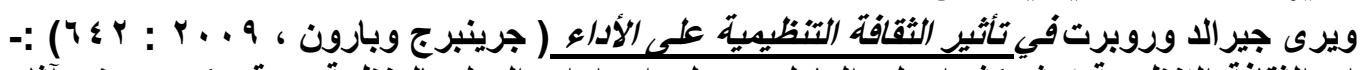

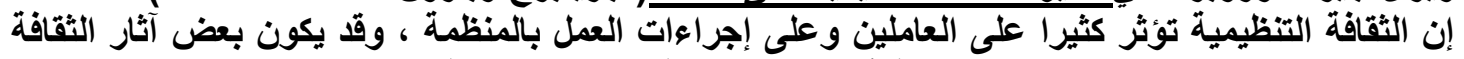

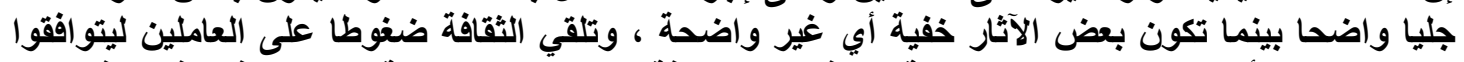

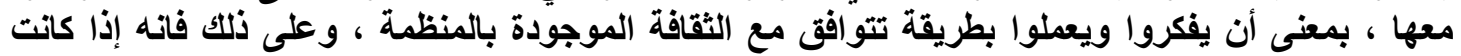

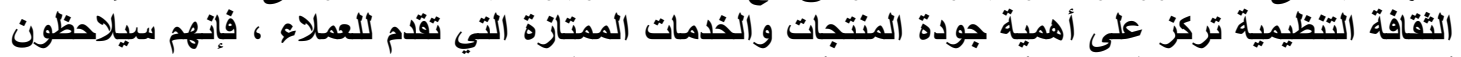

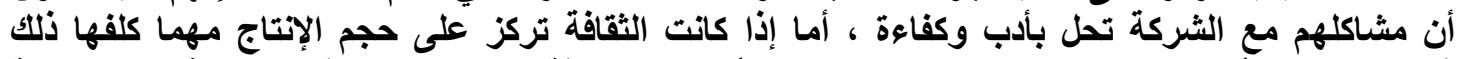

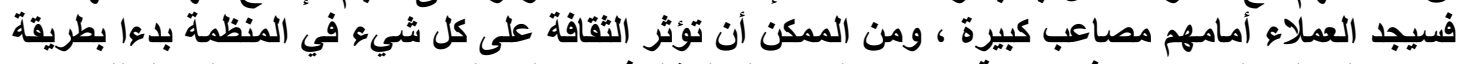

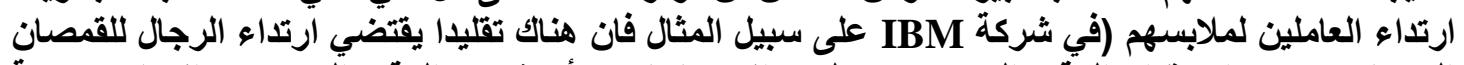

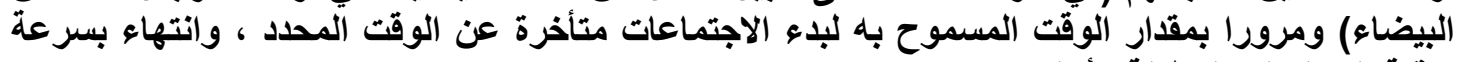

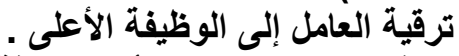

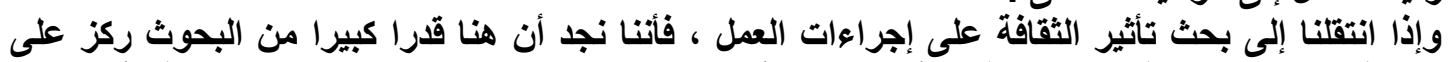

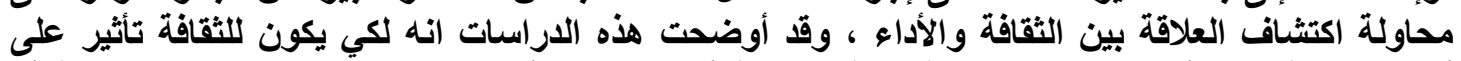

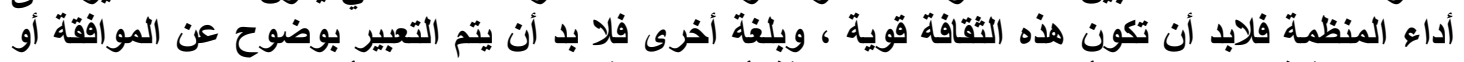

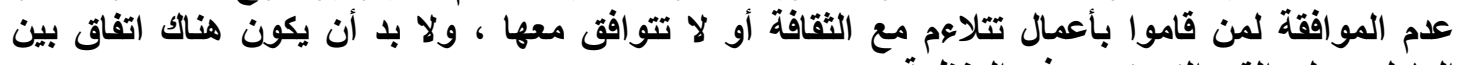
العاملين على القيم التي تسود في المنظمة ـاعمال 
$-r \leqslant q$

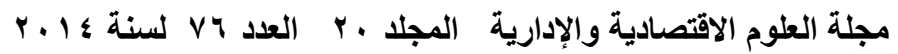

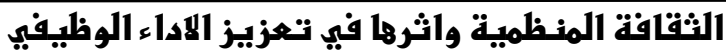

بهث في شركة صناعات الاصباغ العديثة

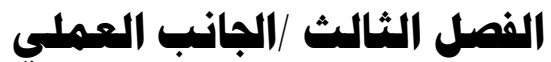

من خلال الشكل رقم (Y) نبين توزيع اجابات افراد العينة حيث يوضح التمنحى البياني لتوزيع بيانات المحور شكل(r) يوضح المنحى لتوزيع بيانات المحور الاول ( ثقافة المنظمة)

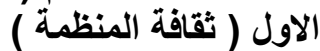

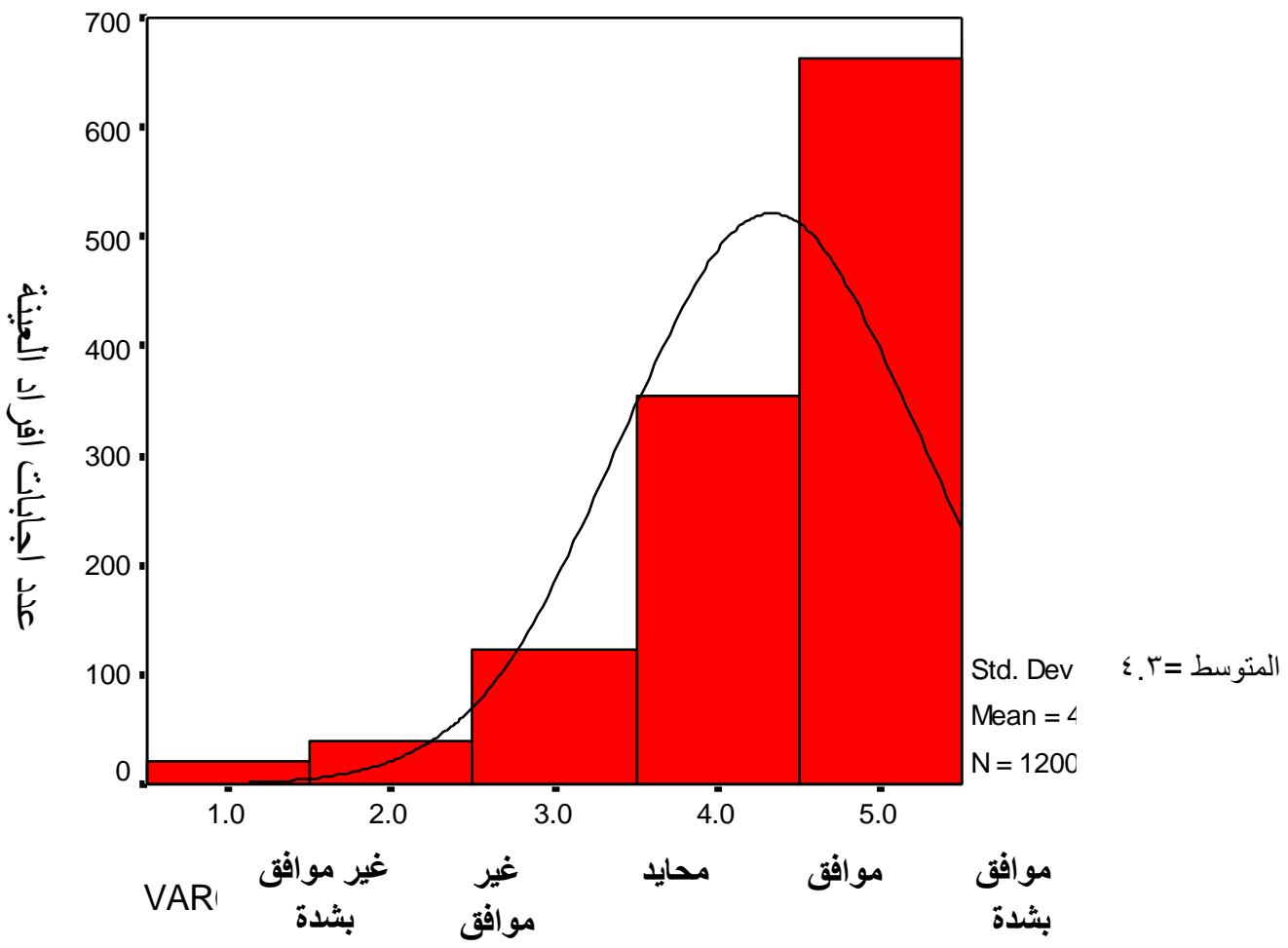

يلاحظ إن المتوسط الحسابي لإجابات إفراد العينة للمحور الاول بلغ (ب.؟؟) ، وهو اعلى من القيمة المعيارية

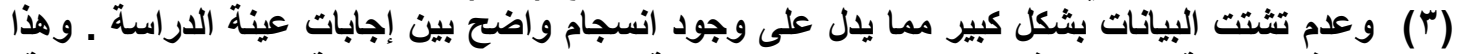

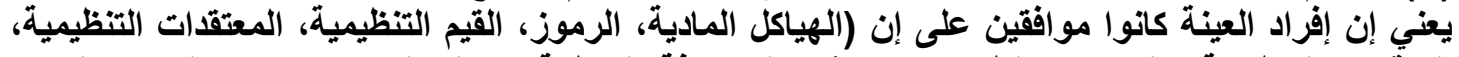

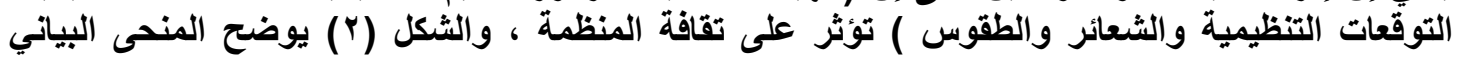

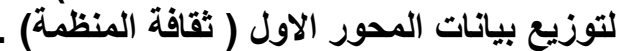
ومن خلال الثكل رقم (ّ) نبين توزيع اجابات الفراد العينة حيث يوضح المنحى البياني لتوزيع بيانات

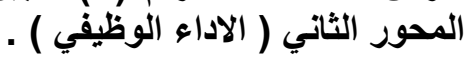




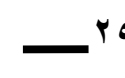

ro.

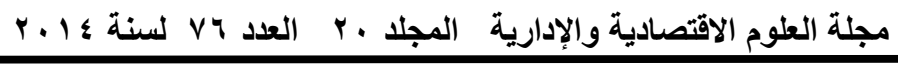

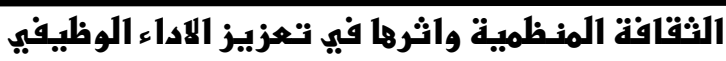

بحث في شركة صنا عات الاصباغ الهديثة

شكل (r) يوضح المنحى البياني لتوزيع بيانات المحور الثاني الاداء الوظيفي

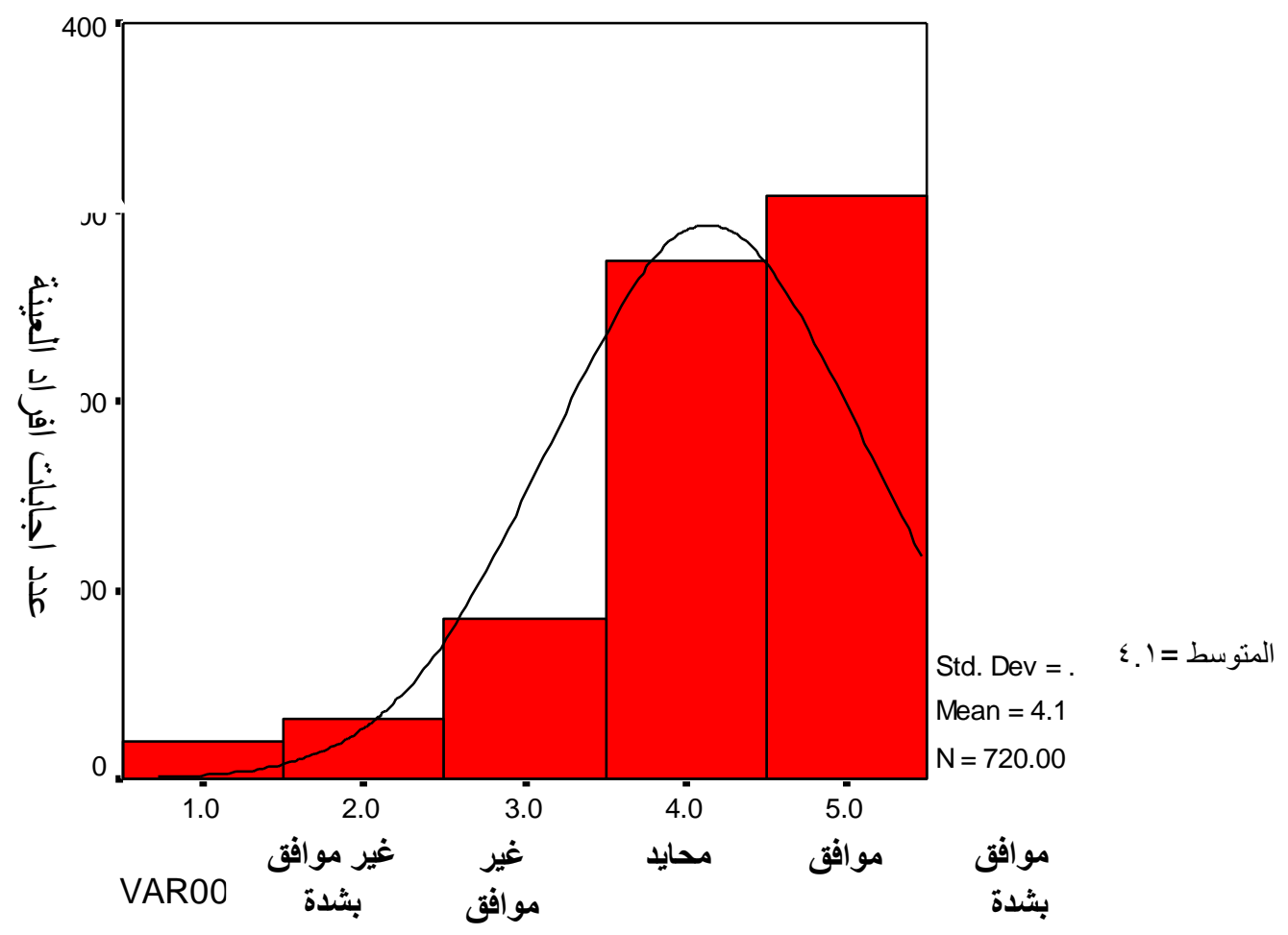

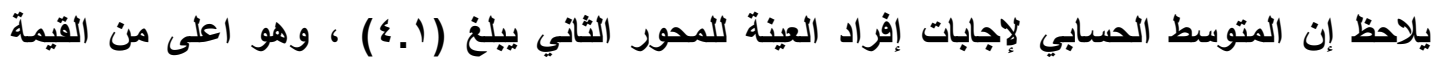

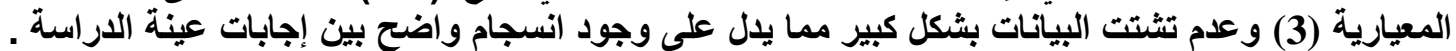

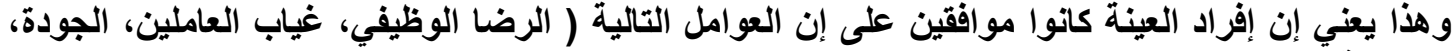

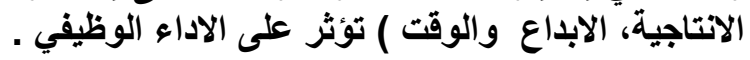

\section{اولا : الفرضية الرئيسية الأولى :}

لاختبار صحة الفرض الأول للبحث :

: H0

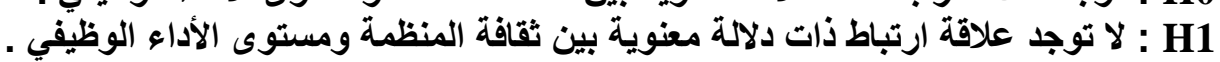

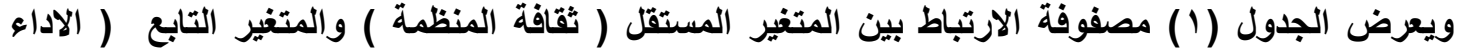

جذول رقم (1) يبين مصفوفة الارتباط بين ثقافة المنظمة والاداء الوظيفي

\begin{tabular}{|c|c|c|}
\hline الاداء الوظيفي & ثُقافة المنظمة & المتغير \\
\hline$\cdot V 0 \leq$ & 1 & ثقافة المنظمة \\
\hline 1 & $\because V 0 \leq$ & الاداء الوظيفي \\
\hline
\end{tabular}

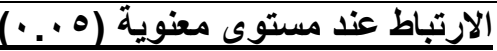

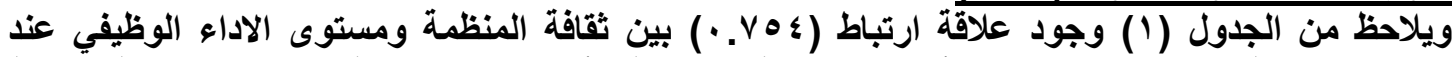

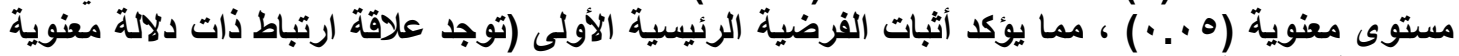

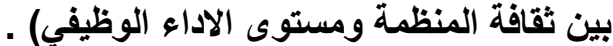

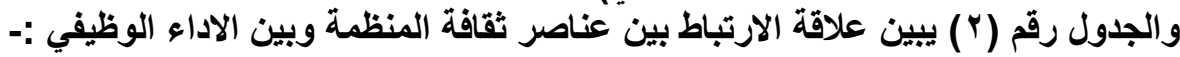


جدول (2) يوضح مصفوفة الارتباط بين متغيرات ثقافة المنظمة والاداء الوظيفي

\begin{tabular}{|c|c|c|c|c|c|c|}
\hline & الماديةكل & الرموز & التيظيمية & التنظيمية & التنظيمية & والطقوسئر \\
\hline الاداء الوظيفي & •.А५। & $\because \vee \vee 9 \wedge$ & $\cdot . V V \varepsilon$ & . VVY &.$\wedge \vee \neg$ & 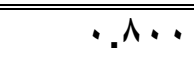 \\
\hline
\end{tabular}

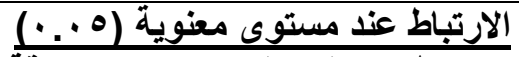

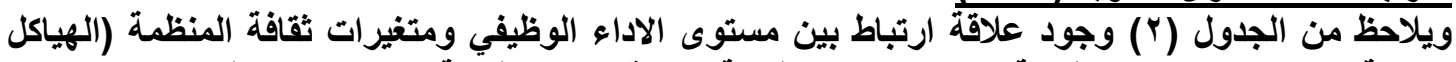

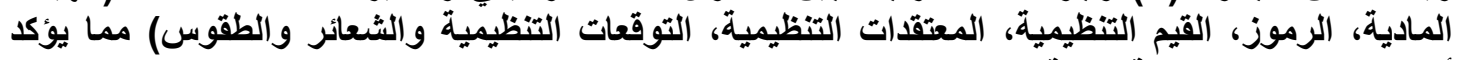
أثبات الفرضيات الفرعية الستة الفية الفية

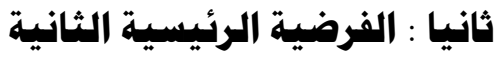

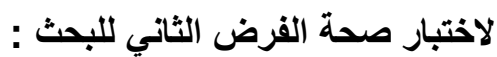
• • •

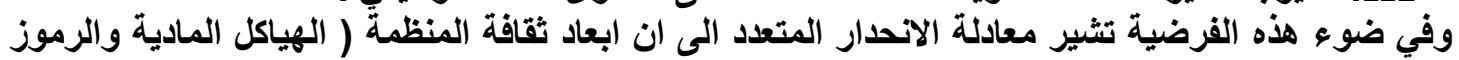

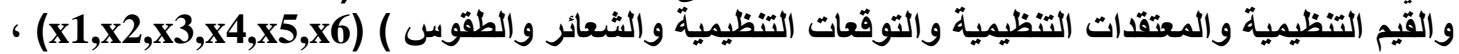
تؤثر في الاداء الوظيفي (Y) مجتمعة في ان واحد ، وهذا التاثير يفترض وجود علاقة دالية والية بين القيمة

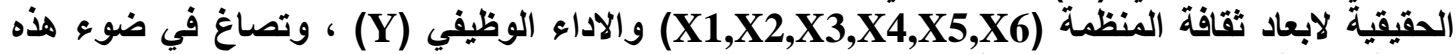
العلاقة معادلة الاتحدار المتعدد الاتية :- لإنة المنظة

\section{$\mathrm{Y}=\mathrm{a}+\mathrm{B} 1 \mathrm{X} 1+\mathrm{B} 2 \mathrm{X} 2+\mathrm{B} 3 \mathrm{X} 3+\mathrm{B} 4 \mathrm{X} 4+\mathrm{B} 5 \mathrm{X} 5+\mathrm{B} 6 \mathrm{X} 6$}

اذ ان (a) اذ انمثل مقدار ثابت (Constant)

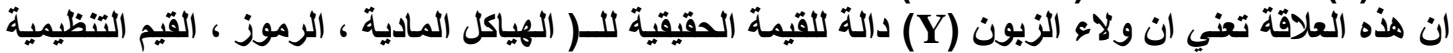

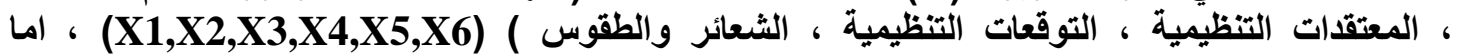

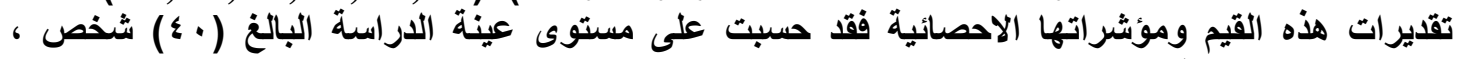

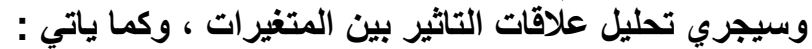

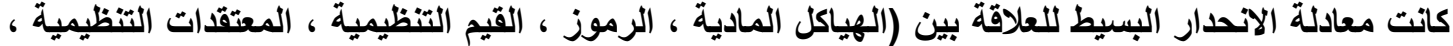

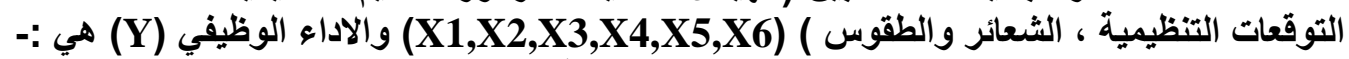

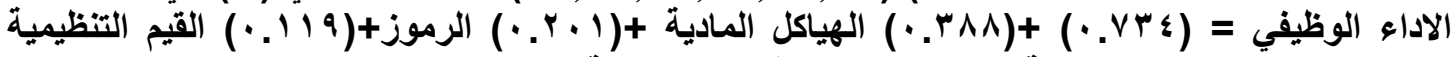

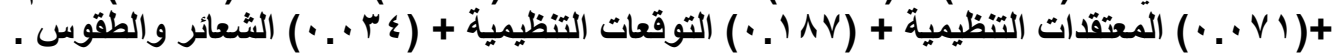
في اطار هذه الصياغة فان جدول تحليل التباين اسفر عن نتائج جرى في ضوائها تحليل التباين بين هذانه

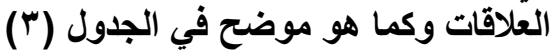

\begin{tabular}{|c|c|c|c|c|c|}
\hline المعنوية & قالمحسة (f) & المربعات متوسط & المربعات & درجة الحرية & مصدر التباين \\
\hline \multirow[t]{3}{*}{$\ldots \cdots$} & 139.947 & rq1.rvi & rq1.rvi & 1 & الانعدار \\
\hline & & 2.79585 & 106.2423 & 38 & الخطأ \\
\hline & & & 497.5133 & 39 & المجموع \\
\hline
\end{tabular}

اما جدول المعاملات فقد اشار الى القيم المبينة وكما ياتي :- 


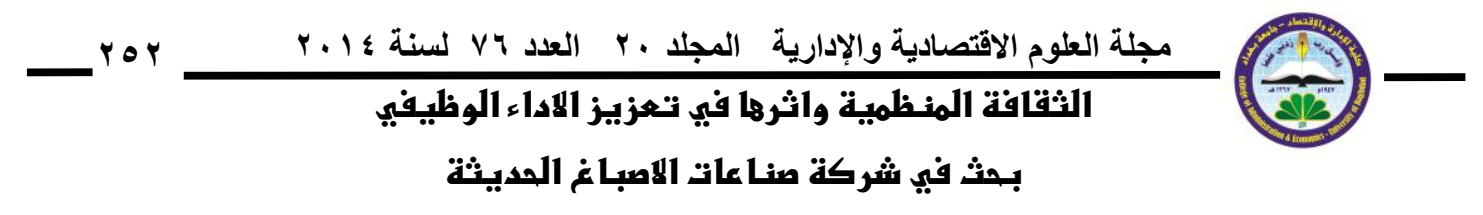

\begin{tabular}{|c|c|c|c|c|c|}
\hline \multicolumn{6}{|c|}{ جدول رقم (ع) المعاملات } \\
\hline \multirow[t]{2}{*}{ مستوى المعنوية } & \multirow[t]{2}{*}{ معامل (t) } & \multirow{2}{*}{ المعيارية } & \multicolumn{2}{|c|}{ المعاملات غير المعيارية } & \multirow[t]{2}{*}{ النموذج } \\
\hline & & & الخطأ المعياري & معامل B & \\
\hline$\because .1 \cdots$ & 3.371 & & $\cdot .218$ & $\cdot .734$ & الثابت \\
\hline$\cdot .0 \vee \wedge$ & 5.294 & $\cdot .494$ & $\cdot .073$ & $\cdot .388$ & الهياكل المادية \\
\hline$\cdot .708$ & .375 & $\cdot .030$ & $\bullet .090$ & $\cdot .201$ & الرموز \\
\hline$\cdot .389$ & $\cdot .863$ & $\cdot .054$ & $\cdot .076$ & 0.119 & القيم التتظيمية \\
\hline$\cdot .132$ & 1.511 & $\cdot .116$ & $\cdot 078$ & 0.071 & التمعتقدات \\
\hline$\cdot .000$ & 7.651 & $\cdot .589$ & •.077 & 0.187 & التوقعات التنظيمية \\
\hline$\cdot .405$ & $\cdot .834$ & $\cdot .071$ & $\cdot .075$ & 0.034 & الثعائر و الطقوس \\
\hline
\end{tabular}

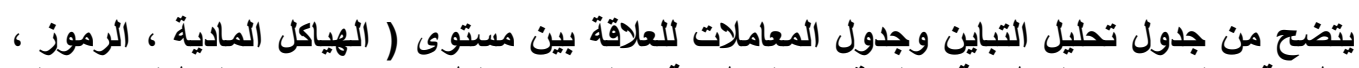

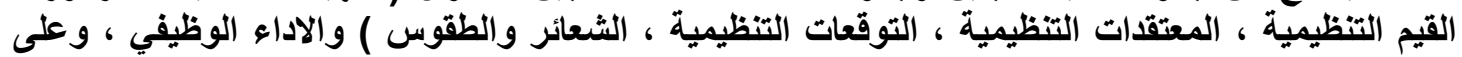

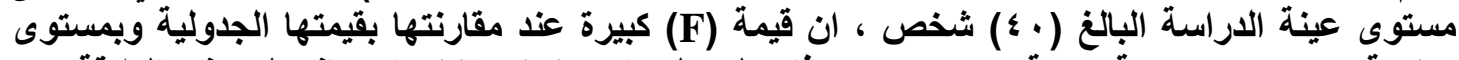

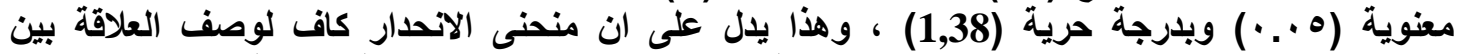

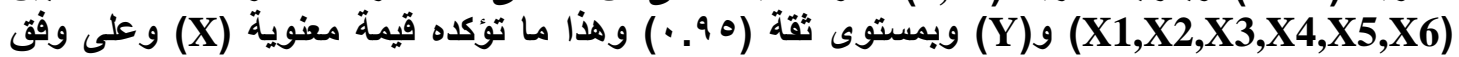

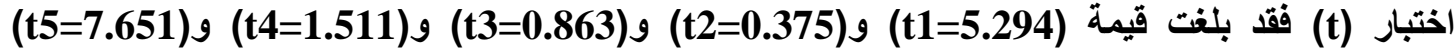

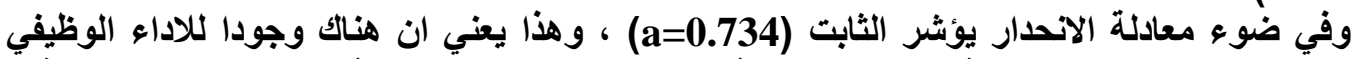
و) و) (t6=0.834)

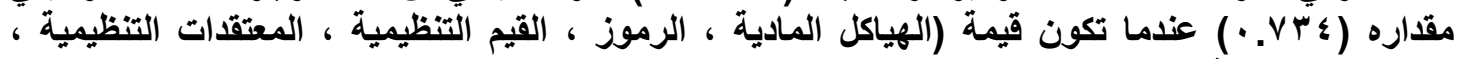

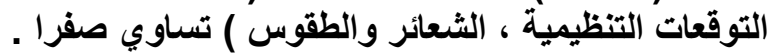

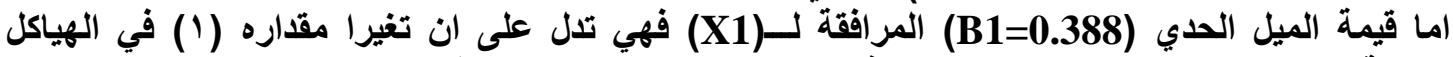

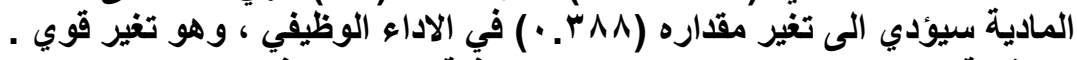

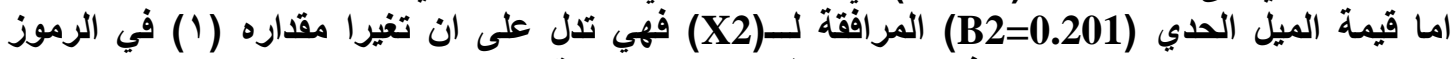

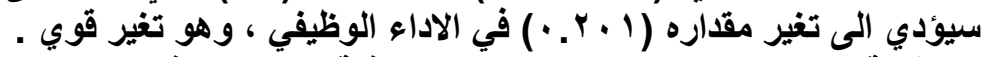

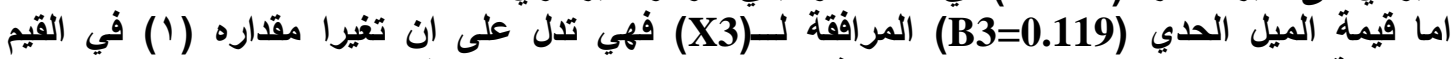

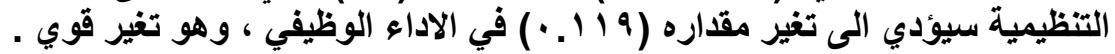

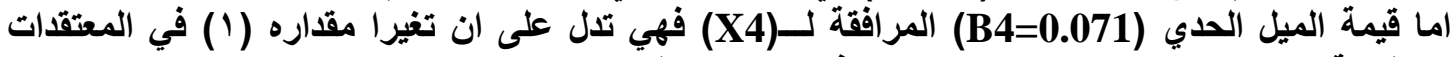

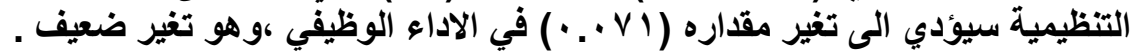

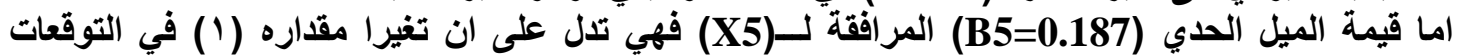

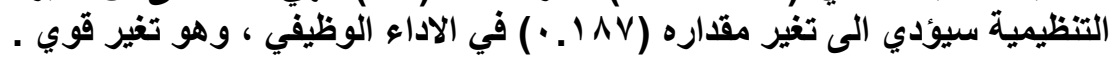

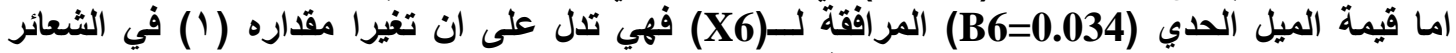

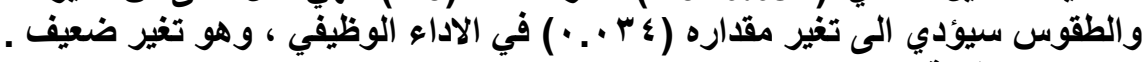

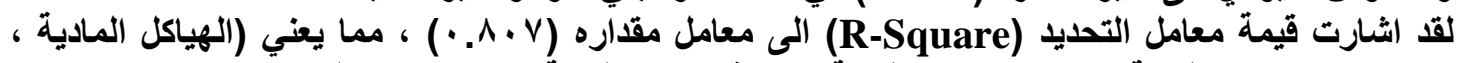

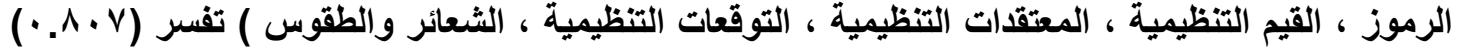

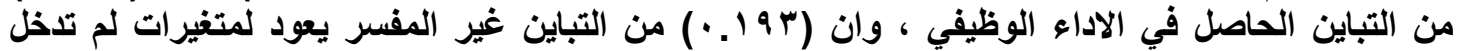

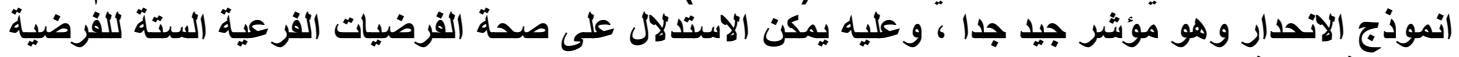
الرئيسية الثانية . 


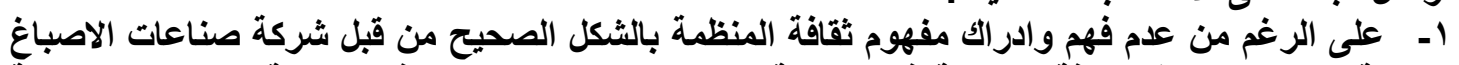

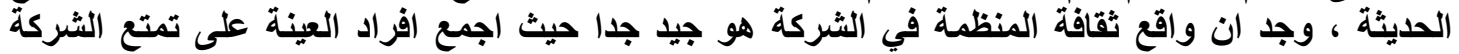

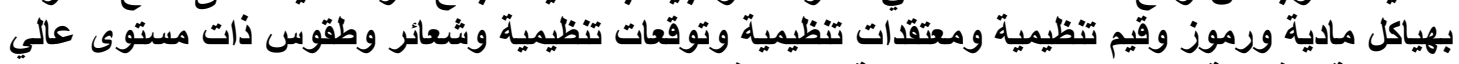

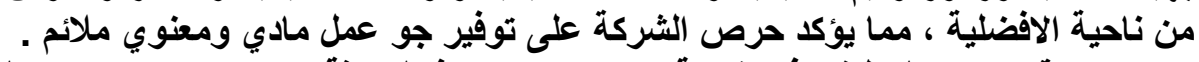

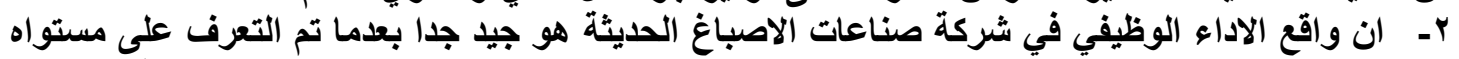

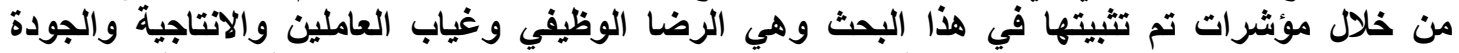

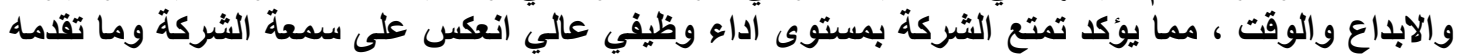
من منتوج محلي ، اضافة الى سعيها مواكبة التطور في مجال الخصائص الحيثة التئة التي تتمتع بها الاصباغ في

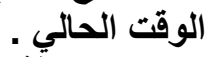

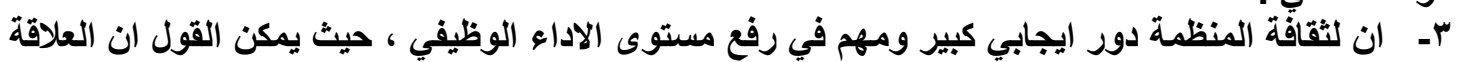

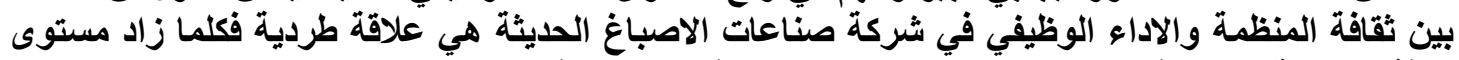

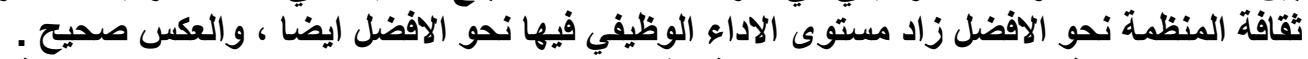

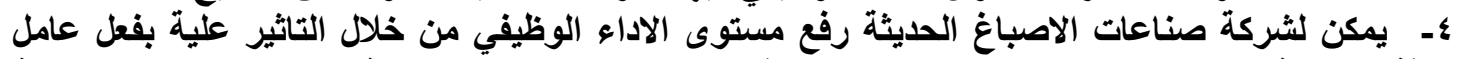

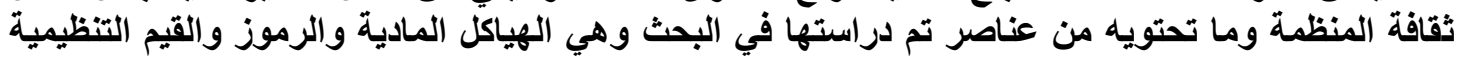

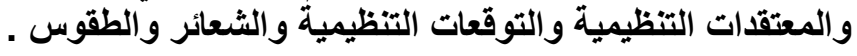

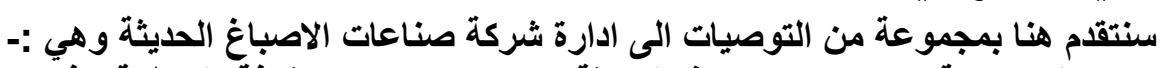

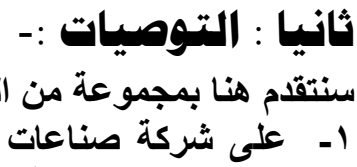

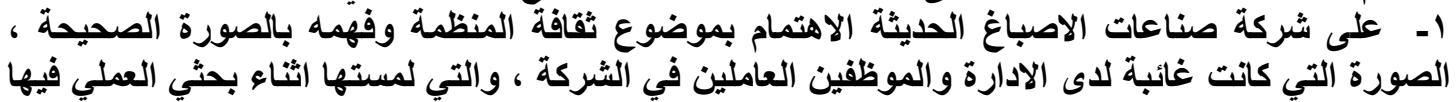

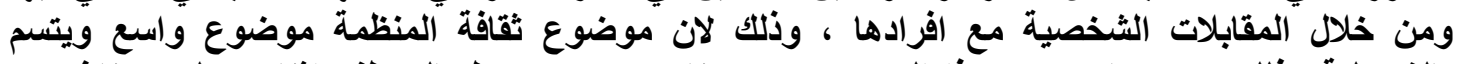

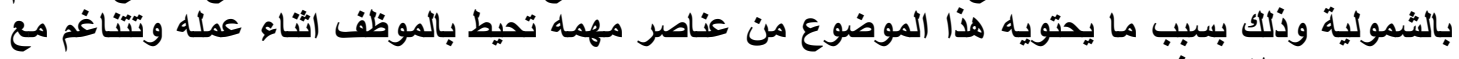

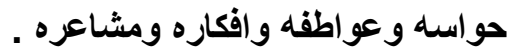

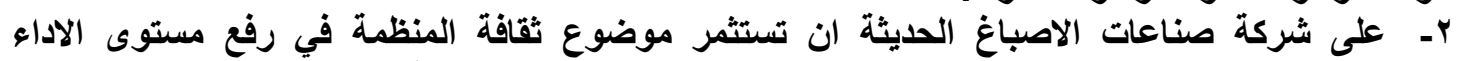

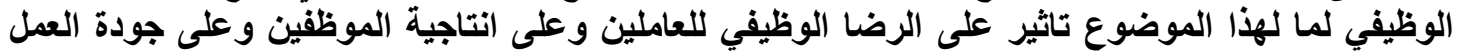

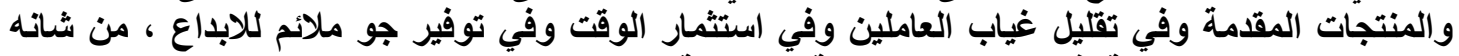

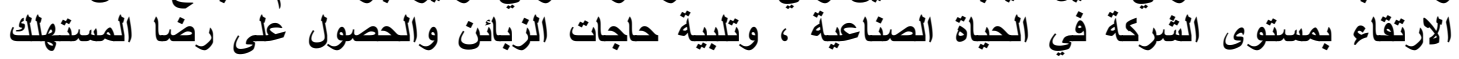

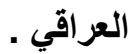

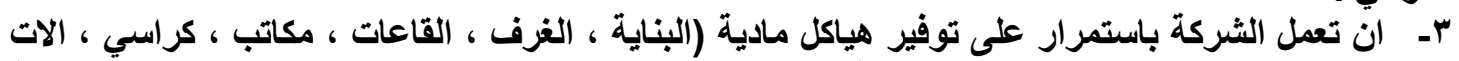

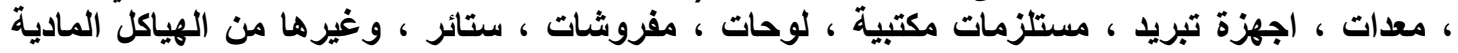

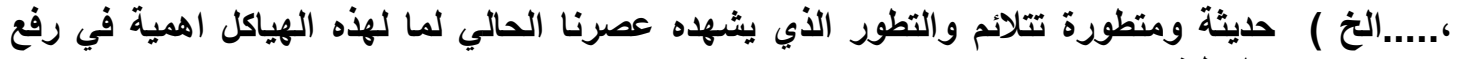

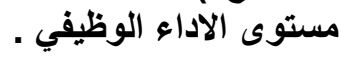




\section{بهث في شركة صنا عات الاصباغ الهديثة}

عـ - ان تراعي الثركة في اختيارها لهذه الهياكل الجاتب المعنوي الذي يمكن ان تلعبه هذه الهياكل في رفع

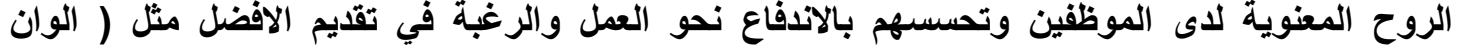

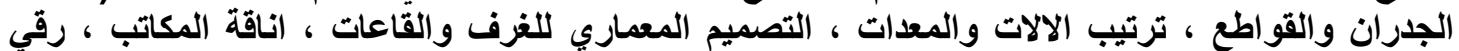

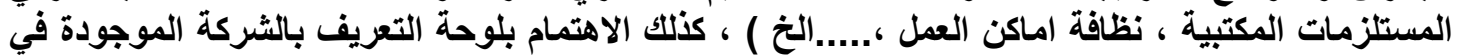

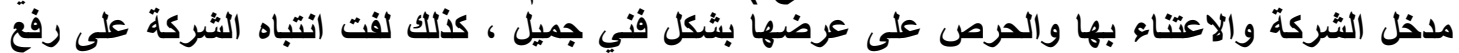

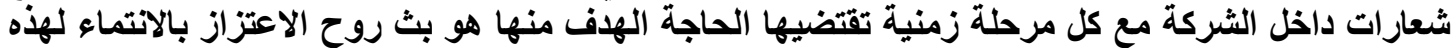

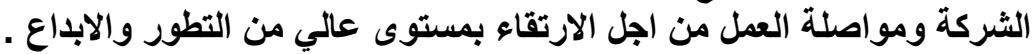

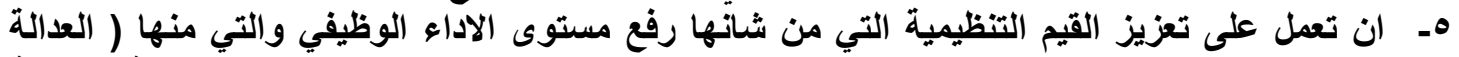

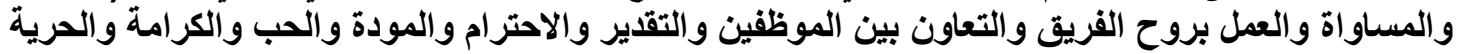

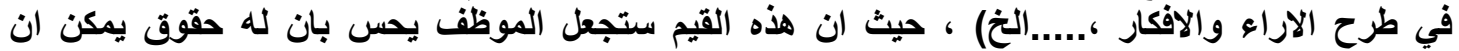

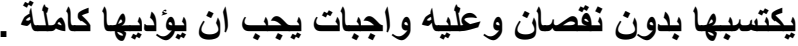

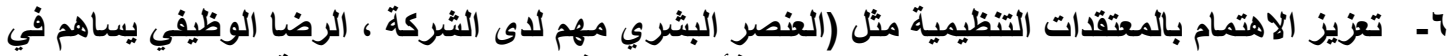

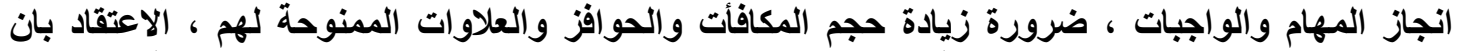

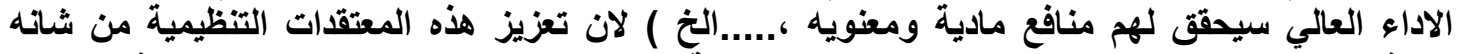

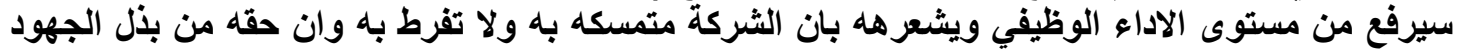

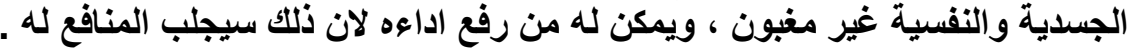

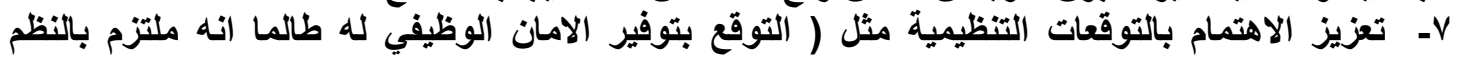

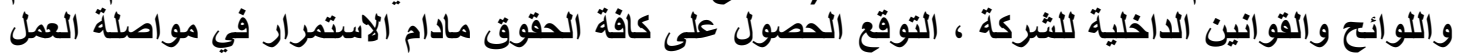

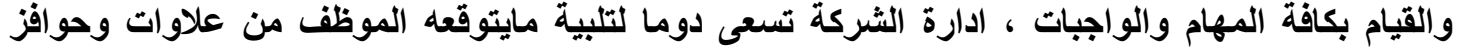

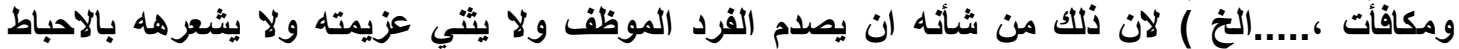

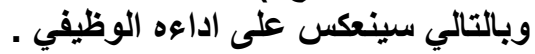

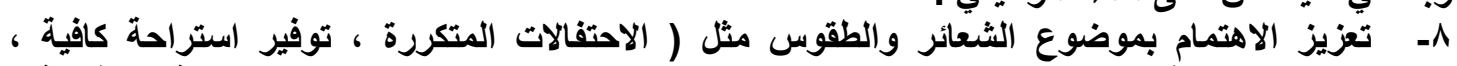

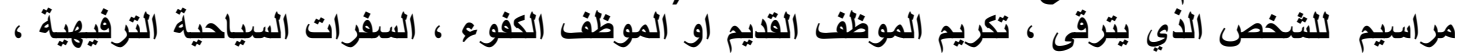

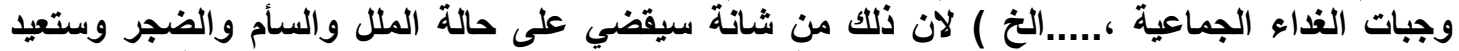

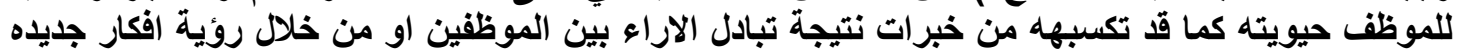

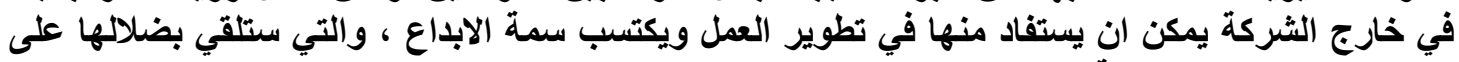

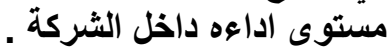

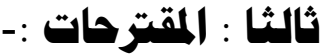

يقترح الباحث على الباحثين الجدد في شركة صناعات الاصباغ الحديثة ما يلي :-

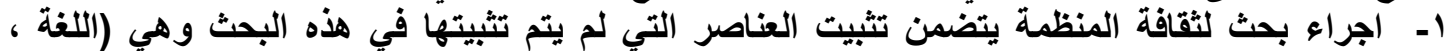

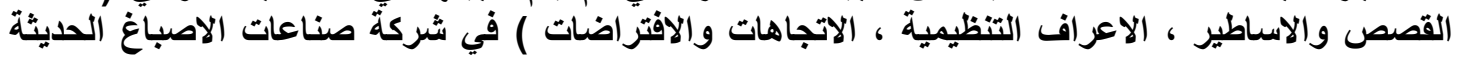

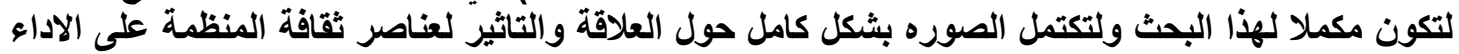

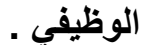

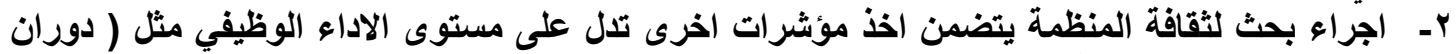

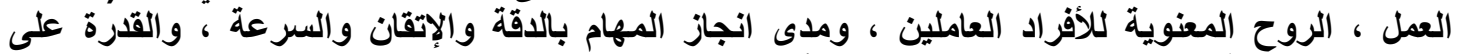

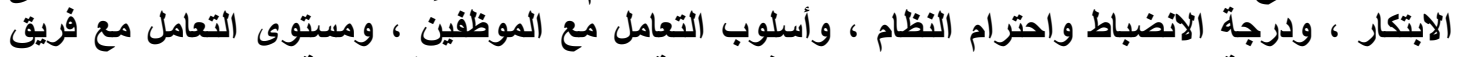

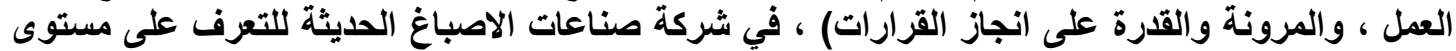

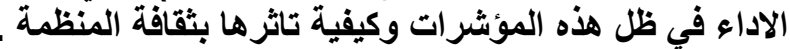

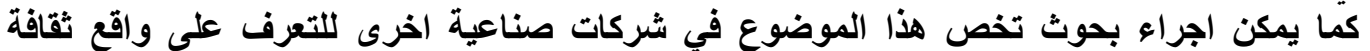

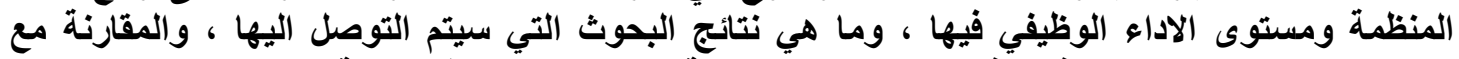

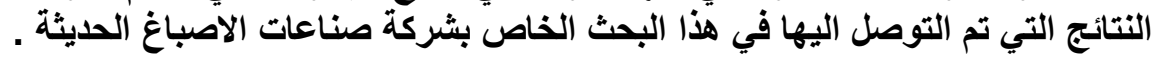




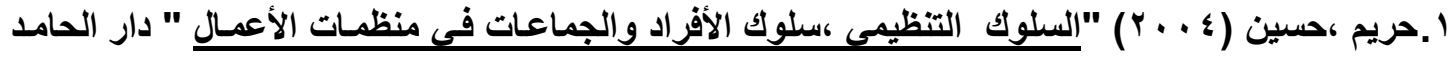

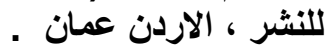

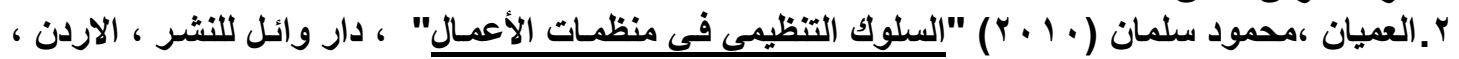

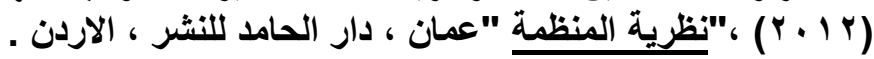

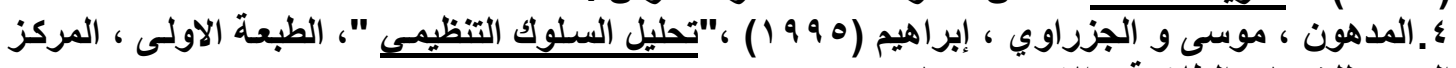

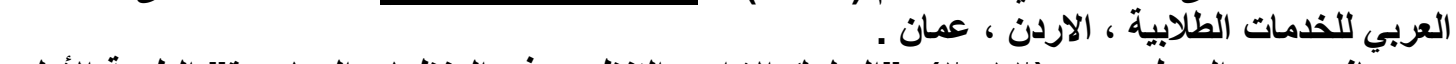

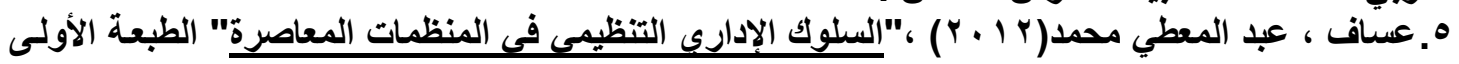

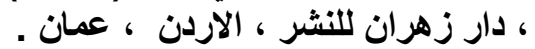

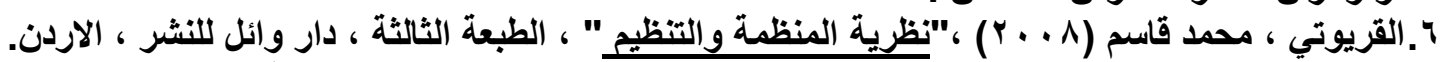

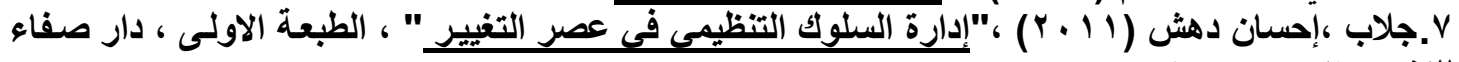

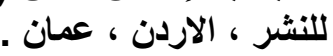

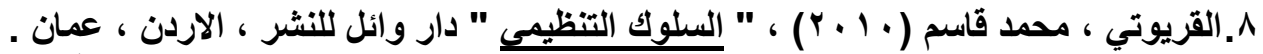

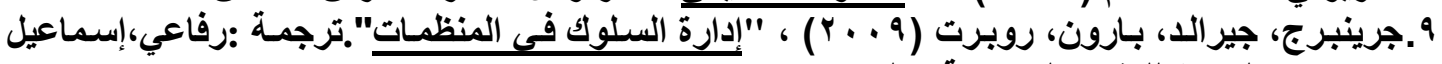

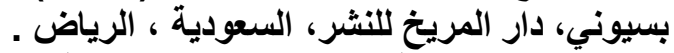

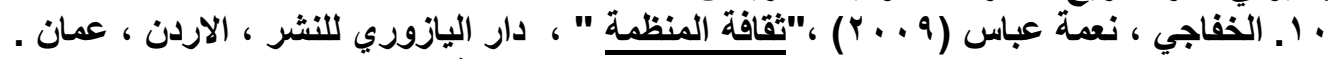

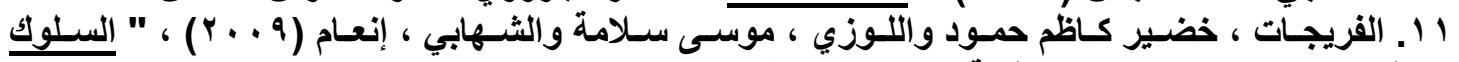

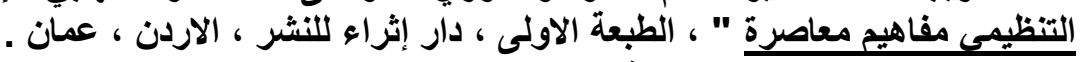

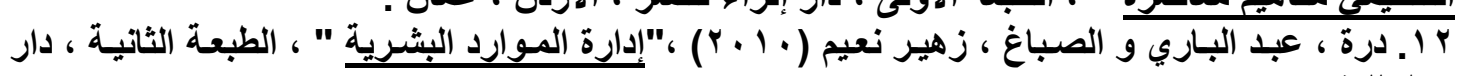

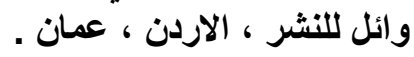

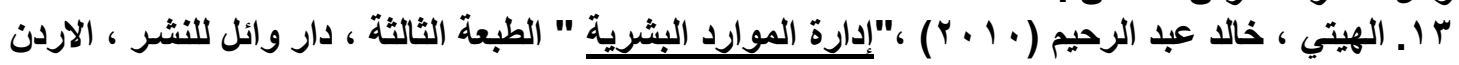

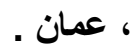

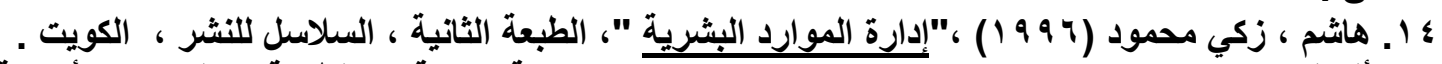

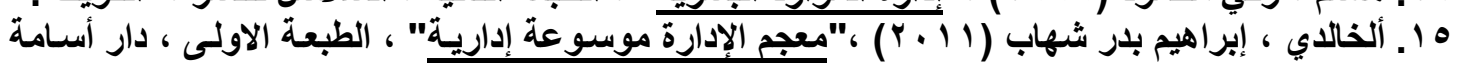

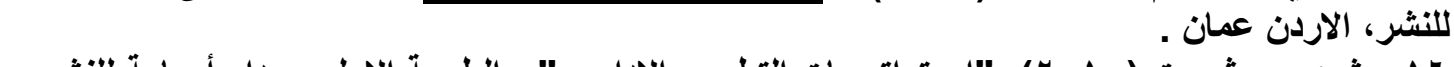

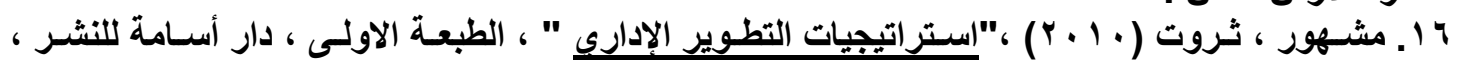

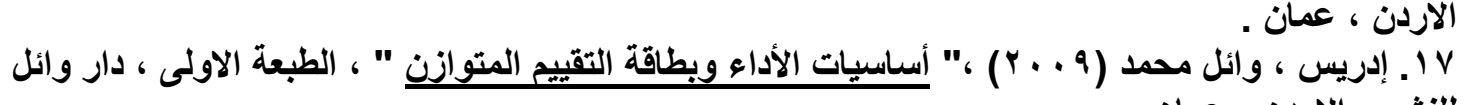

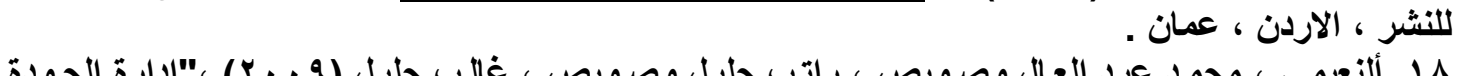

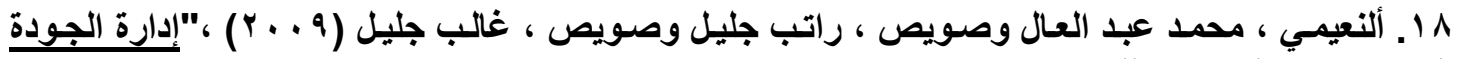

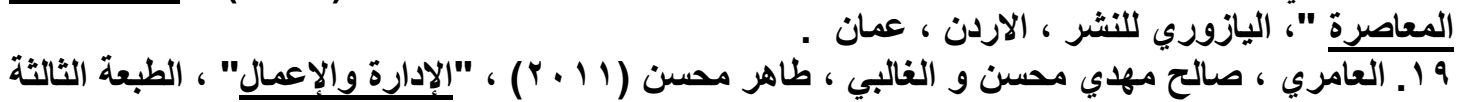

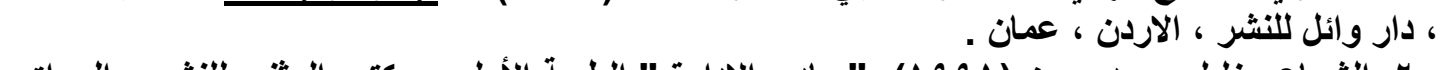
• ب. الثماع ،خليل محمد حسن (1991 9 ) ،"مبادئ الإدارة " الطبعة الأولى ، مكتب المثنى للنشر ، العراق ،

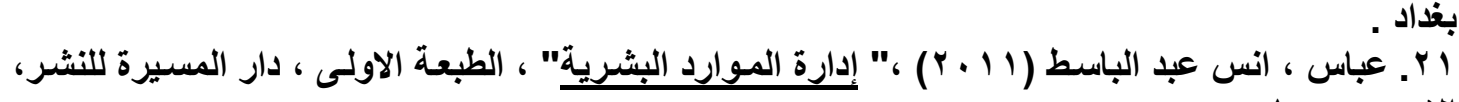

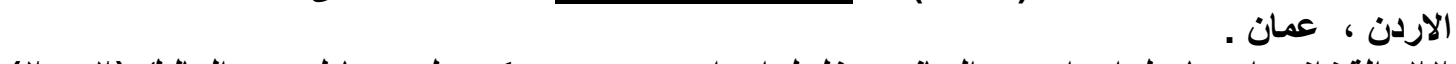

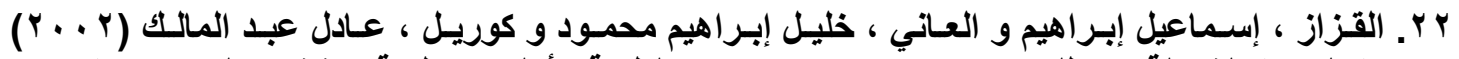

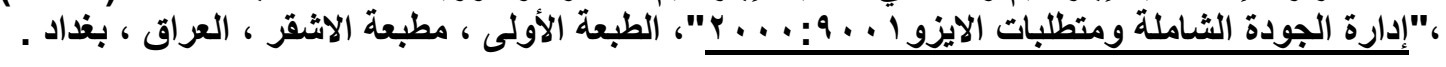




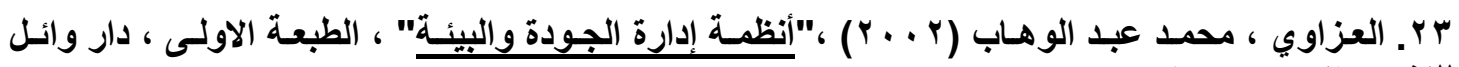

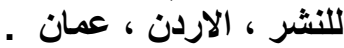

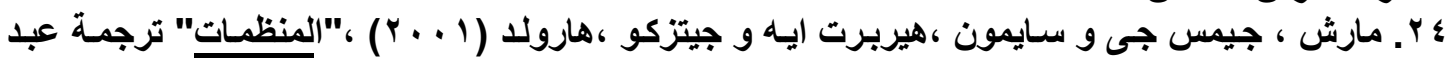

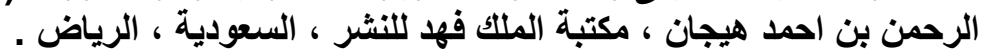

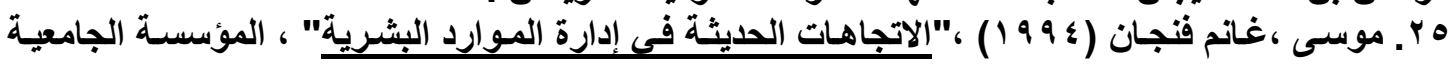

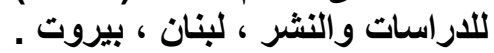

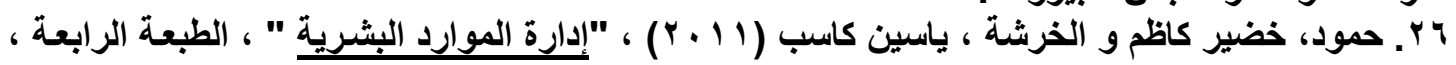

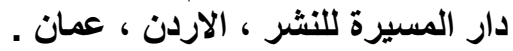

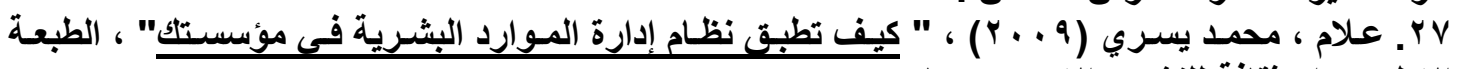

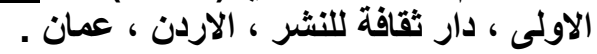

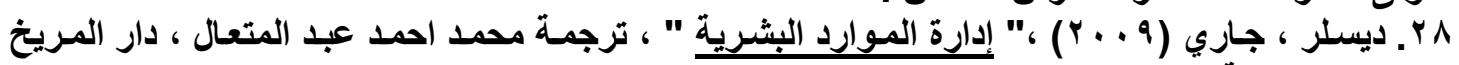

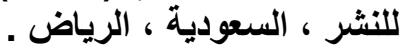

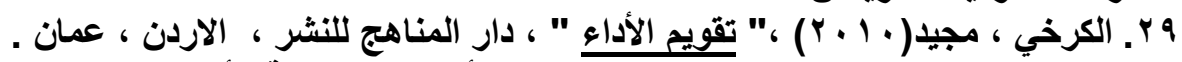

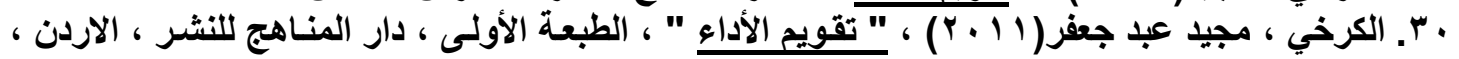

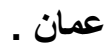

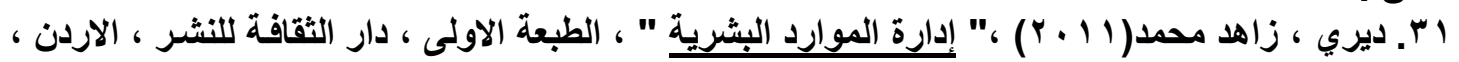
عمان .

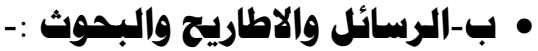

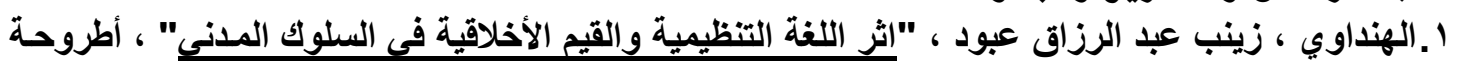

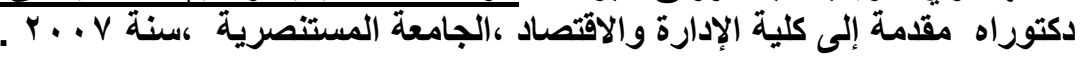

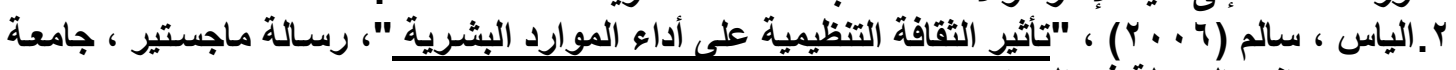

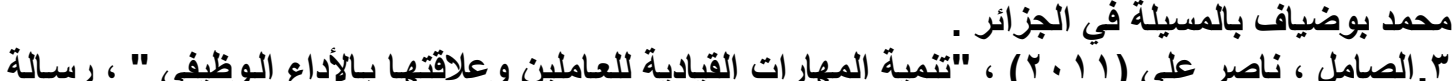

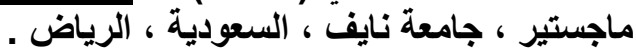

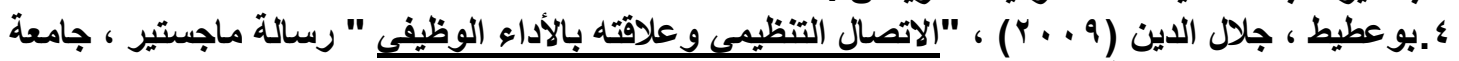

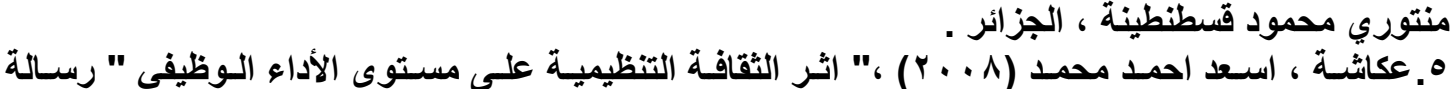

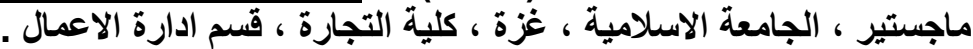

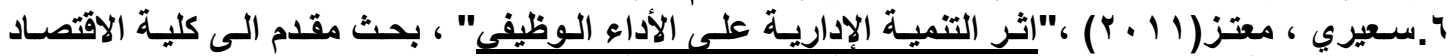

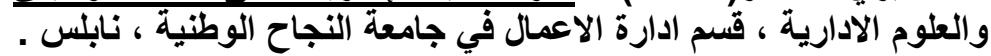

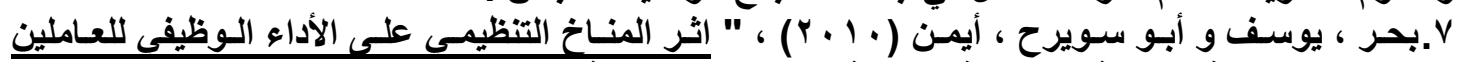

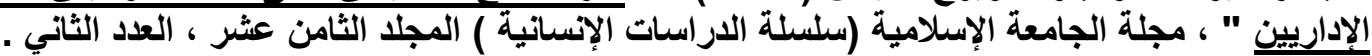

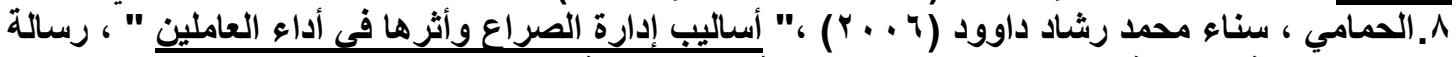

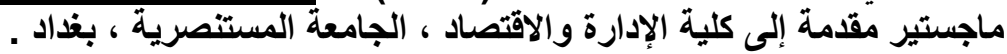

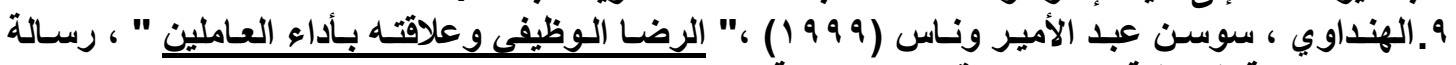

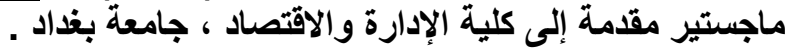



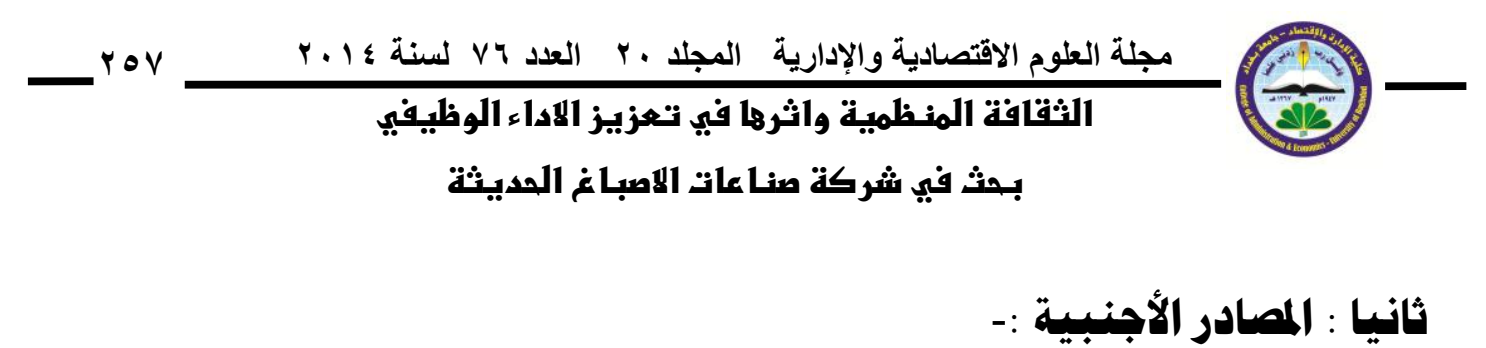

1. - Hellriegel, Don \& Jr, John W.Slocum \& Woodman, Richard W(2000) ," organization behavior "ninth edition, South Western College Publishing, USA . 2. - Kreitner, Robert \& Kinicki,Angelo(2007), "Organizational Behavior",seventh edition, McGraw-Hill Irwin, USA .

3. - Ivancevich,John M \& Matteson,Michael T.(2002)," Organizational Behaviour and Management" ,sixth edition, McGraw-Hill Irwin, USA .

4.- McShane,Steven \& Glinow,Mary Ann Von (2007) , Organizational Behavior" , McGraw-Hill Irwin, USA .

5. - Gibson James L \& Donnelly James H \& Ivancevich,John M \& Konopaske Robert(2003) ,"Organizations", McGraw-Hill Irwin, USA .

6. -Daft,Richard L(2001) ,"Organization Theory and Design", seventh edition , south western ,USA .

7. - Khanka.S.S(2009), "Organizational Behaviour" , Ram Nagar,New Delhi .

8. -Buchanan David \& Huczynski Andrzej (2004), "Organizational Behaviour" , Fifth edition, Prentice Hall, UK, London .

9. - McCOY \& Ridge \& Sabitu \& Ibrahim \& chand \& Hall (2009) ,"Identifying and understanding the determinants of high and low performing" , McGrawHill Irwin, USA .

10. -Armstong,Michael (2009), "performance management " $3^{\text {rd }}$ edition , UK , London .

11. - Hoyle,David (2001) ,"ISO 9000 Quality systems handbook" fourth edition , Butterworth Heinemann ,UK .

12. Sid,Kemp (2006),"Quality management" , McGraw-Hill Irwin, USA .

13. -Heizer,jay \& Render,barry (2006) ,"operation management" , New Jersy, Prentice-Hall, USA .

14. Peaumont,p.b, (1998), "Human Resource management" , USA .

15. -Reid,R.Dan \& Sanders,Nada R (2010), "operations management" ,John Wiley \& Sons, USA .

16. Luthans,Fred (2008) ,"Organization Behavior",eleventh edition , McGrawHill Irwin, USA .

17. McShane \& Glinow,Vor (2008) ,"Organization Behavior" , McGraw-Hill Irwin, USA .

18. -Beardwell,Julie \& Claydon,Tim (2010), "Human Resource Management", Prentice-Hall , USA .

19. - Hellriegel,Don \& Slocum jr,john w \& Woodman Richard w (1996) ,"Organizational Behavior" , , West Publishing ,USA .

20. Evans,james R \& Dean JR, James W (2009), "total quality", South Western , USA . 


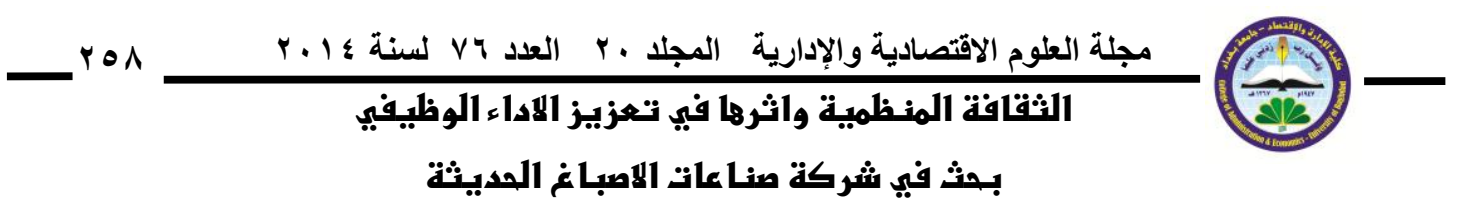

21. -Krajewski,lee \& Ritzman,Larry p \& Malhotra,Manoj k (2007)," Operations Management" ,eighth edition, Prentice-Hall Of India , New Delhi .

22. -Davis,Mark M \& Aquilano,Nicholas J \& Chase, Richard B (2007) "Fundamentals of Operations Management",fourth edition , McGraw-Hill Irwin, USA .

23. -Moorhead,Gregory \& Griffin,Ricky W, (1995) ,"Organizational Behaviour", Houghton Mifflin, Newyork, USA .

24. -Mathis, Robert L \& Jackson,John H,(2003)," Human Resource Management ", tenth edition, South western, USA .

25. -Ivancevich,John M (1995)," Human Resource Management", Irwin , USA .

26. -Denisi,Angelo $S$ \& Griffin,Ricky w ,(2001), "Human Resource Management" ", Houghton Mifflin, Boston , USA .

27. -Bratton,John \& Gold Jeffrey,(2003) ,"Human Resource Management" , Third edition, Palgrave Macmillan , USA .

28. Torrington,Derek \& Hall,Laura, (1998),"Human Resource Management" , prentice-Hall Europe , Italy . 
r०q

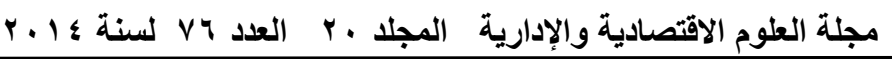

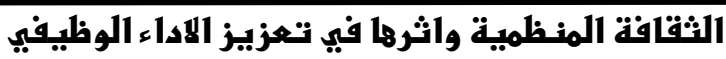

بحث في شركة صناعات الاصبا غ الهديثة

\section{Organizational Culture Impact in Enhancing Job Performance}

A Case Study in the Modern Paint Industries Company

\section{ABSTRACT}

The organizational culture is considered as an important topic. In this research, this topic was studied in modern paints Industries Company to assess its role in job performance and to show if there is this relationship between them or no. it is, also, attempted to measure this strength of this relationship if any. The 40 cases research sample was chosen. This sample included the chief executive, his assistants, key managers, and their assistants. The questioner consists of two sets of questions : the first set ( concerning the organizational culture) covers six variables (Physical structures, Symbols, Values, Beliefs , Expectations, and Rites \& Rituals ), the second set covers the job performance which could be concluded from six indicators (Job Satisfaction, The absence of workers, Quality, Productivity, Time, Creativity ). After statistical analysis it has been shown that there is a strong positive relationship between organizational culture and job performance. It has been shown, also, that the organizational culture has positive effect on job performance. It is recommended that the company: must take into consideration and well recognize the topic of organizational culture, make use of this topic in raising the level of job performance .

Key words: Organizational Culture, Job Performance. 